\title{
Three-Dimensional Surface Geophysical Exploration of the 200-Series Tanks at the 241-C Tank Farm
}

Author Name:

N. Crook, M. McNeill - hydroGEOPHYSICS, Inc.

Ralph Dunham - Columbia Energy and Environmental Services, Inc.

Dan Glaser - Washington River Protection Solutions, LLC

Richland, WA 99352

U.S. Department of Energy Contract DE-AC27-08RV14800

EDT/ECN: DRF UC:

Cost Center: Charge Code:

B\&R Code: $\quad$ Total Pages: 75

Key Words: Surface Geophysical Exploration, SGE, Survey Report, C Tank Farm, 200-Series Tanks

Abstract: A surface geophysical exploration (SGE) survey using direct current electrical resistivity was conducted within the C Tank Farm in the vicinity of the 200-Series tanks at the Hanford Site near Richland, Washington. This survey was the second successful SGE survey to utilize the Geotection ${ }^{\mathrm{TM}}-180$ Resistivity Monitoring System which facilitated a much larger survey size and faster data acquisition rate. The primary objective of the C Tank Farm SGE survey was to provide geophysical data and subsurface imaging results to support the Phase 2 RCRA Facility Investigation, as outlined in the Phase 2 RCRA Facility Investigation / Corrective Measures work plan RPP-PLAN-39114.

TRADEMARK DISCLAIMER. Reference herein to any specific commercial product, process, or service by trade name, trademark, manufacturer, or otherwise, does not necessarily constitute or imply its endorsement, recommendation, or favoring by the United States Government or any agency thereof or its contractors or subcontractors.

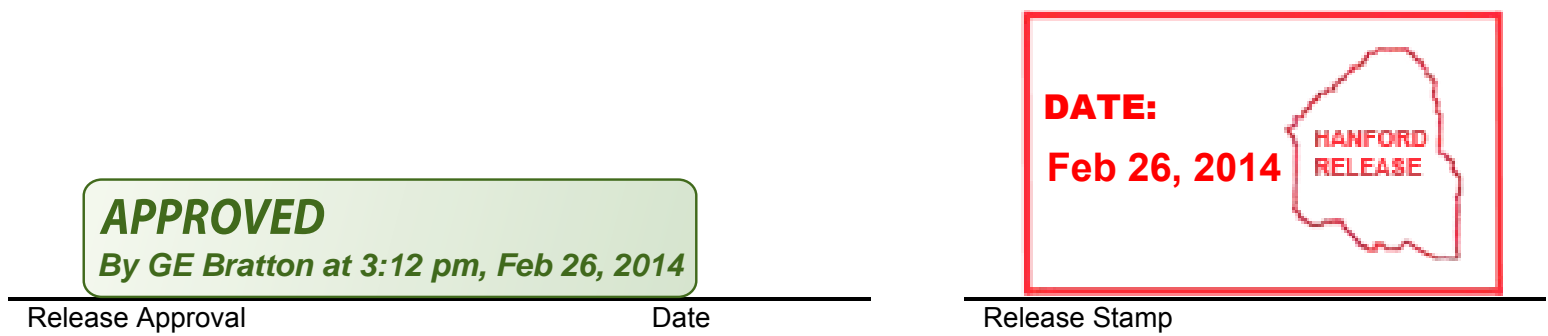

Approved For Public Release 


\section{EXECUTIVE SUMMARY}

A surface geophysical exploration survey using a direct current electrical resistivity method was conducted within the 241-C Tank Farm on the U.S. Department of Energy Hanford Site near Richland, Washington. Specifically, the survey was conducted in the eastern portion of the farm encompassing the 200-Series tanks. This survey was the second successful surface geophysical exploration survey to utilize the Geotection ${ }^{\mathrm{TM}}-180$ Resistivity Monitoring System, which facilitated a larger survey size and faster data acquisition rate. The survey included electrical current transmission and voltage measurements on 318 surface electrodes, within a grid layout, 41 depth electrodes, and 1 groundwater monitoring well acting as a long electrode. Data collection took place between July 24, 2013 and August 1, 2013.

The surface electrode and depth electrode data from the survey were combined to produce a resistivity inversion model for the 200-Series tanks area. The results indicate a low resistivity target in the region between boreholes C8765, C8766, and C8767 and the monitoring well E27-7, on the northeast edge of the survey area. This conductive target extends from an elevation of approximately $166 \mathrm{~m}(545 \mathrm{ft})$ above mean sea level to down below the water table,

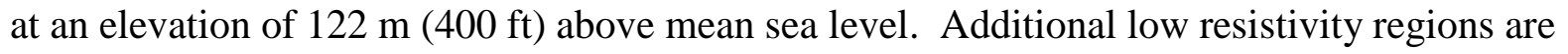
observed between the 100- and 200-Series tanks and to the northwest of tank C-106. Figure ES-1 and Figure ES-2 display a plan view of the distribution of resistivity in the 200-Series tanks survey area, through a series of depth slices and a three-dimensional representation of the tank farm, respectively. Two contours of low resistivity values are highlighted in the three-dimensional representation:

- Opaque value (dark blue)

- Transparent value (light blue) representing 3 ohm-meter representing 10 ohm-meter.

A two-dimensional vertical slice was extracted from the three-dimensional inverse model along a profile through the boreholes $\mathrm{C} 8765, \mathrm{C} 8766$, and C8767, adjacent to the groundwater monitoring well E27-7 (Figure ES-3). Additional resolution is provided to the inverse modeling by the inclusion of the depth electrodes. 
Figure ES-1. Summary of Inversion Model Results for the 200-Series Tanks Survey Area.

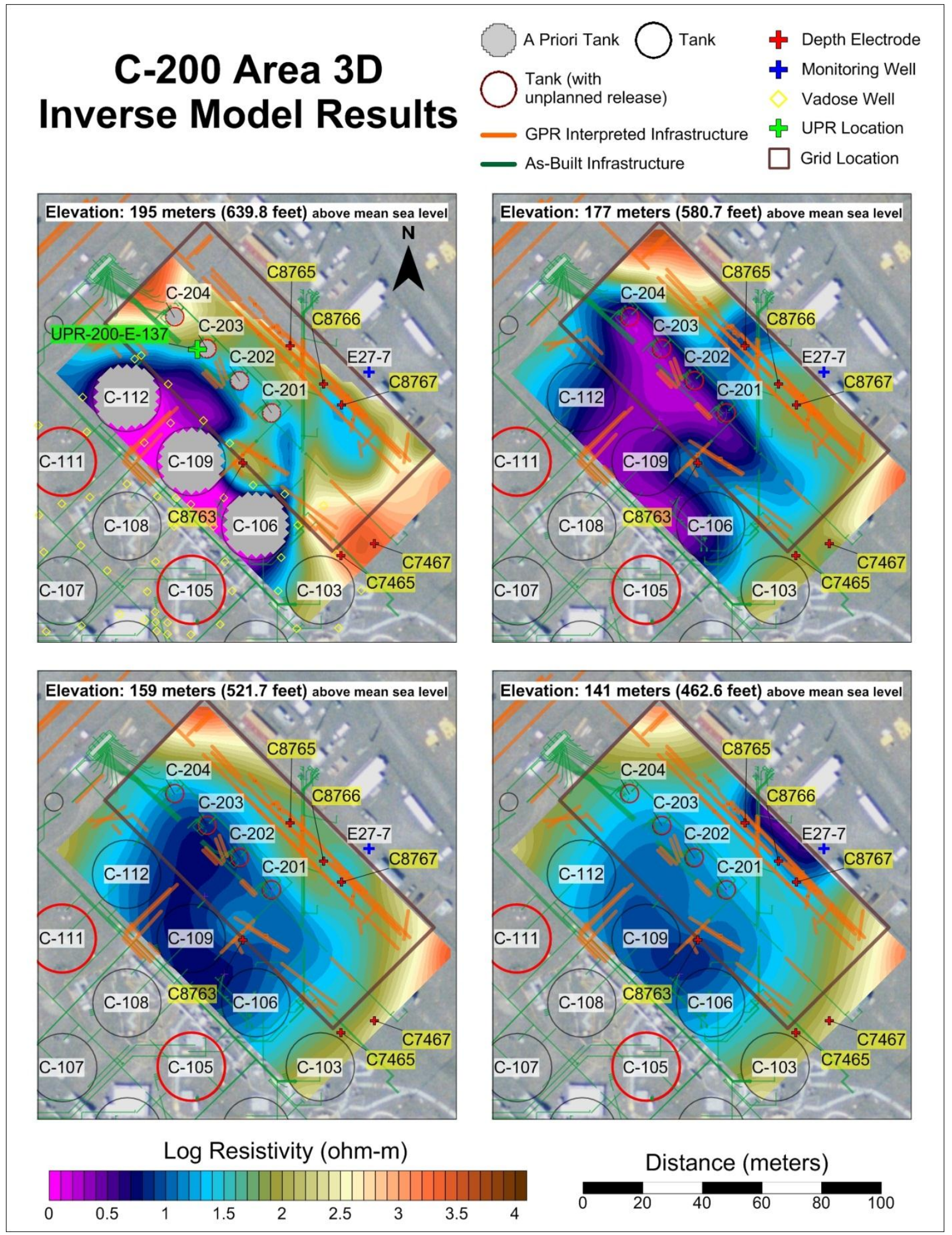


Figure ES-2. Three-Dimensional Rendered Bodies of the Low Resistivity Features from the Inversion Model, Plan View.

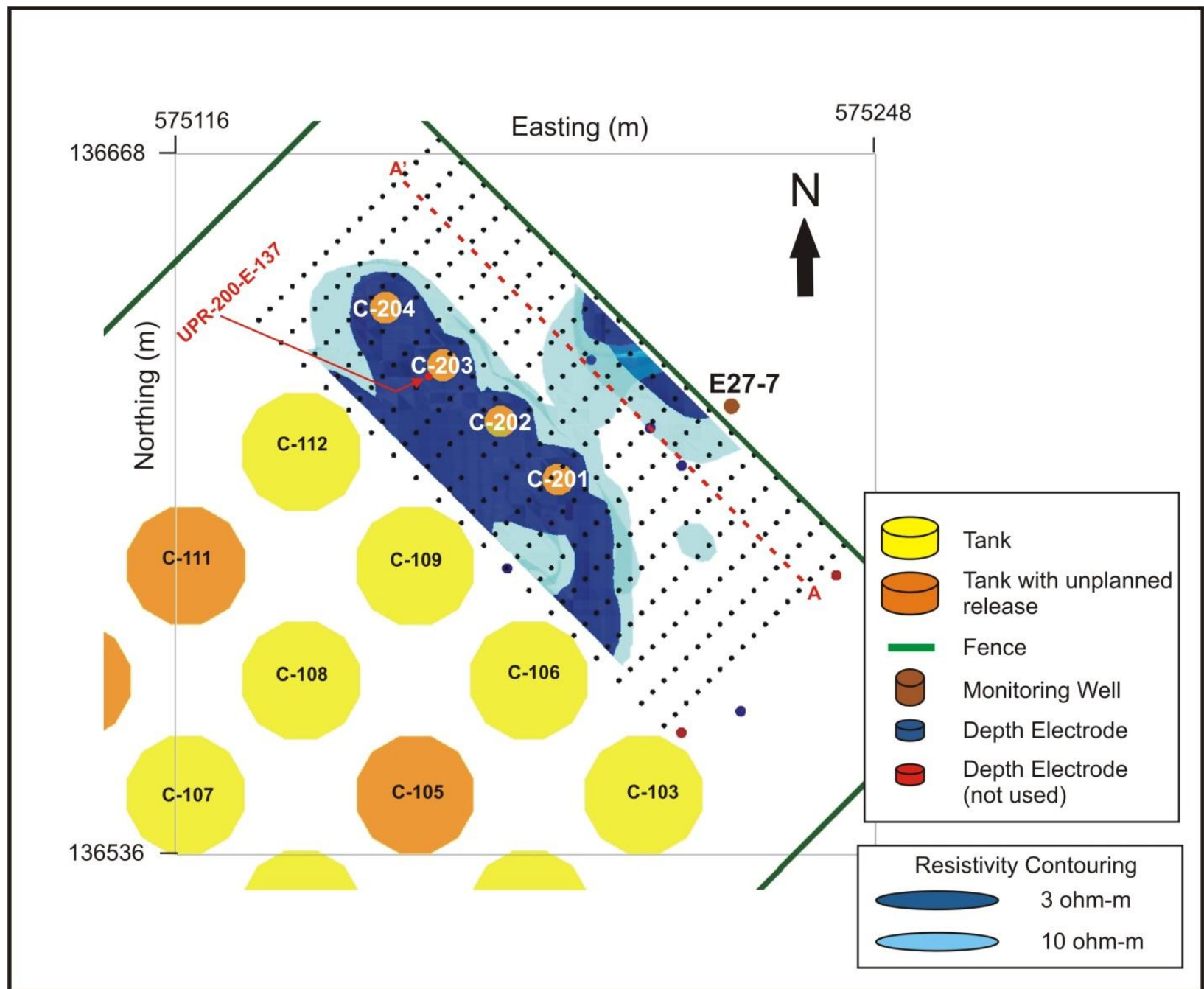


Figure ES-3. Two-Dimensional Vertical Profile, Extracted from Three-Dimensional Inversion Model.

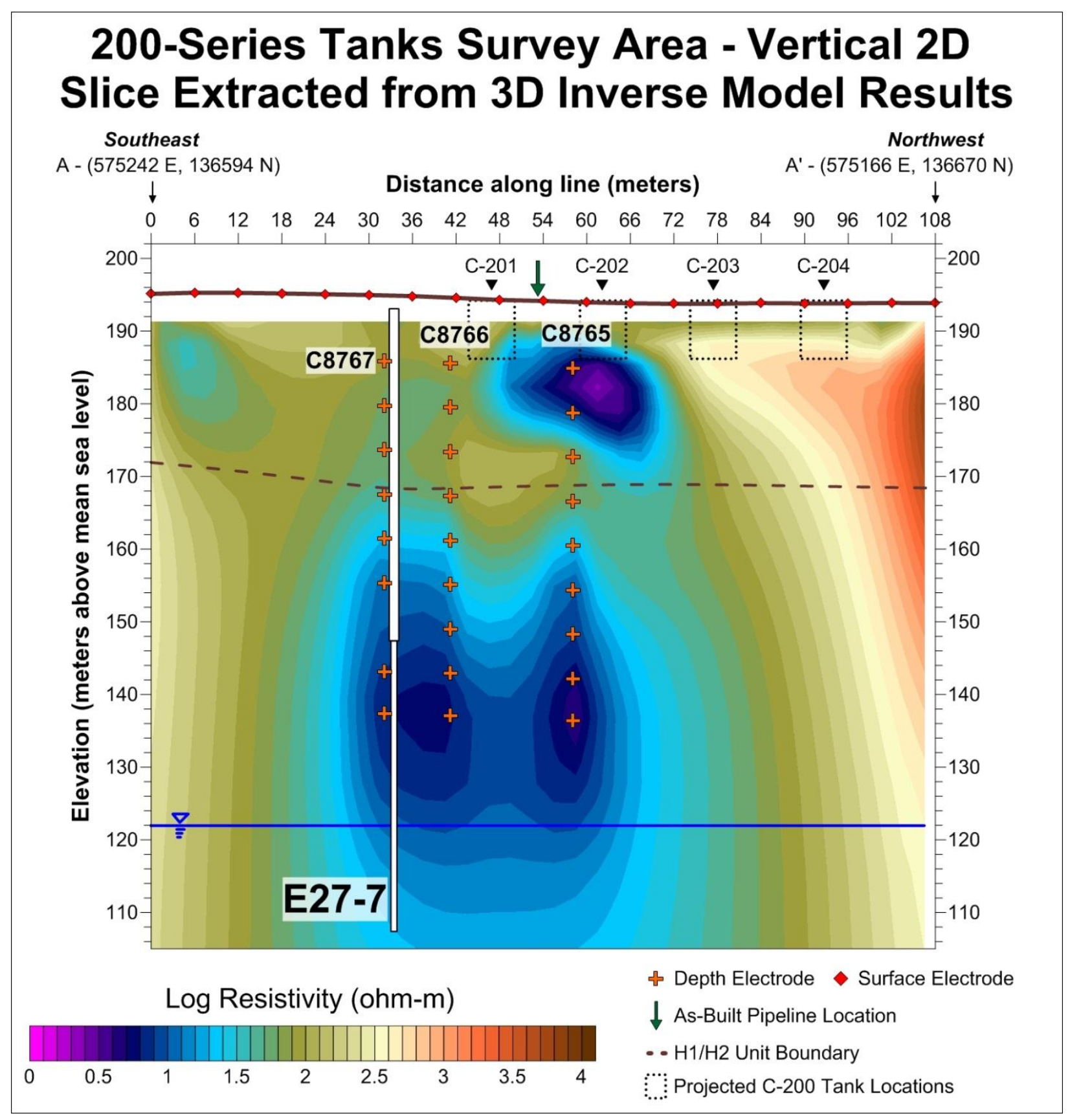




\section{RPP-RPT-56760, Rev. 0}

\section{TABLE OF CONTENTS}

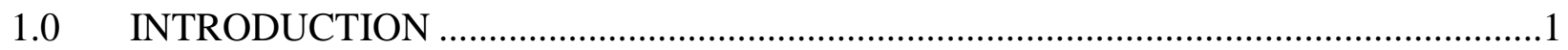

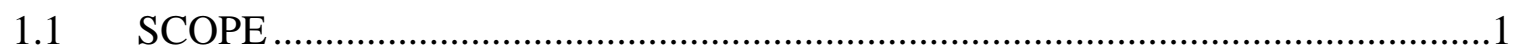

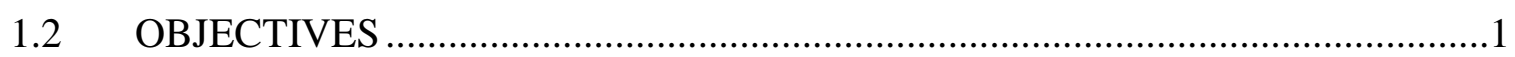

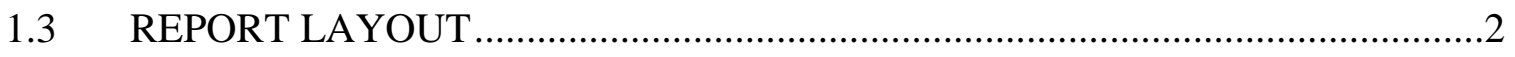

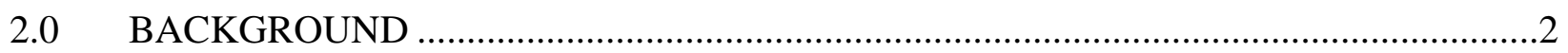

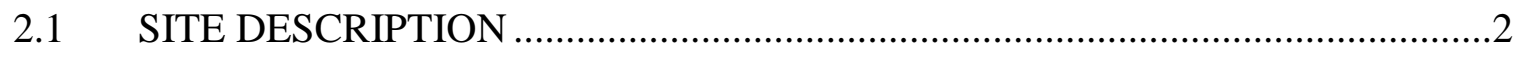

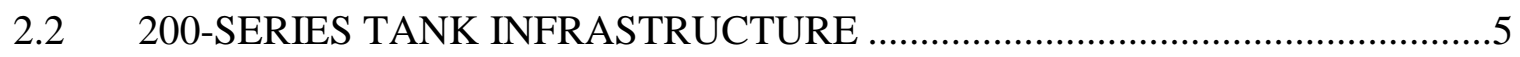

$2.3 \quad 200-$ SERIES TANK OPERATING HISTORY ...................................................

$2.4 \quad$ 200-SERIES TANK WASTE SUMMARY ………...........................................

2.5 PREVIOUS CHARACTERIZATION EFFORTS ..............................................

2.5.1 Drywell Gamma Logging ...................................................................

2.5.2 Direct-Push Sampling …………………………................................16

3.0 DATA ACQUISITION AND PROCESSING METHODOLOGY ……….......................17

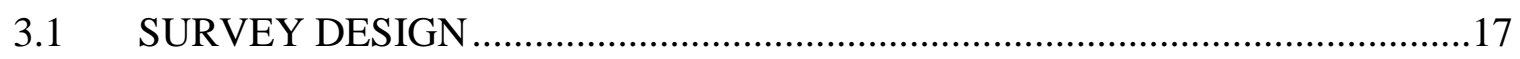

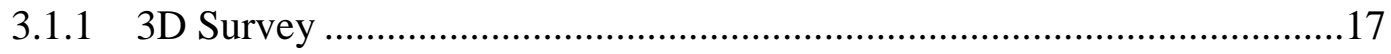

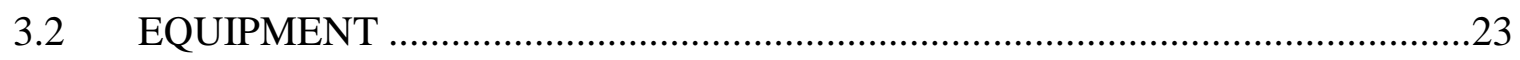

3.2.1 Electrode and Cable Layout...................................................................23

3.2.2 Geotection-180 Resistivity Monitoring System (3D Resistivity) .............23

3.2.3 Quality Assurance ..............................................................................24

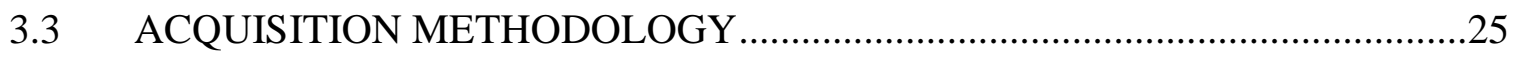

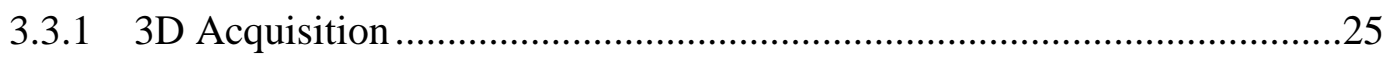

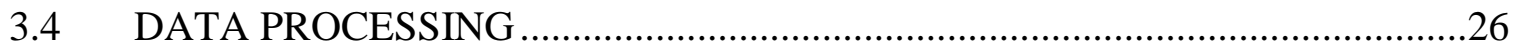

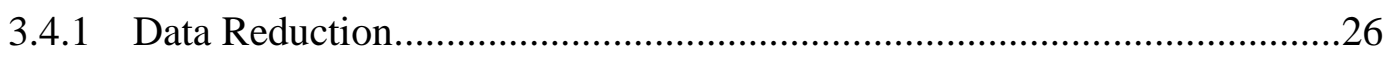

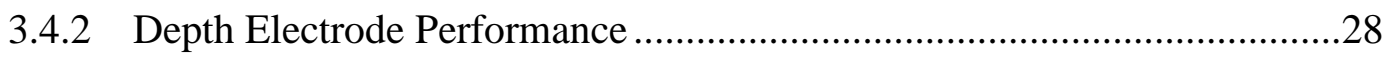

3.4.3 3D Inverse Modeling .............................................................................

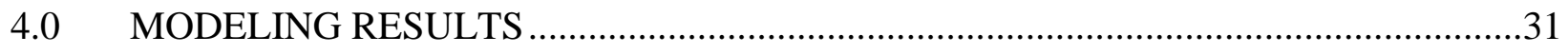

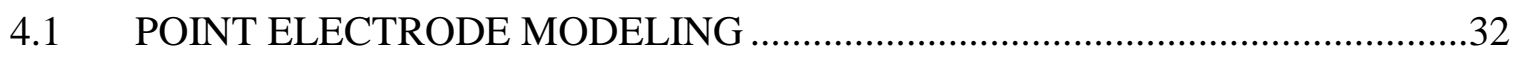

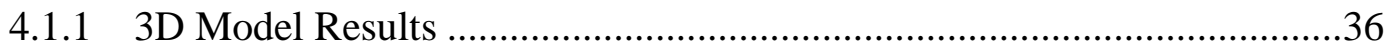

4.1.2 2D Representation of 3D Model Results ...............................................43

4.1.3 Infrastructure Modeling .....................................................................49 


\section{LIST OF APPENDICES}

A Quality Assurance

A-i

\section{LIST OF FIGURES}

Figure 1. Location Map of C Tank Farm in the 200 East Area of the DOE Hanford Site.............3

Figure 2. Map of the $\mathrm{C}$ Tank Farm and Surrounding Facilities. ...............................................

Figure 3. C Tank Farm 200-Series 3D Electrical Resistivity Survey Area...................................5

Figure 4. Typical Configuration and Dimensions of 200-Series Single-Shell Tanks in

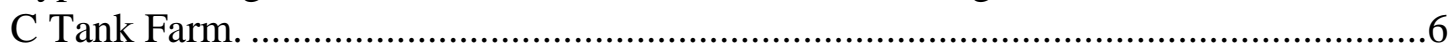

Figure 5. C Tank Farm Area Waste Release Inventory. .........................................................

Figure 6. Visual Interpretation of Drywell Logging Activity at $0.6 \mathrm{~m}(2 \mathrm{ft}) \mathrm{bgs}(197.4 \mathrm{~m}$

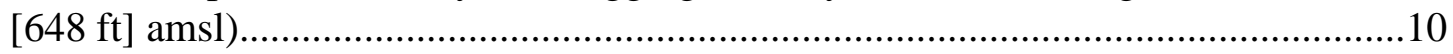

Figure 7. Visual Interpretation of Drywell Logging Activity at $2.4 \mathrm{~m}(8 \mathrm{ft}) \mathrm{bgs}(195.6 \mathrm{~m}$

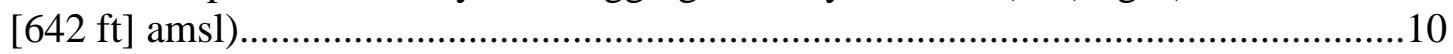

Figure 8. Visual Interpretation of Drywell Logging Activity at $5.5 \mathrm{~m}(18 \mathrm{ft}) \mathrm{bgs}$ $(192.5 \mathrm{~m}[632 \mathrm{ft}] \mathrm{amsl})$. .11

Figure 9. Visual Interpretation of Drywell Logging Activity at $7.3 \mathrm{~m}(24 \mathrm{ft}) \mathrm{bgs}$ (190.7 m [626 ft] amsl).

Figure 10. Visual Interpretation of Drywell Logging Activity at $11.6 \mathrm{~m} \mathrm{(38 \textrm {ft } ) \mathrm { bgs }}$ (186.4 m [612 ft] amsl).

Figure 11. Visual Interpretation of Drywell Logging Activity at $14.3 \mathrm{~m} \mathrm{(47 \textrm {ft } ) \mathrm { bgs }}$ $(183.7 \mathrm{~m}[603 \mathrm{ft}] \mathrm{amsl})$.

Figure 12. Visual Interpretation of Drywell Logging Activity at $17.1 \mathrm{~m}(56 \mathrm{ft}) \mathrm{bgs}$ $(180.9 \mathrm{~m}[594 \mathrm{ft}] \mathrm{amsl})$.

Figure 13. Visual Interpretation of Drywell Logging Activity at $20.7 \mathrm{~m}(68 \mathrm{ft}) \mathrm{bgs}$ $(177.3 \mathrm{~m}[582 \mathrm{ft}] \mathrm{amsl})$.

Figure 14. Visual Interpretation of Drywell Logging Activity at $23.8 \mathrm{~m}(78 \mathrm{ft}) \mathrm{bgs}$ $(174.2 \mathrm{~m}[572 \mathrm{ft}] \mathrm{amsl})$. .14

Figure 15. Visual Interpretation of Drywell Logging Activity at $27.1 \mathrm{~m}(89 \mathrm{ft}) \mathrm{bgs}$ $170.9 \mathrm{~m}[561 \mathrm{ft}] \mathrm{amsl})$.

Figure 16. Visual Interpretation of Drywell Logging Activity at $31.7 \mathrm{~m}(104 \mathrm{ft}) \mathrm{bgs}$ $(166.3 \mathrm{~m}[546 \mathrm{ft}] \mathrm{amsl})$.

Figure 17. Visual Interpretation of Drywell Logging Activity at $34.7 \mathrm{~m}(114 \mathrm{ft}) \mathrm{bgs}$ $(163.3 \mathrm{~m}[536 \mathrm{ft}] \mathrm{amsl})$.

Figure 18. Visual Interpretation of Drywell Logging Activity at $38.1 \mathrm{~m}(125 \mathrm{ft}) \mathrm{bgs}$ $(159.9 \mathrm{~m}[525 \mathrm{ft}] \mathrm{amsl})$. 16

Figure 19. Resistivity Cable and Surface Electrode Layout. .18 
Figure 20. Well Completion Schematic for Monitoring Well 27-7. .......................................21

Figure 21. 3D Survey Depth Electrode and Well Distribution. ............................................22

Figure 22. The SuperSting R8 Resistivity Meter (top) and Geotection-180 Resistivity Monitoring System (bottom). ............................................................24

Figure 23. Location of Remote Electrodes..........................................................................26

Figure 24. Data Distribution for Raw (Combined Reciprocal) and Edited V/I Data for the 3D Survey (Surface and Depth Electrode Data)...................................................27

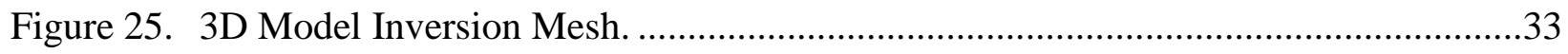

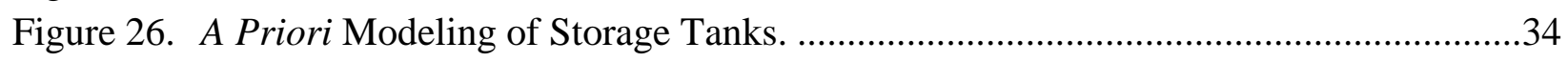

Figure 27. Distribution of Modeled Resistivity Values. ........................................................35

Figure 28. Inverse Model Results for the C-200 Area Survey..............................................37

Figure 29. Inverse Model Results for the C-200 Area Survey.................................................38

Figure 30. 3D Rendered Bodies of the Low Resistivity Features from the Inversion Model, Plan View.

Figure 31. 3D Rendered Bodies of the Low Resistivity Features from the Inversion Model, View Looking from the Northeast..

Figure 32. Location of A-A' Transect for 2D Profile Representation. .......................................44

Figure 33. 2D Vertical Profile, Extracted from 3D Model. ..................................................45

Figure 34. Vertical Slice with Borehole and Well Logging Results. .....................................46

Figure 35. Well E27-7 Groundwater Analytical Results for: A) Nitrate, Uranium, and B)

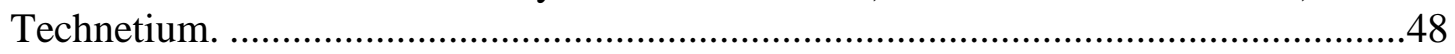

Figure 36. A Priori Modeling of Infrastructure ...................................................................49

Figure 37. Inverse Model Results for Pipeline Infrastructure Modeling. Contours Displayed in Percent Difference from Original Inversion Model Presented in Figure 28 .

\section{LIST OF TABLES}

Table 1. C Tank Farm 200-Series Tank Waste Releases......................................................8

Table 2. Locations for Depth Electrodes used in C Tank Farm 200-Series Electrical Resistivity Survey.........................................................................19

Table 3. Well Location used in C Tank Farm 200-Series Electrical Resistivity Survey..........21

Table 4. Number of Data Points Retained During Data Editing Steps. .................................28

Table 5. Depth Electrode Performance Measure for the C Tank Farm 200-Series Tanks Electrical Resistivity Survey.......................................................................29

Table 6. Inverse Modeling Convergence and Error Statistics. ............................................32 


\section{LIST OF TERMS}

\section{Acronyms and abbreviations}

2D

3D

AGI

CAD

DOE

FY

GPR

GPS

HGI

N/A

NIST

PUREX

RMS

SGE

SST

UL

UPR

WRPS

\section{Units}

AC

amsl

bgs

$\mathrm{cm}$

$\mathrm{ft}$

gal

in.

L

$\mathrm{m}$ two-dimensional

three-dimensional

Advanced Geosciences, Inc.

computer-aided design

U.S. Department of Energy

fiscal year

ground penetrating radar

global positioning system

hydroGEOPHYSICS, Inc.

not applicable

National Institute of Standards and Technology

plutonium-uranium extraction

root-mean-square

surface geophysical exploration

single-shell tank

Underwriters Laboratories

unplanned release

Washington River Protection Solutions, LLC

alternating current

above mean sea level

below ground surface

centimeter

feet

gallon

inch

liter

meter 
RPP-RPT-56760, Rev. 0

\section{LIST OF TRADEMARKS}

AutoCAD is a registered trademark of AutoDesk, Inc.

Geotection is a trademark of hydroGEOPHYSICS, Inc.

Leica is a registered trademark of Leica Technology

Rock Works is a trademark of Rockware, Inc.

SuperSting R8 is a registered trademark of Advanced Geosciences, Inc.

Surfer is a registered trademark of Golden Software, Inc. 


\subsection{INTRODUCTION}

This report documents the results of the surface geophysical exploration (SGE) survey completed within the 241-C Tank Farm at the U.S. Department of Energy (DOE) Hanford Site in Washington State between July 24, 2013 and August 1, 2013. hydroGEOPHYSICS, Inc. (HGI) and Columbia Energy and Environmental Services, Inc., with support from technical staff of Washington River Protection Solutions, LLC (WRPS), conducted a three-dimensional (3D) electrical resistivity survey of the subsurface concentrated in the vicinity of the 200-Series storage tanks. Electrical resistivity data were acquired using 318 surface electrodes (located at the ground surface), 41 depth electrodes, and 1 groundwater monitoring well completed outside the C Tank Farm perimeter fence.

Data acquisition and analysis were performed in accordance with RPP-PLAN-54755, Work Plan for a 3D Electrical Resistivity Survey Encompassing the 200-Series Tanks at the 241-C Tank Farm.

\subsection{SCOPE}

The scope of this electrical resistivity characterization survey included the following:

- Data acquisition on surface electrodes, depth electrodes, and wells

- Statistical evaluation of depth electrodes to ensure quality in data acquisition

- Compilations of 3D electrical resistivity cross-sections of the C Tank Farm

- Analysis and interpretation of the 3D electrical resistivity cross-sections.

\subsection{OBJECTIVES}

The primary objective of the fiscal year (FY) 2013 C Tank Farm 200-Series tanks SGE survey was to provide geophysical data and subsurface imaging results to support characterization of Sites C and D as outlined in RPP-PLAN-39114, Phase 2 RCRA Facility Investigation / Corrective Measures Work Plan. Specifically, Site C is comprised of unplanned release (UPR) 200-UPR-E-137, including storage tank C-203, and site D is comprised of storage tanks C-201, C-202, and C-204. Additionally, the Work Plan (RPP-PLAN-39114) identifies Site O as 3D SGE of suspected releases throughout Waste Management Area (WMA) C, which is in part fulfilled through this survey a as well as the following previous documented geophysical surveys in the vicinity of $\mathrm{C}$ Tank Farm:

- RPP-RPT-31558, Surface Geophysical Exploration of C Tank Farm at the Hanford Site, completed in FY 2006

- RPP-RPT-41236, Surface Geophysical Exploration of UPR 200-E-81 Near the C Tank Farm, completed in FY 2009

- RPP-RPT-47486, Surface Geophysical Exploration of UPR 200 E 86 Near the C Tank Farm, completed in FY 2010

- RPP-RPT-49288, C Farm Surface Geophysical Exploration-Reprocessing, completed in FY 2011 
- RPP-RPT-50052, Surface Geophysical Exploration of UPR-200-E-82 Near the C Tank Farm, completed in FY 2011.

\subsection{REPORT LAYOUT}

The overall scope and content of this report is divided into several main sections as follows:

- Section 1.0, Introduction - Describes the scope and objectives of the investigation.

- Section 2.0, Background - Describes the geologic and hydrologic setting and information regarding the disposal activities in and around C Tank Farm.

- Section 3.0, Data Acquisition and Processing - Presents general layout of the data acquisition and processing with methods and controls used to ensure the quality and control of data collection, reduction, and processing used in this study.

- Section 4.0, Results and Interpretations - Presents the preliminary modeling results from the electrical resistivity surveying effort.

- Section 5.0, Conclusions - Provides a summary and conclusions drawn from the results and interpretations.

- Section 6.0, References - Provides a listing of references cited in the report.

- Appendix A, Quality Assurance - Presents general methods and controls used to ensure the quality and control of data collection, reduction, and processing and configuration control of software and database changes used in this study.

\subsection{BACKGROUND}

\subsection{SITE DESCRIPTION}

The C Tank Farm is located in the 200 East Area and is one of 12 single-shell tank (SST) farms on the Hanford Site (Figure 1). The C Tank Farm contains twelve 100-Series SSTs and four 200-Series SSTs that were constructed between 1943 and 1944, put into service in 1946, and are currently out of service pending final waste retrieval actions. The C Tank Farm received waste generated by the majority of the major chemical processing operations at the Hanford Site. This included waste from the bismuth phosphate fuel processing, uranium recovery, plutoniumuranium extraction (PUREX) fuel processing, and fission product recovery (RPP-14430, Subsurface Conditions Description of the C and A-AX Waste Management Areas). As a result of tank farm operations, the groundwater under $C$ Tank Farm is contaminated. Monitoring data from wells in and around the C Tank Farm is summarized in reports publicly available on the Hanford.gov website via an interactive report viewer. In summary, nitrate, iodine-129, technetium-99, and uranium form extensive groundwater plumes in the 200 East Area and adjacent portions of the surrounding 600 Area. Other contaminants such as cyanide, tritium, strontium-90, cesium-137 and plutonium-239/240 are also present to a more limited extent (DOE/RL-2013-22, Hanford Site Groundwater Monitoring Report for 2012). 


\section{Figure 1. Location Map of C Tank Farm in the 200 East Area of the DOE Hanford Site.}

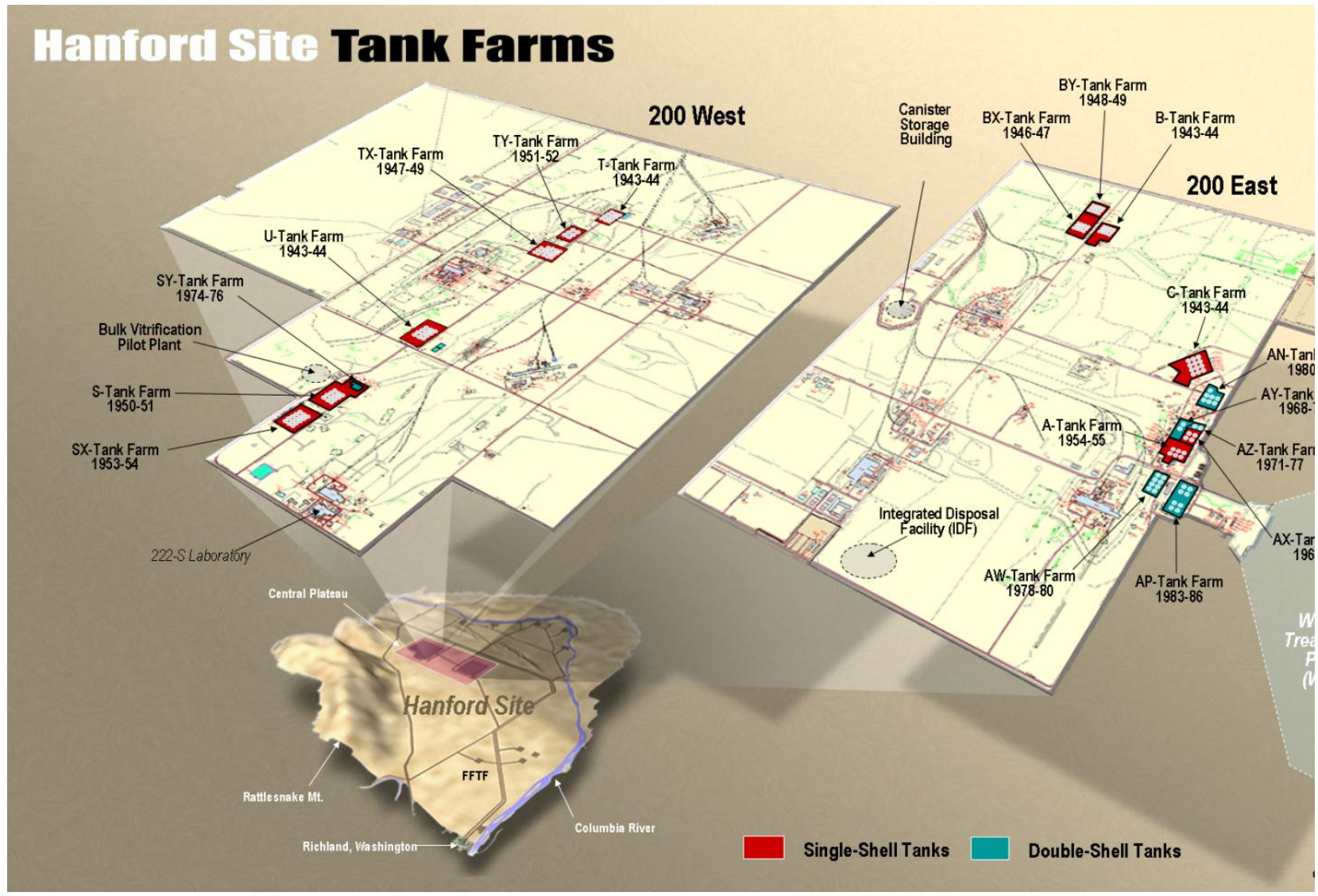

Information on the geology and hydrology of the C Tank Farm area can be found in RPP-35484, Field Investigation Report for Waste Management Areas $C$ and A-AX, and RPP-23748, Geology, Hydrogeology, Geochemistry, and Mineralogy Data Package for the Single-Shell Tank Waste Management Areas at the Hanford Site. A brief description of site infrastructure and waste inventory as it pertains to the $\mathrm{C}$ Tank Farm investigation follows.

The C Tank Farm area consists of the following facilities, shown graphically in Figure 2.

- Twelve 100-Series SSTs with a 530,000-gal (2,000,000-L) capacity

- Four 200-Series SSTs with a 55,000-gal (210,000-L) capacity

- 244-CR vault

- Eight diversion boxes

- Waste transfer lines

- Leak detection systems

- Tank ancillary equipment.

Specifically, this geophysical investigation was conducted near the 200-Series tanks in the northeast portion of the C Tank Farm; therefore, the following descriptions will concentrate on this area (Figure 3). 
Figure 2. Map of the C Tank Farm and Surrounding Facilities.

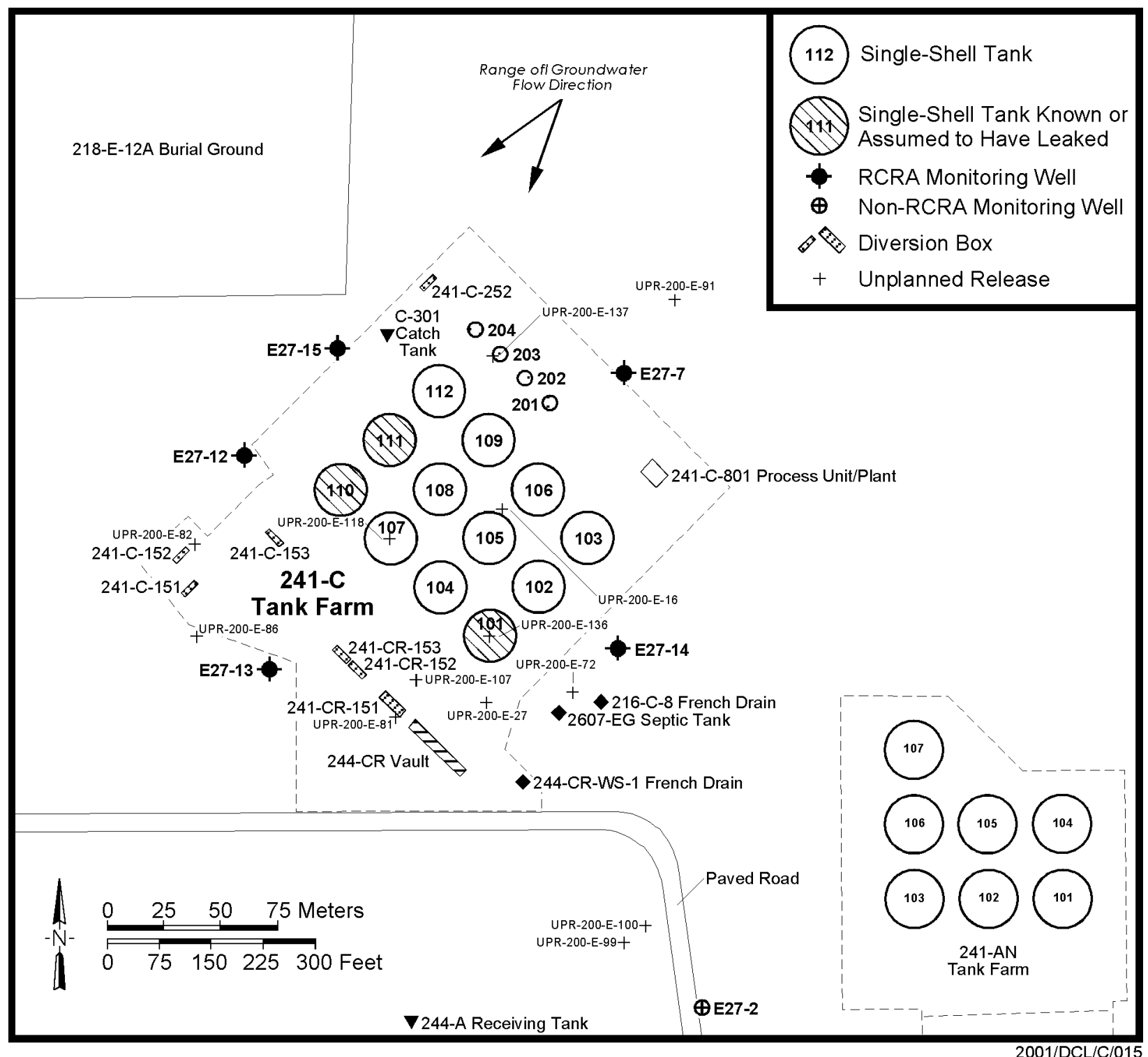

Taken from RPP-RPT-31558 
Figure 3. C Tank Farm 200-Series 3D Electrical Resistivity Survey Area.

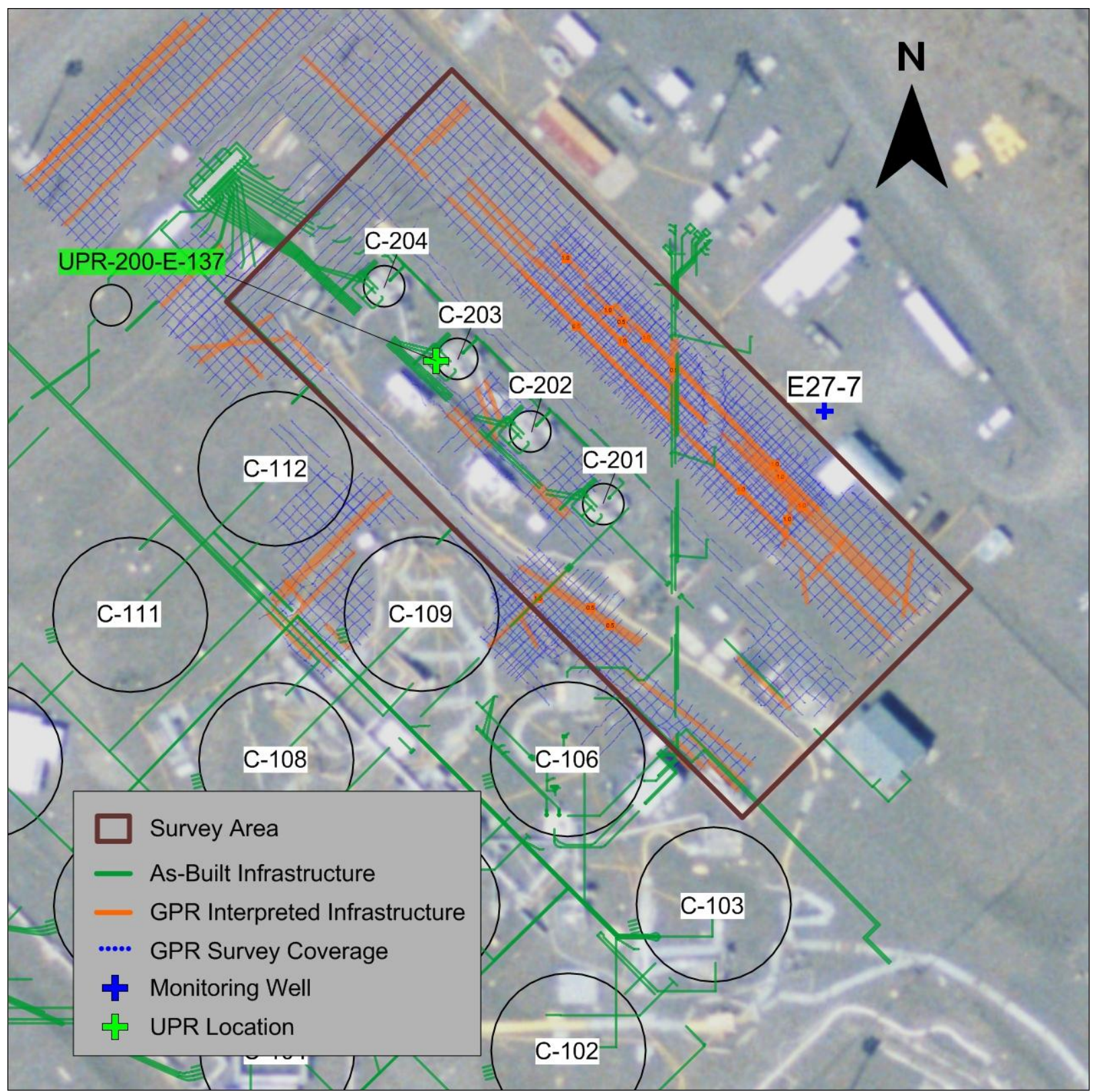

\section{$2.2 \quad 200-S E R I E S$ TANK INFRASTRUCTURE}

The 200-Series tanks are $20 \mathrm{ft}(6.1 \mathrm{~m})$ in diameter and $37 \mathrm{ft}(11.3 \mathrm{~m})$ tall from base to top. The tanks have a 24-ft $(7.3-\mathrm{m})$ operating depth and an operating capacity of 55,000 gal $\left(0.21 \times 10^{6} \mathrm{~L}\right)$ each. The 200-Series tanks are situated entirely below the ground surface, with $11 \mathrm{ft}(3.4 \mathrm{~m})$ of backfill covering the concrete tanks. Typical tank configuration and dimensions are shown in Figure 4. 


\section{Figure 4. Typical Configuration and Dimensions of 200-Series Single-Shell Tanks in C Tank Farm.}

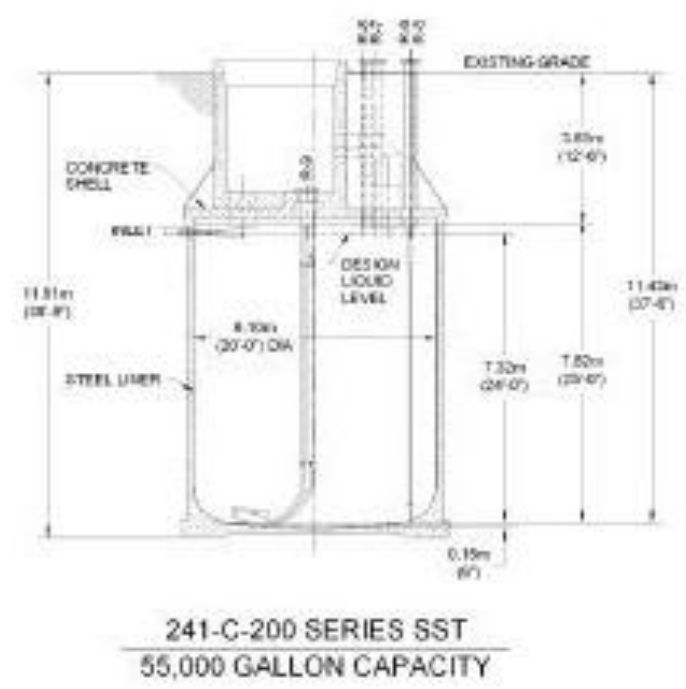

The 200-Series SSTs consist of a carbon steel liner covered with a reinforced-concrete shell that completely encases the steel liner and extends continuously above the liner wall to form a dome cover over the tank. Between the steel liner and concrete shell is a $3 / 8$-in. $(0.95-\mathrm{cm})$ thick asphalt membrane that serves as a waterproofing layer. Tanks C-201, C-202, C-203, and C-204 have tie lines between each tank to equalize the waste volumes in each tank (DOE/RL-88-30, Hanford Site Waste Management Units Report).

The backfill that covers the SSTs came from screened (i.e., large stones removed), excavated soil material. The heavy equipment that was used for excavation and for completing the tank construction is thought to have produced a compaction layer under and around each tank. The backfill between and over the tanks is relatively homogeneous compared with the undisturbed soil under the tanks.

\section{$2.3 \quad$ 200-SERIES TANK OPERATING HISTORY}

The 200-Series tanks received metal waste from the 221-B Bismuth Phosphate Separations Plant and 221-B Plant from November 1947 through January 1948. From March 1953 through January 1955, retrieval of mixed waste supernate and sludge to the 241-CR vault and 241-WR vault was performed. Tanks C-203 and C-204 received cold uranium from the 202-A-PUREX Plant in November 1955 that was then transferred to the 216-A-19 ditch in December 1955. From May 1955 through October 1956, all four tanks received waste from the 201-C Hot Semi-Works Facility at which point they were filled and no longer used to receive waste. In 1970, the liquids in the 200-series were transferred to 100-Series tanks C-104 and C-109. In 1980, the remaining liquids were transferred to tank C-106 (RPP-15408, Origin of Wastes in C-200 Series Single Shell Tanks; RPP-RPT-42294, Hanford Waste Management Area C Soil Contamination Inventory Estimates). 


\section{$2.4 \quad 200-S E R I E S$ TANK WASTE SUMMARY}

All four 200-Series tanks (C-201 through C-204) are listed as confirmed or assumed leakers (HNF-EP-0182,Waste Tank Summary Report for Month Ending July 31, 2013); however, all waste has since been retrieved and no evidence of leaks during retrieval were observed for these storage tanks (RPP-RPT-42294). Due to assumed historical leaks, the 200-Series tanks had their waste retrieved using a vacuum retrieval system to minimize the addition of water during retrieval (RPP-RPT-30181, Retrieval Data Report for Single-Shell Tank 241-C-201; RPP-RPT-29095, Retrieval Data Report for Single-Shell Tank 241-C-202; RPP-RPT-26475, Retrieval Data Report for Single-Shell Tank 241-C-203; RPP-RPT-34062, Retrieval Data Report for Single-Shell Tank 241-C-204).

Tanks C-201, C-202, and C-204 were filled above elevation of the spare inlet nozzles and cascade lines on several occasions (RPP-RPT-42294). This may have resulted in waste being lost to the ground from these SSTs. This waste may have included 201-C Hot Semi-Works waste from PUREX flowsheet tests and/or 201-C Building flush solutions. Dates of overfill were December 1955 - January 1956 and June 1961 - June 1963 for tank C-201; January 1957 March 1957, June 1957 - October 1958, and June 1961 - December 1963 for tank C-202; and March 1968 - March 1970 for tank C-204. Eleven pipelines are also known or suspected of failure in WMA C while transferring tank wastes. RPP-PLAN-39114, Phase 2 RCRA Facility Investigation/Corrective Measures Study Work Plan for Waste Management Area C, describes ongoing field investigations in WMA $\mathrm{C}$ to investigate past leaks or overflows. Pending completion of this Phase II assessment, volumes as documented in HNF-EP-0182 are referenced below and summarized in Table 1, and assumed as current inventory estimates:

- Tank C-201 Nominal Waste Volume: Total waste 545 L (144 gal); sludge 538 L (142 gal); supernate 7.5 L (2 gal) (RPP-29441, Post-Retrieval Waste Volume Determination for Single-Shell Tank 241-C-201)

- Tank C-202 Nominal Waste Volume: Total waste 556 L (147 gal); sludge 549 L (145 gal); supernate 7.5 L (2 gal) (RPP-RPT-29095)

- Tank C-203 Nominal Waste Volume: Total waste 536 L (139 gal); sludge 477 L (126 gal); supernate 49 L (13 gal) (RPP-RPT-26475)

- Tank C-204 Nominal Waste Volume: Total waste 519 L (137 gal); sludge 507 L (134 gal); supernate 11.4 L (3 gal) (RPP-RPT-34062). 
Table 1. C Tank Farm 200-Series Tank Waste Releases.

\begin{tabular}{|l|l|c|c|c|}
\hline $\begin{array}{c}\text { Tank } \\
\text { Number }\end{array}$ & \multicolumn{1}{|c|}{ Tank Status } & $\begin{array}{c}\text { Nominal Volume of Remaining } \\
\text { Waste after Retrieval (gal) }\end{array}$ & $\begin{array}{c}\text { Assumed } \\
\text { Leaker }\end{array}$ & $\begin{array}{c}\text { Estimated Leak } \\
\text { Volume (gal) }\end{array}$ \\
\hline $241-\mathrm{C}-201$ & $\begin{array}{l}\text { Retrieval Completed } \\
\text { (March 2006) }\end{array}$ & 144 & 1988 & 550 \\
\hline $241-\mathrm{C}-202$ & $\begin{array}{l}\text { Retrieval Completed } \\
\text { (August 2005) }\end{array}$ & 147 & 1988 & 450 \\
\hline $241-\mathrm{C}-203$ & $\begin{array}{l}\text { Retrieval Completed } \\
\text { (March 2005) }\end{array}$ & 139 & 1984 & 400 \\
\hline $241-\mathrm{C}-204$ & $\begin{array}{l}\text { Retrieval Completed } \\
\text { (December 2006) }\end{array}$ & 134 & 1988 & 350 \\
\hline
\end{tabular}

Source: HNF-EP-0182,2013, Waste Tank Summary Report for Month Ending July 31, 2013, Rev. 304.

Note: 1 gallon $=3.79$ liters.

In addition, UPR-200-E-137 occurred when, as stated in Waste Information Data System (WIDS), water entered tank C-203, migrated through the salt cake, and either became entrained in the salt cake or leaked out of the tank. The leak was $1514 \mathrm{~L}$ ( $400 \mathrm{gal}$ ) of PUREX high-level waste. The waste in tank C-203 was subsequently determined to be sludge and was retrieved to a double-shell tank in 2006.

A number of other locations in the C Tank Farm were subject to waste releases, from several SSTs and other infrastructure-related or surface-based UPRs. These waste releases are highlighted in Figure 5. 
Figure 5. C Tank Farm Area Waste Release Inventory.

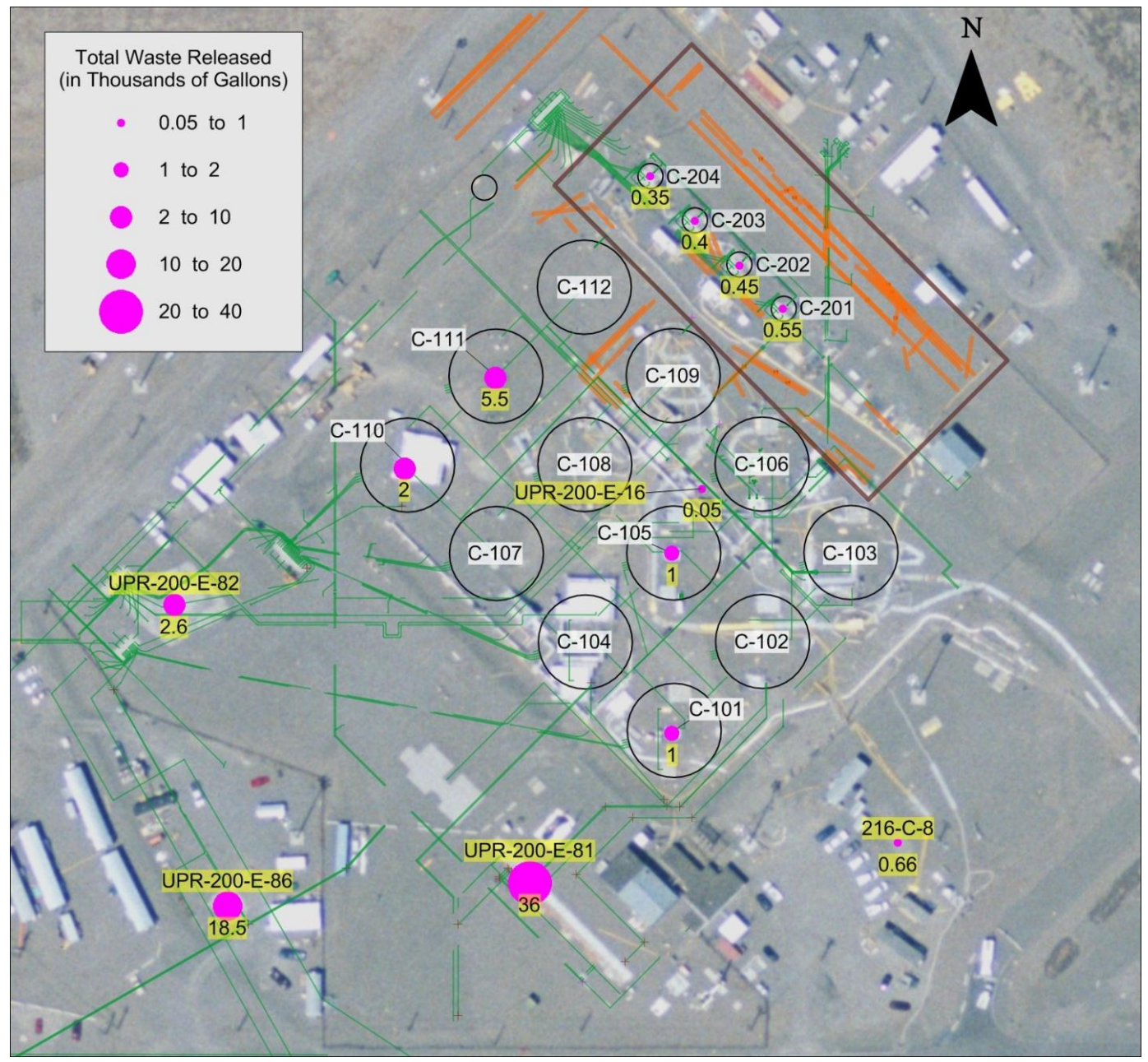

\subsection{PREVIOUS CHARACTERIZATION EFFORTS}

\subsubsection{Drywell Gamma Logging}

A series of cross-section visualizations based on spectral gamma drywell measurements in the tank farm are provided in Figure 6 through Figure 18, taken directly from GJO-98-39-TARA, C Tank Farm Visualizations. Although there is extremely limited drywell coverage relative to the 200-Series tanks resistivity survey area, gamma measurements taken in the vicinity of the 100-Series tanks may provide some insight into the movement of contamination in a broader sense. A review of these figures indicates relatively wide spread gamma contamination near the tank farm surface and several disjointed areas of contamination at depth. The results at $27.1 \mathrm{~m}$ ( $89 \mathrm{ft}$ ) below ground surface (bgs) and below are of note due to the detection of cobalt- 60 near tanks C-103, C-106, and C-109, as these are nearest to the 200-Series tanks resistivity survey area and cobalt-60 was detected at monitoring well E27-7. 
Figure 6. Visual Interpretation of Drywell Logging Activity at $0.6 \mathrm{~m}(2 \mathrm{ft})$ bgs $(197.4 \mathrm{~m}[648 \mathrm{ft}] \mathrm{amsl})$.

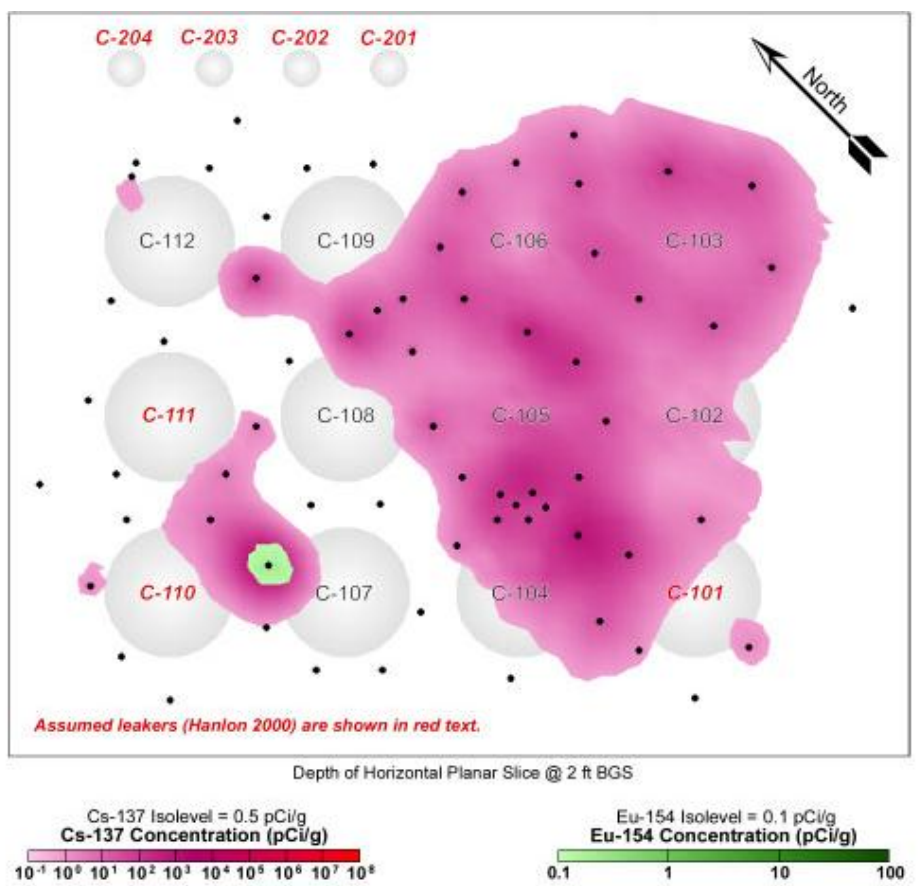

Figure 7. Visual Interpretation of Drywell Logging Activity at $2.4 \mathrm{~m}(8 \mathrm{ft})$ bgs $(195.6 \mathrm{~m}[642 \mathrm{ft}]$ amsl).

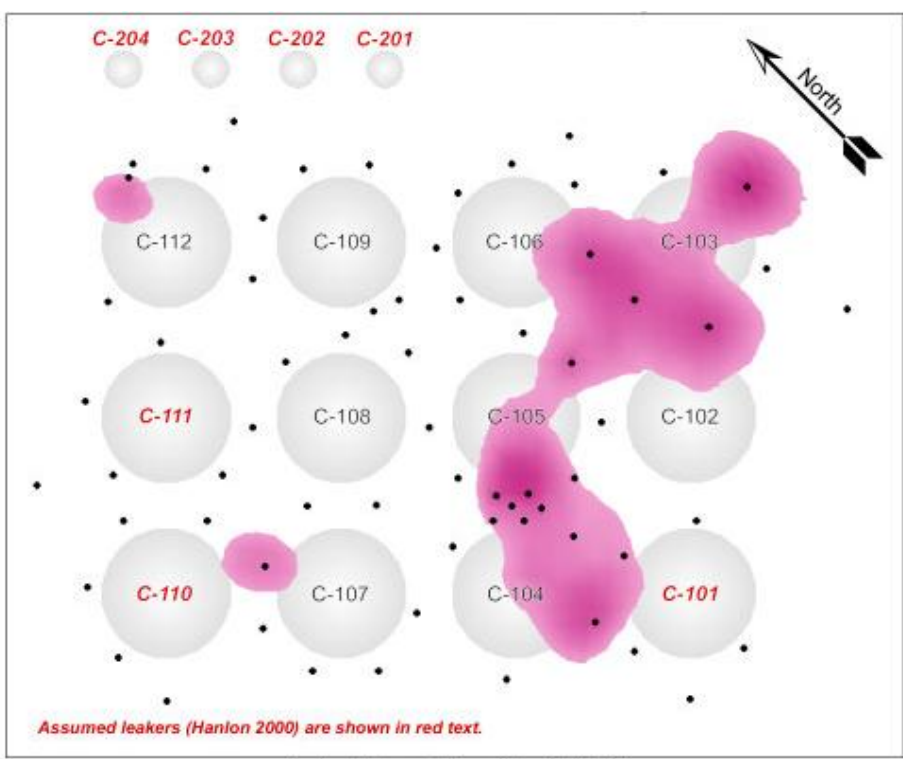

Depth of Horizontal Planar Slice @ 8 if BGS

Cs- 137 Isolevel $=0.5 \mathrm{pCi} / \mathrm{g}$
s-137 Concentration (pCi/g) $10^{-4} 10^{\circ} 10^{4} 10^{2} 10^{3} 10^{4} 10^{3} 10^{6} 10^{7} 10^{4}$ 
Figure 8. Visual Interpretation of Drywell Logging Activity at $5.5 \mathrm{~m}(18 \mathrm{ft})$ bgs $(192.5 \mathrm{~m}[632 \mathrm{ft}]$ amsl $)$.

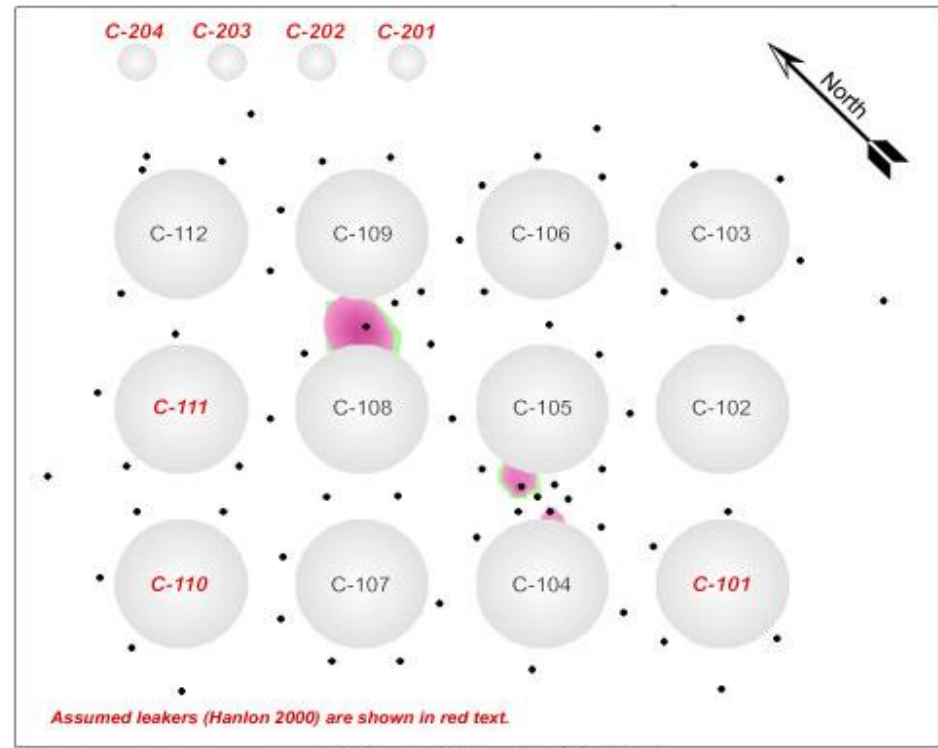

Depth of Horizontal Planar Slice @ 18 ft BGS
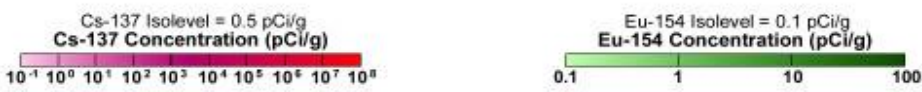

Figure 9. Visual Interpretation of Drywell Logging Activity at $7.3 \mathrm{~m}(24 \mathrm{ft})$ bgs $(190.7 \mathrm{~m}[626 \mathrm{ft}]$ amsl).

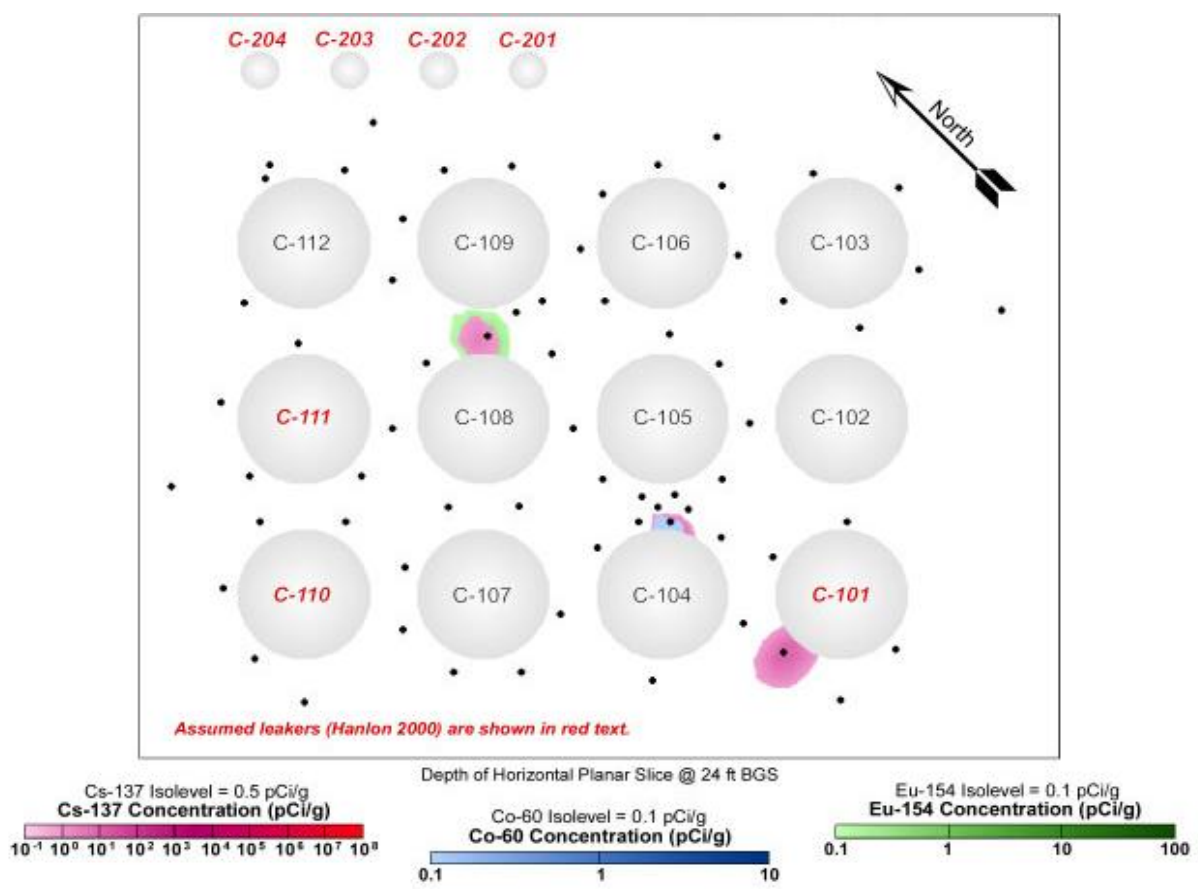


Figure 10. Visual Interpretation of Drywell Logging Activity at $11.6 \mathrm{~m}(38 \mathrm{ft})$ bgs $(186.4 \mathrm{~m}[612 \mathrm{ft}]$ amsl $)$.

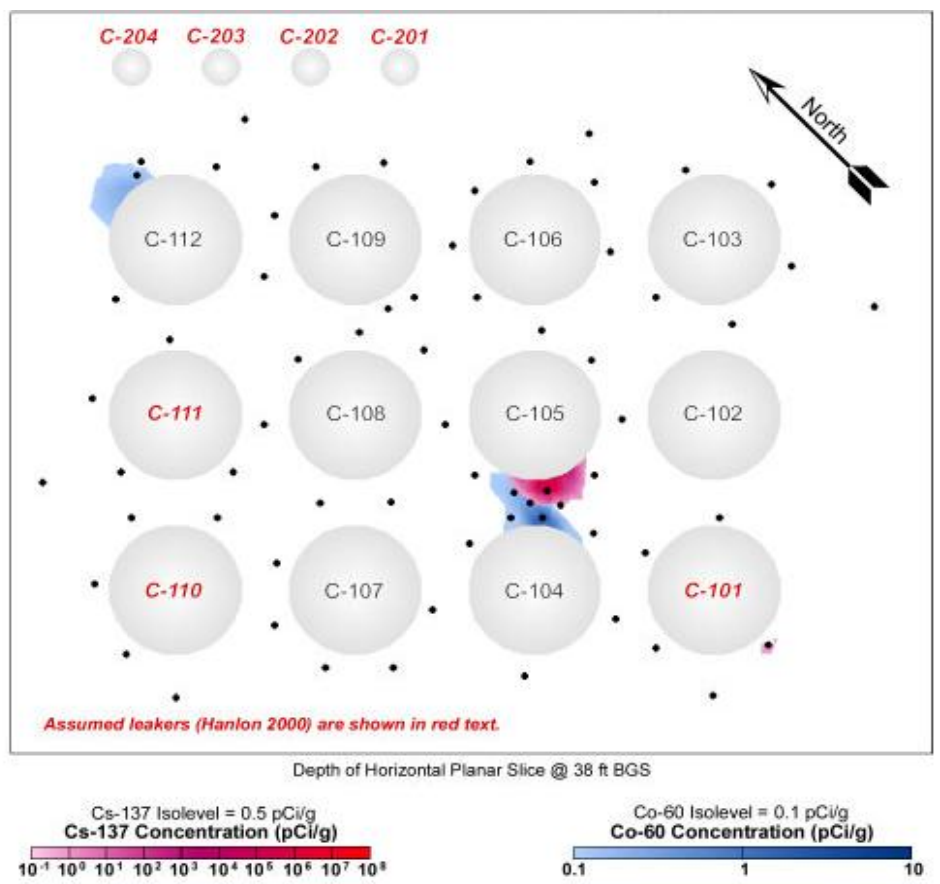

Figure 11. Visual Interpretation of Drywell Logging Activity at $14.3 \mathrm{~m}(47 \mathrm{ft})$ bgs $(183.7 \mathrm{~m}[603 \mathrm{ft}] \mathrm{amsl})$.

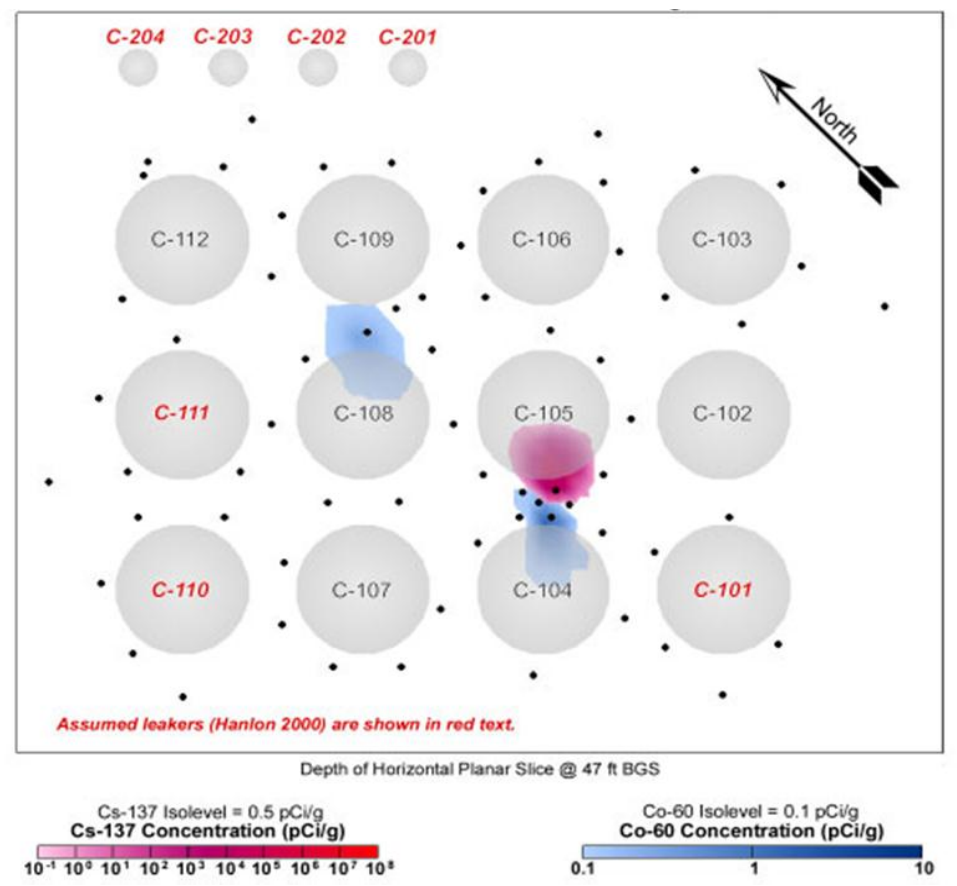


Figure 12. Visual Interpretation of Drywell Logging Activity at $17.1 \mathrm{~m} \mathrm{(56} \mathrm{ft)} \mathrm{bgs}(180.9 \mathrm{~m}$ [594 ft] amsl).

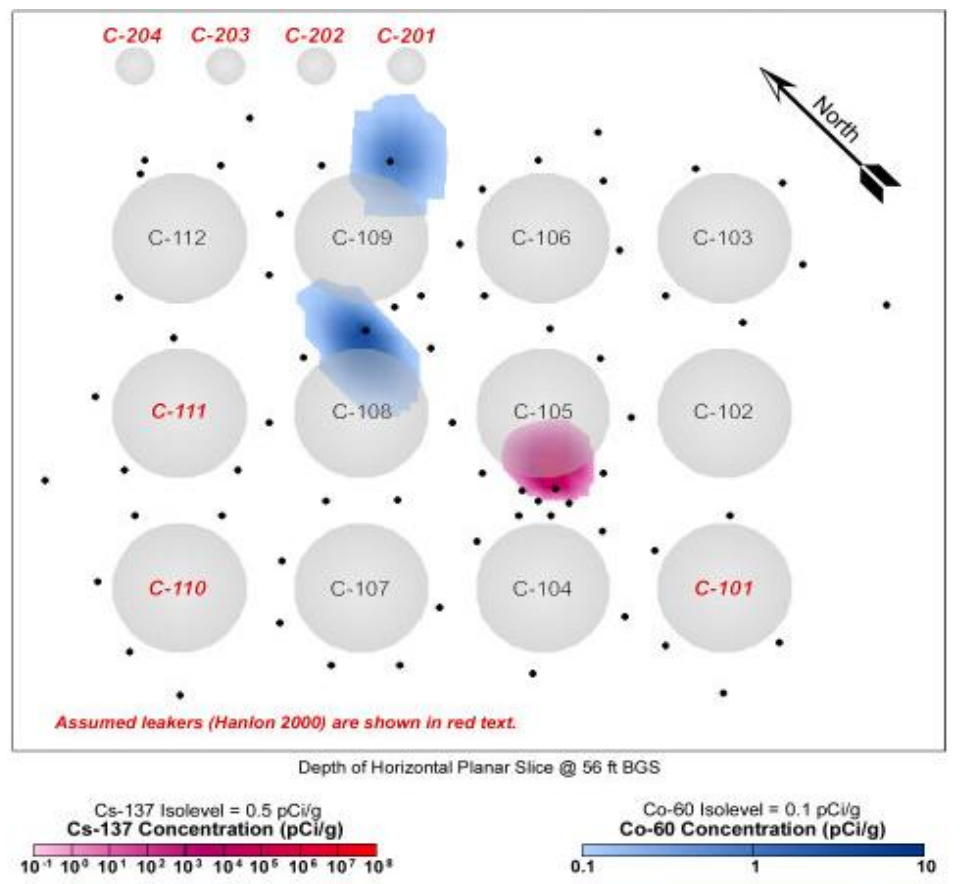

Figure 13. Visual Interpretation of Drywell Logging Activity at $20.7 \mathrm{~m}(68 \mathrm{ft})$ bgs $(177.3 \mathrm{~m}$ [582 ft] amsl).

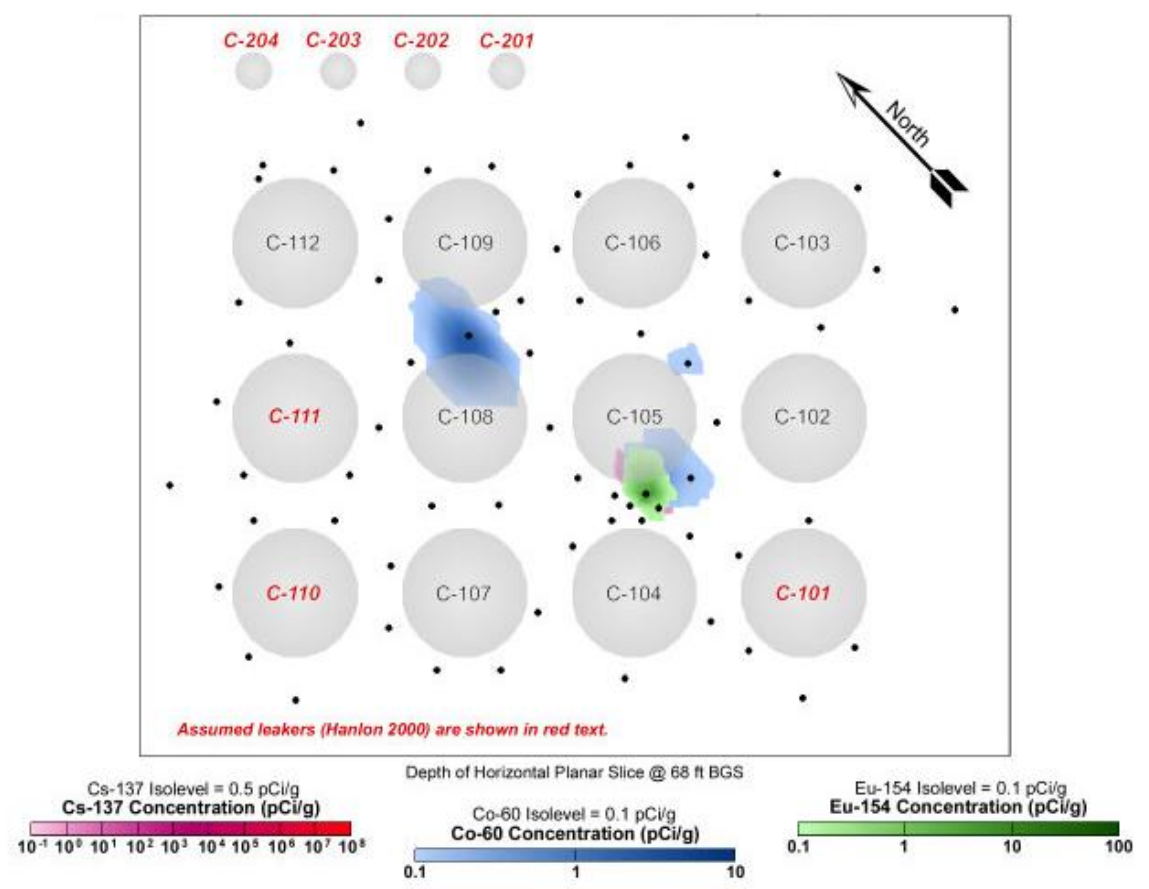


Figure 14. Visual Interpretation of Drywell Logging Activity at $23.8 \mathrm{~m}$ (78 ft) bgs (174.2 $\mathrm{m}$ [572 ft] amsl).

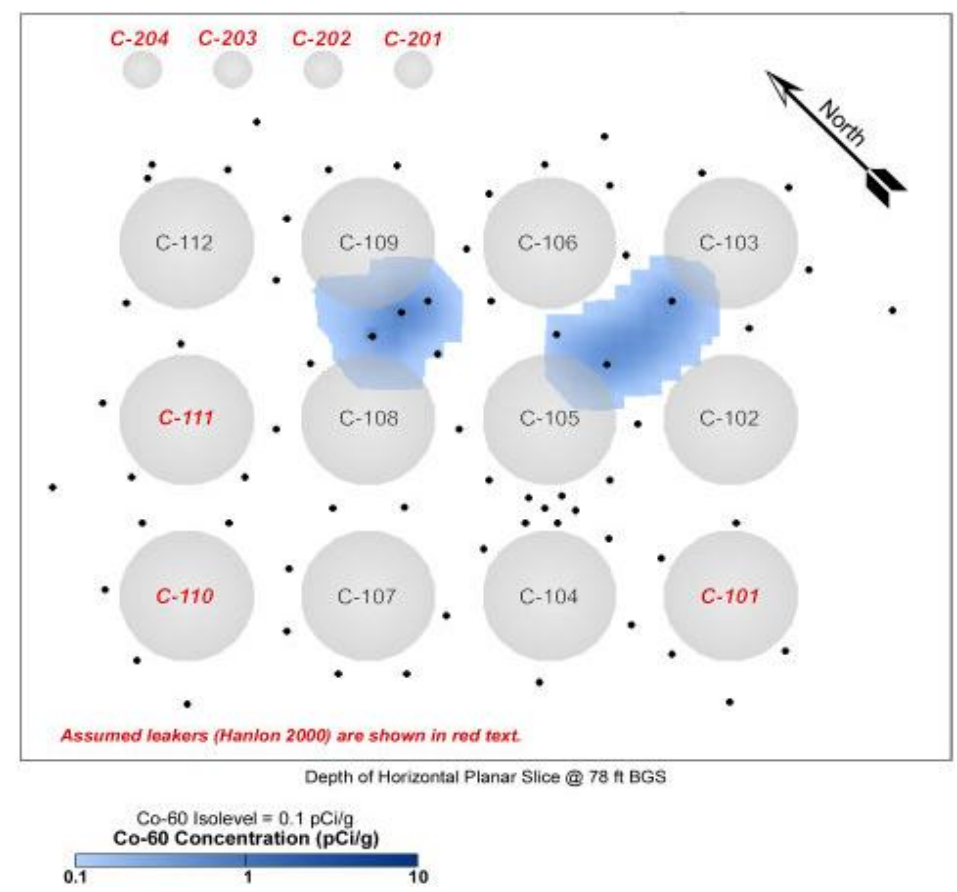

Figure 15. Visual Interpretation of Drywell Logging Activity at $27.1 \mathrm{~m}(89 \mathrm{ft})$ bgs $170.9 \mathrm{~m}$ [561 ft] amsl).

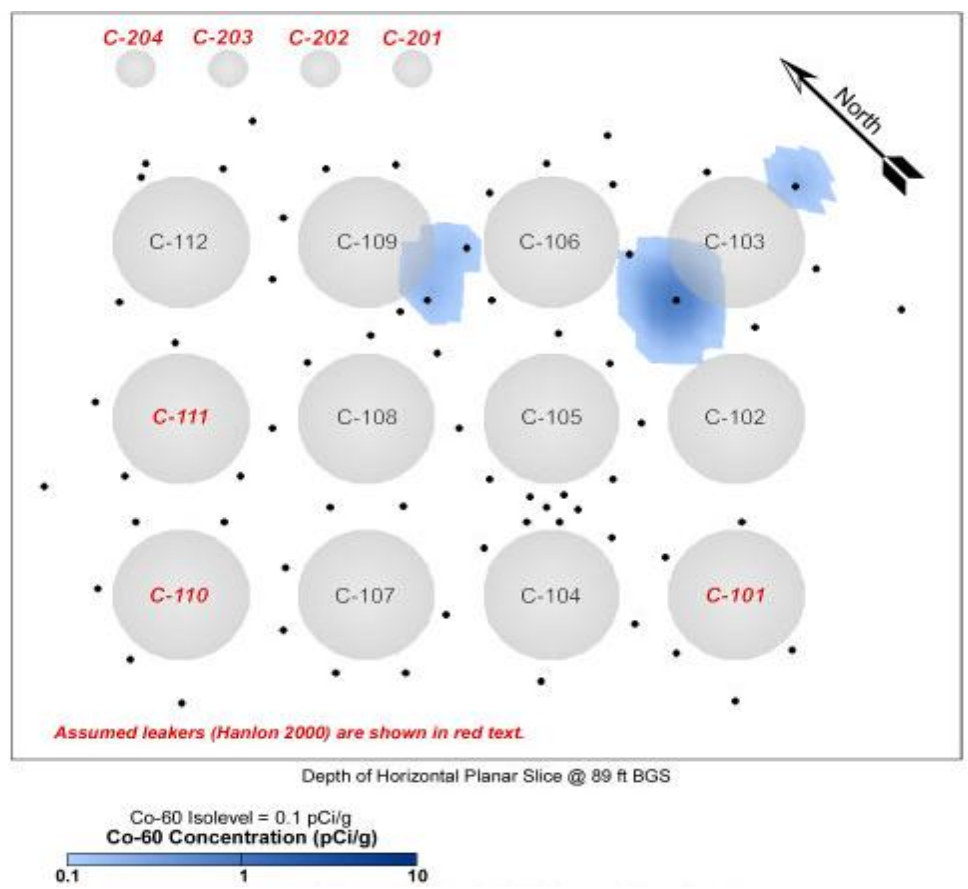


Figure 16. Visual Interpretation of Drywell Logging Activity at $31.7 \mathrm{~m}(104 \mathrm{ft})$ bgs $(166.3 \mathrm{~m}[546 \mathrm{ft}]$ amsl $)$.

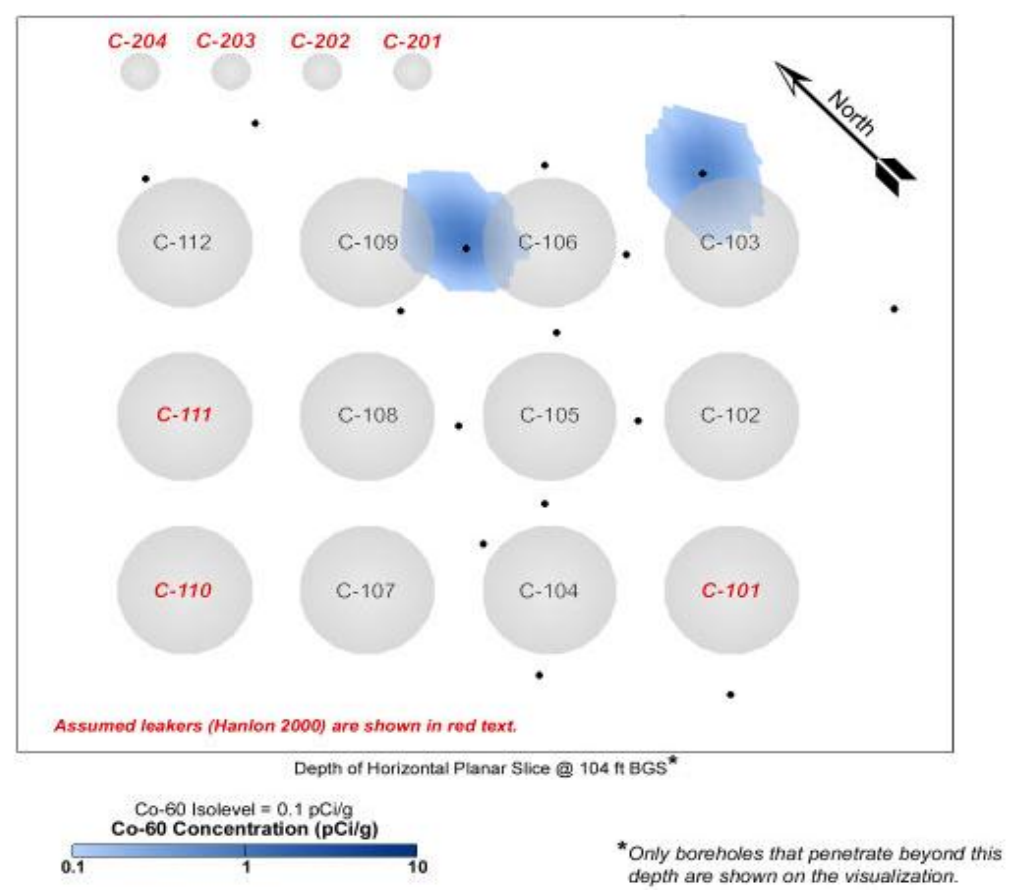

Figure 17. Visual Interpretation of Drywell Logging Activity at $34.7 \mathrm{~m}(114 \mathrm{ft})$ bgs $(163.3 \mathrm{~m}$ [536 ft] amsl).

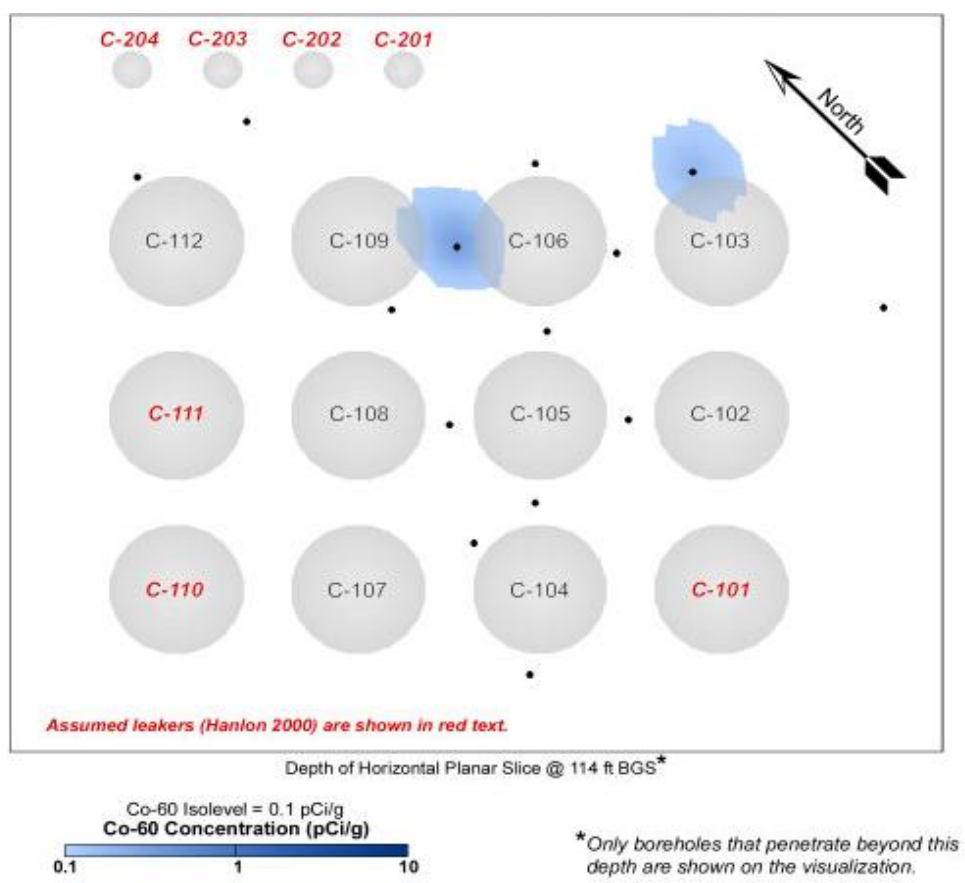




\section{Figure 18. Visual Interpretation of Drywell Logging Activity at $38.1 \mathrm{~m}(125 \mathrm{ft})$ bgs $(159.9 \mathrm{~m}[525 \mathrm{ft}]$ amsl $)$.}

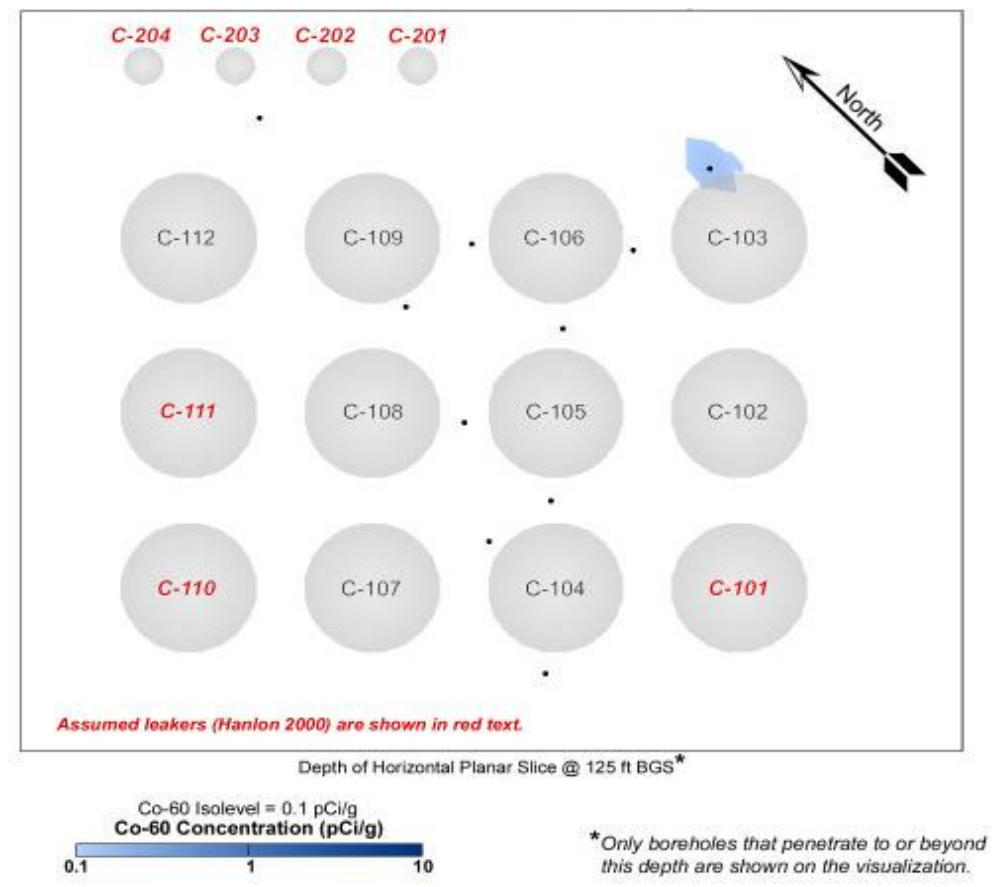

\subsubsection{Direct-Push Sampling}

Direct-push probe holes were completed at C Tank Farm starting in 2007 and continuing through 2013 to obtain soil sediment samples for later geochemical analysis (RPP-RPT-53055, Management Area C Resistivity Depth Electrode Locations), and to install electrical resistivity electrodes at depth. While most of the probe holes were installed within the 100-Series tank area and near UPR sites, several are located within the current 200-Series survey area. Moisture and gamma logging was conducted at each location as the probe holes were installed. Although some of the logging results are presented with the resistivity data at a later point in this report, the complete results for the $\mathrm{C}-200$ direct-push probes can be found in the following reports:

- RPP-RPT-42714, Completion Report for Single-Shell Tank 241-C-103 Direct Push Soil Investigation (C7465, C7467)

- RPP-RPT-47461, Completion Report for Direct Push Characterization at Three Sites in 241-C Tank Farm (C7471)

- RPP-RPT-51384, Completion Report for the 241-C Tank Farm C-203 Angle Direct Push Characterization (C8105)

- RPP-RPT-55481, Completion Report for 241-C Tank Farm 200 Series Tank Activities (C8763, C8765, C8766, C8767). 


\subsection{DATA ACQUISITION AND PROCESSING METHODOLOGY}

Data acquisition for a 3D electrical resistivity survey at the C Tank Farm began on July 24, 2013 and was completed on August 1,2013. The geophysical survey was initiated to collect data on surface electrodes and electrodes buried beneath the surface (i.e., depth electrodes).

Data collection activities, equipment, and data processing are described in the following sections.

\subsection{SURVEY DESIGN}

\subsubsection{D Survey}

The 3D electrical resistivity data were collected on surface electrodes and depth electrodes within the C Tank Farm perimeter fence. Data were collected based on a 3D data acquisition method that utilized numerous different electrode arrangements. The surface electrodes were distributed across a uniform grid to optimize the numerical inversion models used in the data analysis and interpretation. The significantly larger amounts of data associated with a 3D survey, relative to a two-dimensional (2D) survey, makes an optimized geometry crucial to reduce modeling run times and analysis. For the 3D C Tank Farm survey, 318 surface electrodes were distributed across a grid, with dimensions $48 \mathrm{~m}(157.5 \mathrm{ft})$ by $108 \mathrm{~m}(354.3 \mathrm{ft})$, with electrodes spaced nominally every $3 \mathrm{~m}(9.8 \mathrm{ft})$ in the northeast-southwest direction and $6 \mathrm{~m}$ $(19.7 \mathrm{ft})$ in the northwest-southeast directions. Some positions within this grid were skipped based on proximity to buried near-surface infrastructure or surface obstructions. Figure 19 shows the layout of the surface electrodes with associated resistivity cables. 
Figure 19. Resistivity Cable and Surface Electrode Layout.

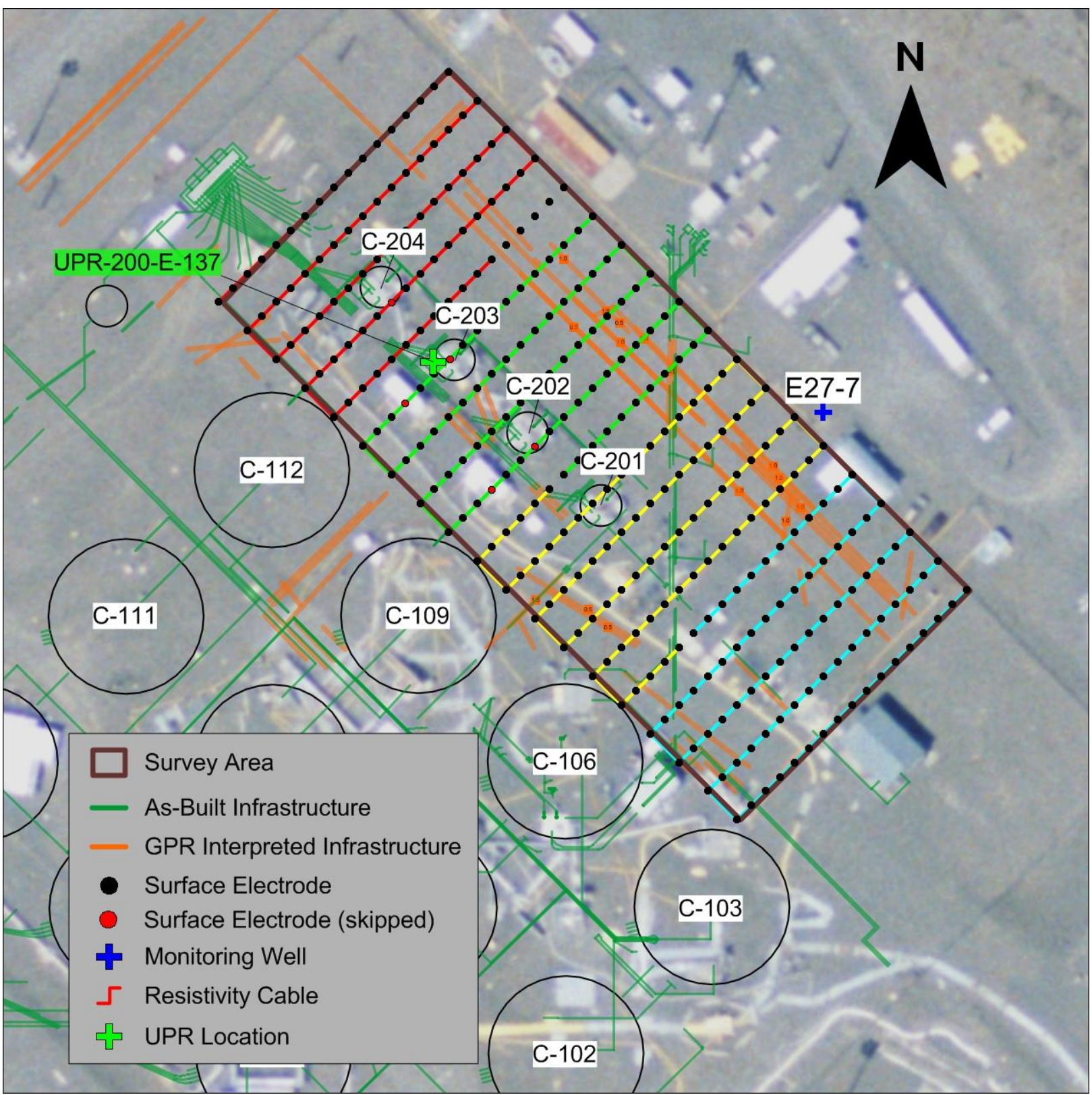

To minimize interference, the 3D grid of surface electrodes was positioned to avoid dense clusters of above ground and near-surface infrastructure based on the results from field observations, as-built computer-aided design (CAD) maps, and the FY 2012 Ground Penetrating Radar (GPR) survey. The GPR survey was designed to map subsurface infrastructure (shown as orange lines in Figure 19) in support of a separate drilling campaign and included two small sites within the larger C Tank Farm 3D survey area (RPT-2013-001, Summary of C-farm Site Clearance Survey). Note: the GPR coverage area did not encompass the full extent of the current electrical resistivity survey area. 
Further resolution improvements are possible by adding depth electrodes to a surface electrode geometry, whereby electrical current and voltage measurements can be made near or within a target in the subsurface. Depth electrodes have the added benefit of being further from nearsurface infrastructure and associated electrical interference and noise. For the C Tank Farm 3D electrical resistivity survey, eight boreholes with various numbers of depth electrodes were incorporated into the survey. The location of the depth electrode boreholes did not necessarily align to the surface electrode grid. Table 2 displays the locations and depths associated with each depth electrode for the current survey per RPP-RPT-53055.

Table 2. Locations for Depth Electrodes used in C Tank Farm 200-Series Electrical Resistivity Survey. (2 sheets)

\begin{tabular}{|c|c|c|c|c|c|c|c|}
\hline ID & $\begin{array}{c}\text { Completion } \\
\text { Date }\end{array}$ & Easting (m) & Northing (m) & Depth (m) & Depth (ft) & $\begin{array}{c}\text { Elevation } \\
\text { (m amsl) }\end{array}$ & $\begin{array}{c}\text { Elevation } \\
\text { (ft amsl) }\end{array}$ \\
\hline C7465 & Aug-09 & 575211.4 & 136559 & 26.2 & 86.0 & 171.8 & 564.0 \\
\hline C7465 & Aug-09 & 575211.4 & 136559 & 41.2 & 135.0 & 156.8 & 515.0 \\
\hline C7467 & Aug-09 & 575222.6 & 136563 & 14.0 & 46.0 & 184.0 & 604.0 \\
\hline C7467 & Aug-09 & 575222.6 & 136563 & 38.4 & 126.0 & 159.6 & 524.0 \\
\hline C7471 & Aug-10 & 575240.6 & 136588.6 & 11.3 & 37.0 & 182.7 & 600.0 \\
\hline C7471 & Aug-10 & 575240.6 & 136588.6 & 17.4 & 57.0 & 176.6 & 580.0 \\
\hline C7471 & Aug-10 & 575240.6 & 136588.6 & 23.5 & 77.0 & 170.5 & 560.0 \\
\hline C7471 & Aug-10 & 575240.6 & 136588.6 & 29.6 & 97.0 & 164.4 & 540.0 \\
\hline C7471 & Aug-10 & 575240.6 & 136588.6 & 35.7 & 117.0 & 158.3 & 520.0 \\
\hline C7471 & Aug-10 & 575240.6 & 136588.6 & 41.8 & 137.0 & 152.2 & 500.0 \\
\hline C7471 & Aug-10 & 575240.6 & 136588.6 & 47.9 & 157.0 & 146.1 & 480.0 \\
\hline C7471 & Aug-10 & 575240.6 & 136588.6 & 54.0 & 177.0 & 140.0 & 460.0 \\
\hline C7471 & Aug-10 & 575240.6 & 136588.6 & 59.7 & 196.0 & 134.3 & 441.0 \\
\hline $\mathrm{C} 8105$ & Oct-11 & 575167.17 & 136653.9 & 12.3 & 40.5 & 181.7 & 596.5 \\
\hline C8763 & May-13 & 575178.6 & 136589.9 & 15.9 & 52.0 & 182.1 & 598.0 \\
\hline C8763 & May-13 & 575178.6 & 136589.9 & 22.0 & 72.0 & 176.0 & 578.0 \\
\hline C8763 & May-13 & 575178.6 & 136589.9 & 28.0 & 92.0 & 170.0 & 558.0 \\
\hline C8763 & May-13 & 575178.6 & 136589.9 & 34.1 & 112.0 & 163.9 & 538.0 \\
\hline C8763 & May-13 & 575178.6 & 136589.9 & 40.2 & 132.0 & 157.8 & 518.0 \\
\hline C8763 & May-13 & 575178.6 & 136589.9 & 46.3 & 152.0 & 151.7 & 498.0 \\
\hline C8763 & May-13 & 575178.6 & 136589.9 & 52.4 & 172.0 & 145.6 & 478.0 \\
\hline C8763 & May-13 & 575178.6 & 136589.9 & 58.3 & 191.2 & 139.7 & 458.8 \\
\hline C8765 & Jun-13 & 575194.5 & 136629.2 & 8.8 & 29.0 & 185.2 & 608.0 \\
\hline C8765 & Jun-13 & 575194.5 & 136629.2 & 14.9 & 49.0 & 179.1 & 588.0 \\
\hline C8765 & Jun-13 & 575194.5 & 136629.2 & 21.0 & 69.0 & 173.0 & 568.0 \\
\hline C8765 & Jun-13 & 575194.5 & 136629.2 & 27.1 & 89.0 & 166.9 & 548.0 \\
\hline C8765 & Jun-13 & 575194.5 & 136629.2 & 33.2 & 109.0 & 160.8 & 528.0 \\
\hline
\end{tabular}


Table 2. Locations for Depth Electrodes used in C Tank Farm 200-Series Electrical Resistivity Survey. (2 sheets)

\begin{tabular}{|c|r|r|r|r|r|r|r|}
\hline ID & $\begin{array}{c}\text { Completion } \\
\text { Date }\end{array}$ & Easting (m) & Northing (m) & Depth (m) & Depth (ft) & $\begin{array}{c}\text { Elevation } \\
\text { (m amsl) }\end{array}$ & $\begin{array}{c}\text { Elevation } \\
\text { (ft amsl) }\end{array}$ \\
\hline C8765 & Jun-13 & 575194.5 & 136629.2 & 39.3 & 129.0 & 154.7 & 508.0 \\
\hline C8765 & Jun-13 & 575194.5 & 136629.2 & 45.4 & 149.0 & 148.6 & 488.0 \\
\hline C8765 & Jun-13 & 575194.5 & 136629.2 & 51.5 & 169.0 & 142.5 & 468.0 \\
\hline C8765 & Jun-13 & 575194.5 & 136629.2 & 57.4 & 188.3 & 136.6 & 448.7 \\
\hline C8766 & May-13 & 575205.5 & 136616.3 & 8.8 & 29.0 & 185.2 & 608.0 \\
\hline C8766 & May-13 & 575205.5 & 136616.3 & 14.9 & 49.0 & 179.1 & 588.0 \\
\hline C8766 & May-13 & 575205.5 & 136616.3 & 21.0 & 69.0 & 173.0 & 568.0 \\
\hline C8766 & May-13 & 575205.5 & 136616.3 & 27.1 & 89.0 & 166.9 & 548.0 \\
\hline C8766 & May-13 & 575205.5 & 136616.3 & 33.2 & 109.0 & 160.8 & 528.0 \\
\hline C8766 & May-13 & 575205.5 & 136616.3 & 39.3 & 129.0 & 154.7 & 508.0 \\
\hline C8766 & May-13 & 575205.5 & 136616.3 & 45.4 & 149.0 & 148.6 & 488.0 \\
\hline C8766 & May-13 & 575205.5 & 136616.3 & 51.5 & 169.0 & 142.5 & 468.0 \\
\hline C8766 & May-13 & 575205.5 & 136616.3 & 57.4 & 188.3 & 136.6 & 448.7 \\
\hline C8767 & May-13 & 575211.5 & 136609.3 & 8.8 & 29.0 & 185.2 & 608.0 \\
\hline C8767 & May-13 & 575211.5 & 136609.3 & 14.9 & 49.0 & 179.1 & 588.0 \\
\hline C8767 & May-13 & 575211.5 & 136609.3 & 21.0 & 69.0 & 173.0 & 568.0 \\
\hline C8767 & May-13 & 575211.5 & 136609.3 & 27.1 & 89.0 & 166.9 & 548.0 \\
\hline C8767 & May-13 & 575211.5 & 136609.3 & 33.2 & 109.0 & 160.8 & 528.0 \\
\hline C8767 & May-13 & 575211.5 & 136609.3 & 39.3 & 129.0 & 154.7 & 508.0 \\
\hline C8767 & May-13 & 575211.5 & 136609.3 & 45.4 & 149.0 & 148.6 & 488.0 \\
\hline C8767 & May-13 & 575211.5 & 136609.3 & 51.5 & 169.0 & 142.5 & 468.0 \\
\hline C8767 & May-13 & 575211.5 & 136609.3 & 57.4 & 188.3 & 136.6 & 448.7 \\
\hline
\end{tabular}

One groundwater monitoring well outside of the C Tank Farm perimeter fence (299-E27-7) was used as a 'long electrode' in the 3D data acquisition; this method has been used in past survey designs to improve data quality in areas of increased buried infrastructure. This well was also included in the survey as a potential "mise-a-la-masse" current source, as recent well logging results have indicated the presence of anthropogenic radiation (cobalt-60 and uranium) and thereby possibly placing the well in contact with a contaminant plume. Recent advances in inversion software allow for the simultaneous processing of point source electrodes (surface and depth electrodes) and linear electrodes (wells). The location of well E27-7 is provided in Table 3, with a well completion schematic provided in Figure 20. 
Table 3. Well Location used in C Tank Farm 200-Series Electrical Resistivity Survey.

\begin{tabular}{|c|c|c|c|c|c|c|c|}
\hline $\begin{array}{l}\text { Well } \\
\text { Name }\end{array}$ & $\begin{array}{l}\text { Tank } \\
\text { Farm }\end{array}$ & $\begin{array}{c}\text { Easting } \\
(\mathbf{m})\end{array}$ & $\begin{array}{l}\text { Northing } \\
\text { (m) }\end{array}$ & $\begin{array}{c}\text { Casing Length } \\
\text { (m) }\end{array}$ & $\begin{array}{c}\text { Casing Length } \\
\text { (ft) }\end{array}$ & $\begin{array}{l}\text { Elevation } \\
\quad(\mathbf{m})\end{array}$ & $\begin{array}{c}\text { Elevation } \\
\text { (ft) }\end{array}$ \\
\hline E27-7 & $\mathrm{C}$ & 575221 & 136620 & 85.7 & 281 & 108.4 & 356 \\
\hline
\end{tabular}

Figure 20. Well Completion Schematic for Monitoring Well 27-7.

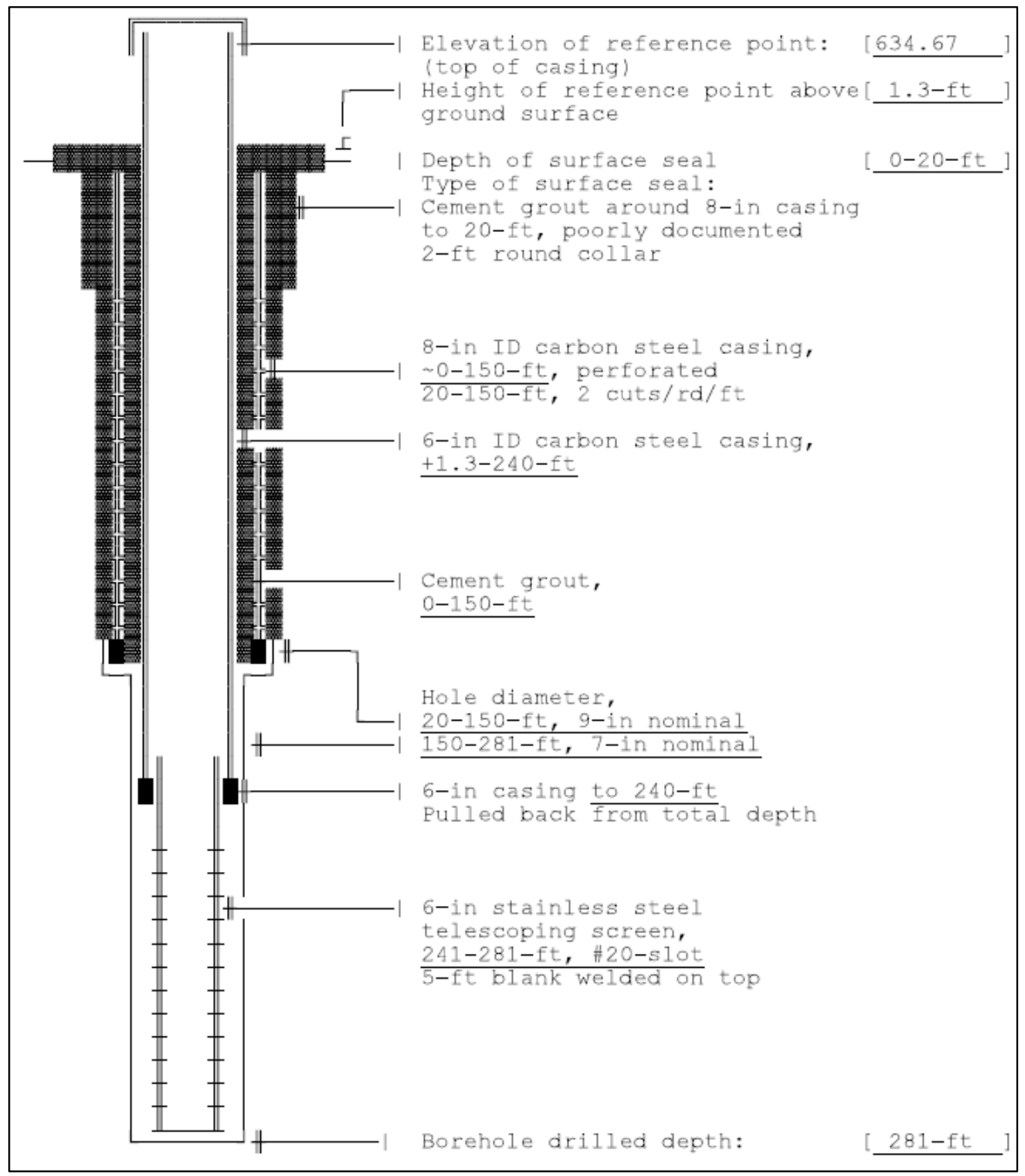

Source:

http://idmsweb.rl.gov/idms/livelink.exe/fetch/2000/18814/13256931/43106165/44466164/50344655/NA_\%5B N07295975\%5D.pdf?nodeid $=50367264 \&$ vernum $=-2$ 
Figure 21 shows the distribution of wells and depth electrodes within the 3D survey area.

Figure 21. 3D Survey Depth Electrode and Well Distribution.

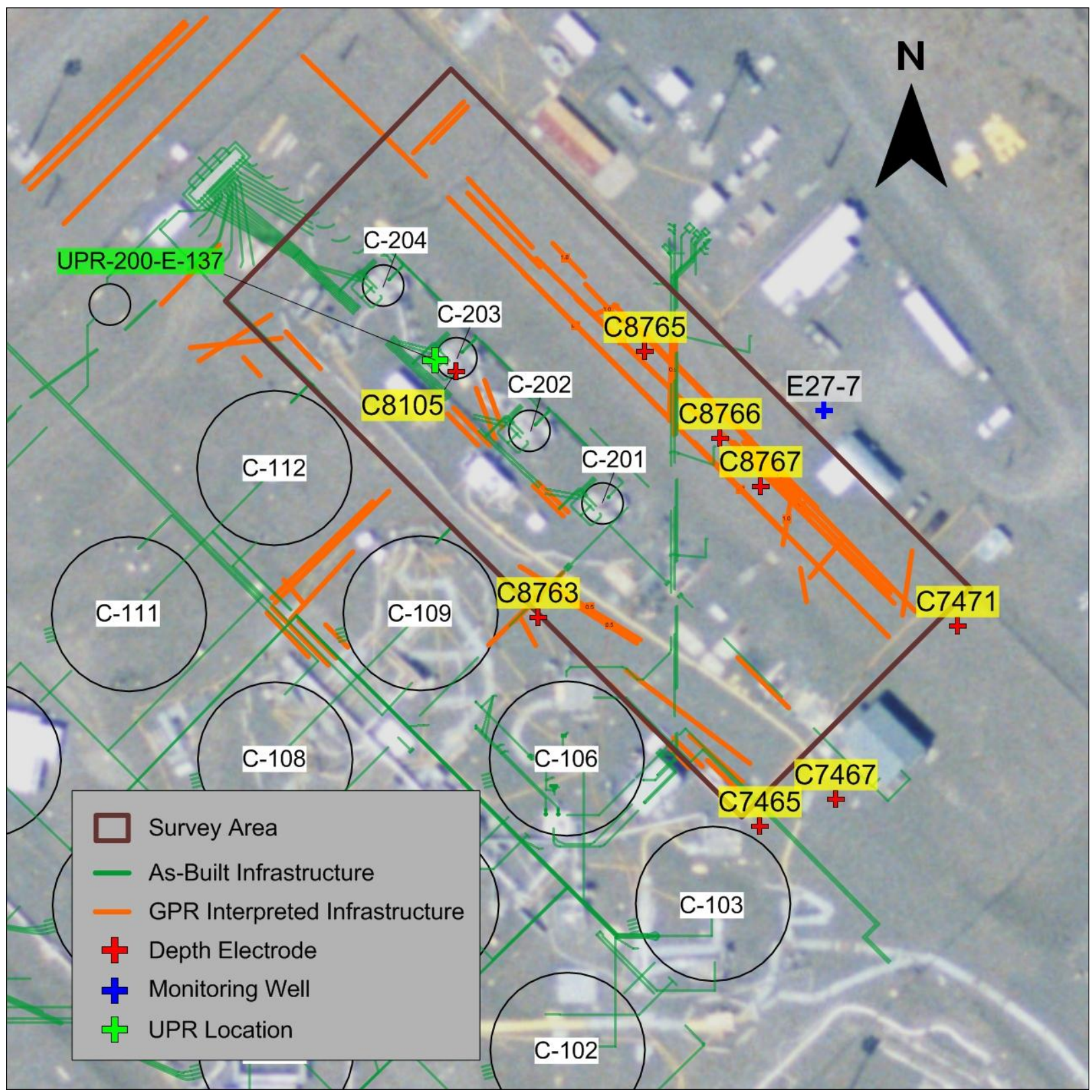




\subsection{EQUIPMENT}

\subsubsection{Electrode and Cable Layout}

The first stage of the project was to assemble all available infrastructure maps for the C Tank Farm and specifically the 200-Series tanks area. The resulting maps were combined into an AutoCAD ${ }^{\circledR}$ drawing and subsequently used to define the coordinates for electrode placement. The maps containing infrastructure locations, including subsurface pipes/structures and surface structures, were digitized and combined with the electrode locations. Electrode locations were then modified to avoid being directly over infrastructure where possible. Electrode placement was limited by maintaining a uniform grid layout to support data processing procedures. The final electrode layout was then uploaded into a Leica ${ }^{\circledR} 1200$ Global Positioning System (GPS) which was used to mark electrode locations on the ground surface. The Leica system has subcentimeter accuracy, ensuring the survey geometry is retained.

The electrodes are connected to the resistivity acquisition systems by way of multi-cored cables. For the C Tank Farm 3D survey, a total of four cables were deployed; each cable allowing up to 84 electrodes to be connected. The cables were placed in a serpentine pattern, with jumpers connecting the stainless steel probe to the electrode cable. In some areas, the specific location of the cable was modified to accommodate the storage tanks. Extension cables were deployed from the survey area to the Geotection ${ }^{\mathrm{TM}}-180$ data acquisition trailer, located as close to the cable layout as possible while being outside the tank farm perimeter fence.

\subsubsection{Geotection-180 Resistivity Monitoring System (3D Resistivity)}

For 3D resistivity data acquisition, the Geotection-180 Resistivity Monitoring System, designed and fabricated by HGI, was used (Figure 22). The Geotection system is Underwriters Laboratories (UL)-compliant and is contained in a mobile trailer and powered by a 220 -volt AC source (for this survey a portable generator was used as a power source).

The Geotection-180 Resistivity Monitoring System has 180 channels, in comparison to the 8 channels available on the SuperSting R8 ${ }^{\circledR}$ system, manufactured by Advance Geosciences, Inc. (AGI). This equates to a data collection rate that is 15 to 20 times faster than previous SGE projects using the Supersting R8 system. In addition, since the Geotection-180 Resistivity Monitoring System has a greater number of channels, the number of times the depth electrodes are transmitted on decreases significantly. On previous surveys it was possible to overuse the depth electrodes through continuous current transmission, which increased the contact resistance of the electrode by reducing the available moisture. The improved dynamic range allows the output electrical power to be reduced while still producing a usable signal, improving the lifespan of the historically poor performing depth electrodes. 
Figure 22. The SuperSting R8 Resistivity Meter (top) and Geotection-180 Resistivity Monitoring System (bottom).

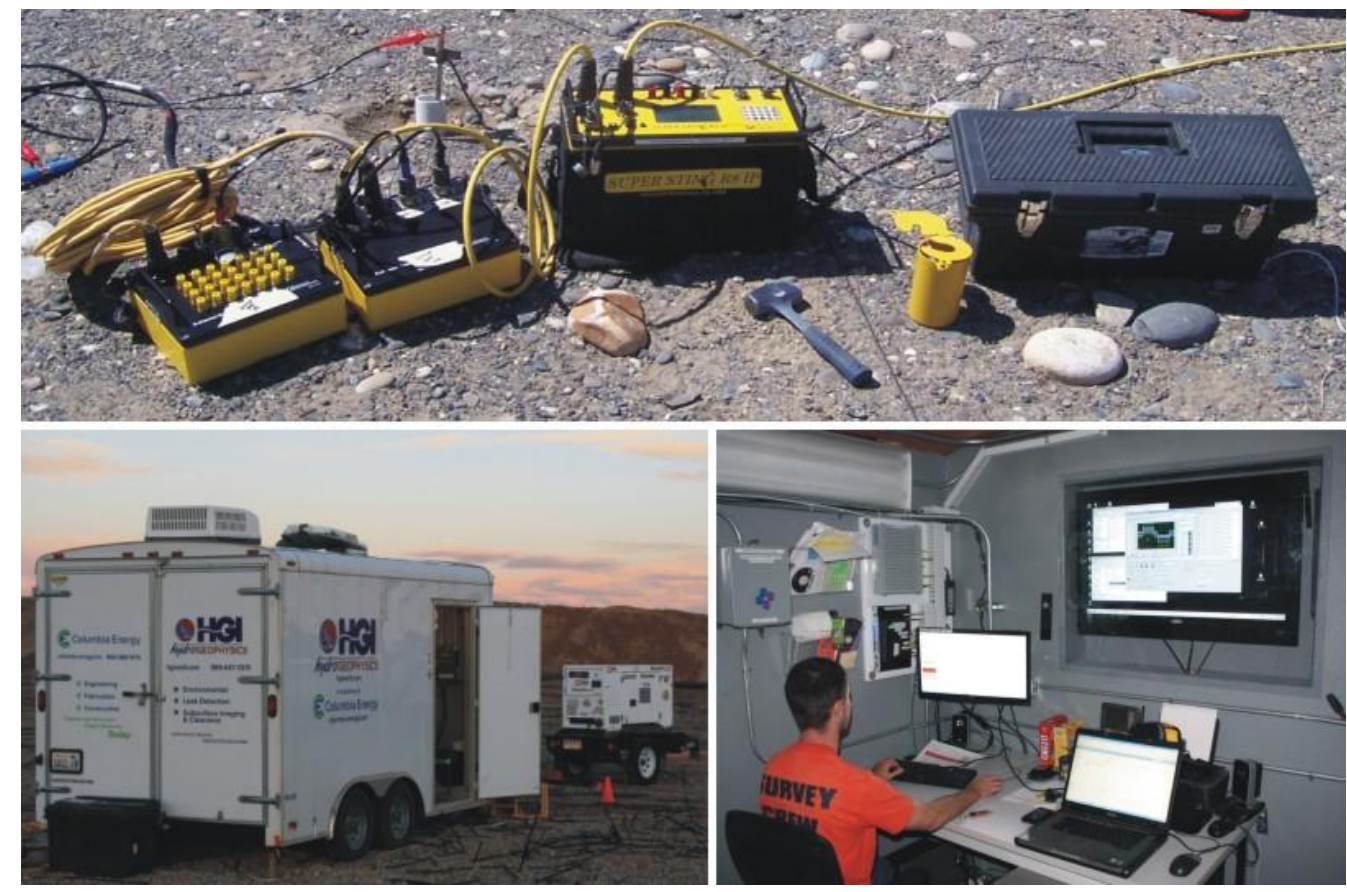

\subsubsection{Quality Assurance}

Quality assurance was completed before and after the survey to ensure the equipment was functioning appropriately and the quality of data was acceptable. Calibration requirements are described for hardware used to collect geophysical data in CEES-0360, Surface Geophysical Exploration System Design Description. As an example, the manufacturer (AGI) of the SuperSting R8 resistivity meter recommends a yearly calibration of internal calibration resistors. The calibration is performed at the manufacturer's facility and a certificate of calibration is provided. A copy of the calibration documentation, serial numbers, and expiration dates are maintained in project files.

Daily inspection of the receiver calibration was also performed onsite using the manufacturersupplied calibration resistor test box. The supplied test box is connected to the Geotection-180 Resistivity Monitoring System or SuperSting R8 resistivity meter before commencing the daily survey. A specific calibration test firmware is provided within the SuperSting R8 resistivity meter and provides the operator with a pass/fail indication for each of the eight receiver channels. For the Geotection-180 Resistivity Monitoring System, a specific calibration test sequence file is used to test all possible measurement combinations. The resulting data file is copied into a controlled spreadsheet that contains the known National Institute of Standards and Technology (NIST) resistance values. The sheet identifies if any of the channels fail, and if so, operators elect to recalibrate, repair the faults, or remove the faulty channels from use during the survey. 


\subsection{ACQUISITION METHODOLOGY}

The 3D electrical resistivity survey data collection occurred between July 24, 2013 and August 1, 2013. Data were collected approximately 8 hours a day. Personnel were maintained onsite at all times during acquisition to monitor data collection and to keep the cable area clear of vehicles and equipment that could damage cables and impact data quality.

Both forward and reverse data sets were collected during data acquisition in order to increase the resolution of the resistivity survey and evaluate data quality. Forward and reverse measurements are acquired by switching the transmitting and receiving electrodes to produce a reciprocal dataset. The two sets of data ensured that each electrode acted as both transmitter and receiver; both are needed for quality control. The theory of reciprocity implies that a homogeneous earth should allow for consistent measurements in both forward and reverse measurement conditions. Thus, by varying selected reciprocal percent difference thresholds, the ratio between data quality and quantity can be assessed. For this survey effort, data measurements with a relative percent difference greater than 2 percent were considered unacceptable and removed from the dataset before numerical inverse modeling. For comparison, prior surveys within C Tank Farm and at other tank farms have used a threshold of 5 percent.

\subsubsection{D Acquisition}

For the 3D electrical resistivity survey a pole-pole array was selected; where one electrode from each of the transmitting and receiving electrode pairs were placed effectively at infinity. Practically, these poles are placed remotely, anywhere from 2 to 5 times the maximum in farm electrode distance away from the survey area in opposite directions. Figure 23 shows the locations of the remotes used in the FY 2013 SGE project. 
Figure 23. Location of Remote Electrodes.

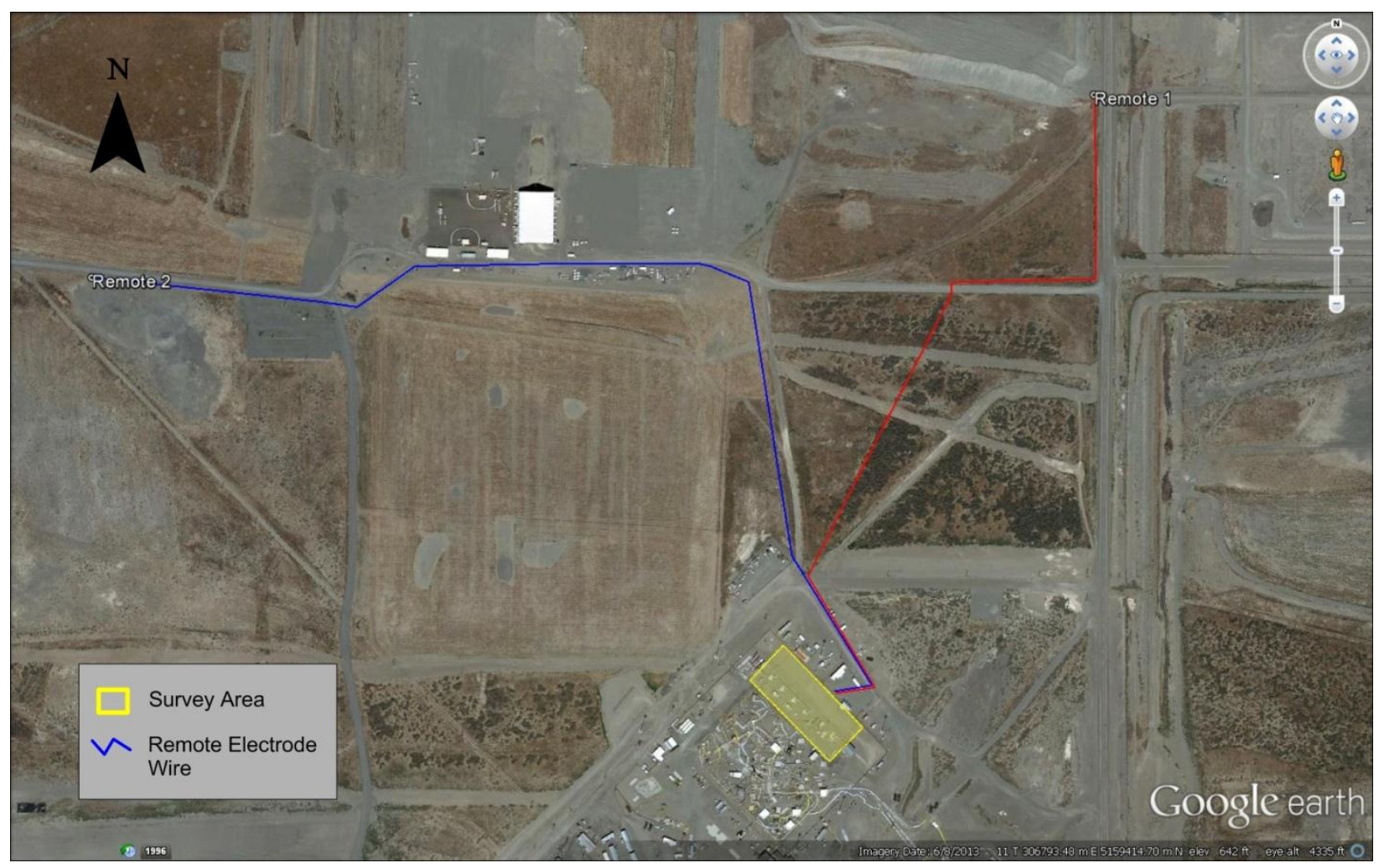

Source: ( 2013 Google.

\subsection{DATA PROCESSING}

\subsubsection{Data Reduction}

All raw data collected at the site were compiled into a relational database. Raw data included both electrical resistivity data and GPS positional data to geo-reference the resistivity data. A set of queries was designed to segregate reciprocal pair data points. This information included electrode type (surface, depth, well/long electrode) and a sequential electrode number (as designated in the survey design). Additional data fields were added for the calculated distance between electrodes and percent error between reciprocal data. The data were then exported from the database for graphical filtering and plotting in a spreadsheet.

The diagnostic parameters used for quality control of the raw data include voltage/current (resistance), point (repeat) error, reciprocal error, and electrical current output. The point error is a calculated percent error between cycled/repeated measurements. A plot of these data can provide information with regards to the statistical variation of the data population.

The process of data editing identifies and eliminates data points, but no data modification (rounding, averaging, smoothing, or splining) is permitted. The rationale is to seek out and remove spurious points that do not conform to the data population or points that violate potential theory. The first step in this editing process was to remove data outside of the statistical population; negative V/I values, high repeat or point errors, low output current values, low 
measured voltage, and high contact resistance. The next step in data reduction was to apply a data quality filter based on reciprocity. Reciprocal measurements were used to assess the quality of the results. Secondary reciprocal measurements were generated for each initial data point by switching the transmitting and receiving electrodes. Electrical theory suggests that the measurements should be the same. All data with a reciprocal percent difference greater than 2 percent was removed from the dataset. Figure 24 displays the 3D data distribution before and after filtering. The process used to filter the raw data is further described in CEES-0360.

Figure 24. Data Distribution for Raw (Combined Reciprocal) and Edited V/I Data for the 3D Survey (Surface and Depth Electrode Data).
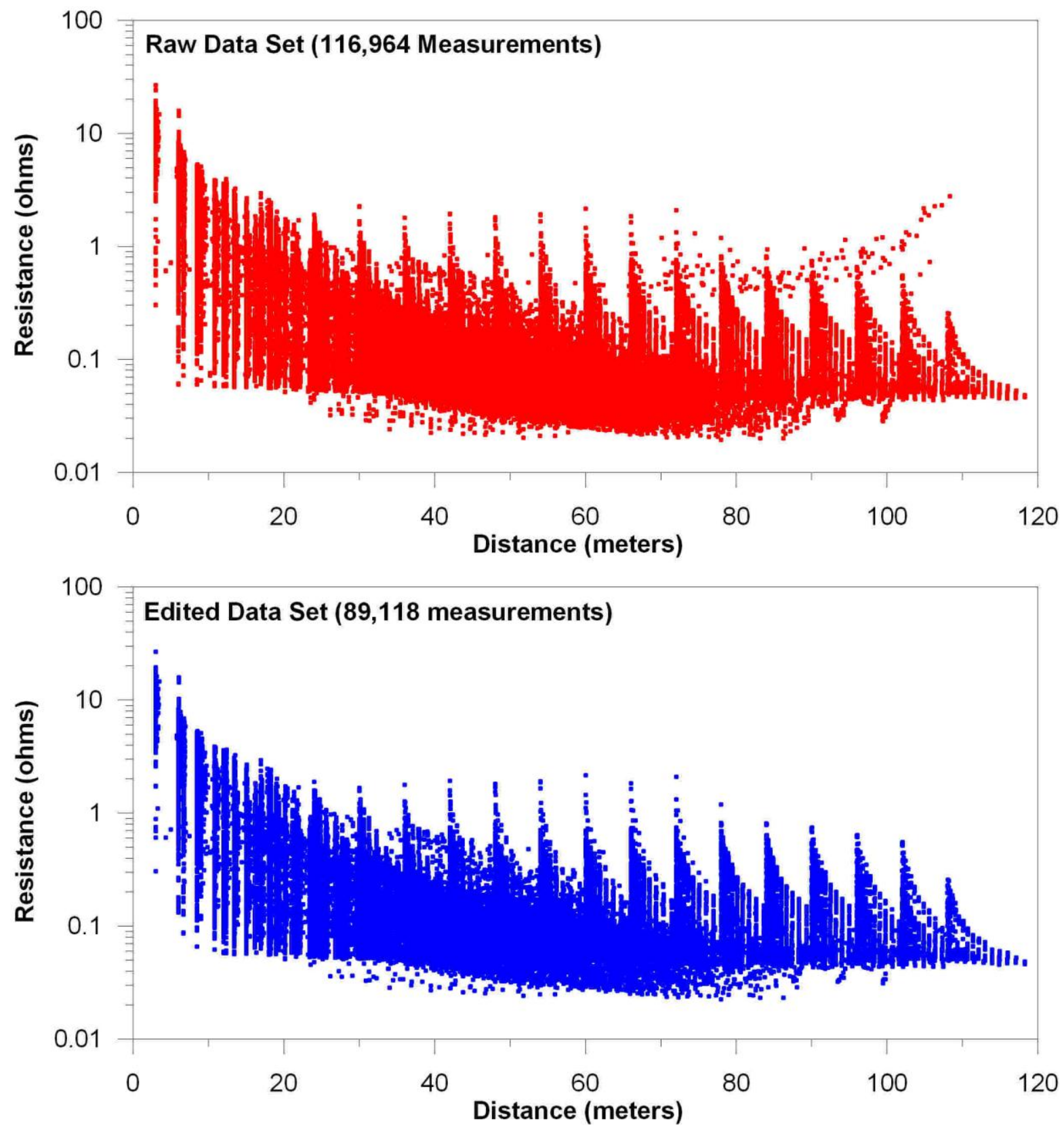
Table 4 displays the percentages of data retained during steps of the editing process.

Table 4. Number of Data Points Retained During Data Editing Steps.

\begin{tabular}{|l|r|r|r|r|}
\hline \multicolumn{1}{|c|}{--} & \multicolumn{1}{c|}{ Forward } & \multicolumn{1}{c|}{ Reverse } & \multicolumn{1}{c|}{ Sum } & Percent of Total \\
\hline Total Raw & 121,318 & 121,107 & 242,425 & $100 \%$ \\
\hline $\begin{array}{l}\text { Total Combined } \\
\text { Reciprocal }\end{array}$ & 120,244 & 120,244 & 240,488 & $99 \%$ \\
\hline $\begin{array}{l}\text { Total Remaining } \\
\text { after Editing }\end{array}$ & $89,118^{*}$ & $89,118^{*}$ & $178,236^{*}$ & $74 \%$ \\
\hline
\end{tabular}

*Totals include data points collected using monitoring well E27-7.

\subsubsection{Depth Electrode Performance}

The C Tank Farm depth electrodes that were used during this survey were completed at various dates ranging from August 2009 to June 2013. The boreholes were of varying construction, with some having up to nine electrodes installed. The construction details for the 2013 installations are provided below (RPP-RPT-55481):

- Resistivity probes were placed at pre-determined levels as the boreholes were decommissioned. The drive tip was knocked out of the bottom of the tubing, and the tubing was back-pulled filling the borehole with bentonite until the desired depth was reached. Then $15 \mathrm{~cm}$ ( 6 in.) of silica sand was added to the borehole. Next, the sensor,

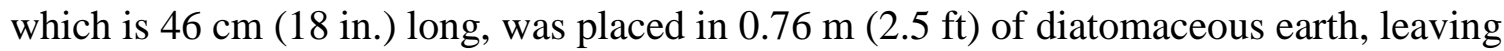
$15 \mathrm{~cm}$ (6 in.) below and above the sensor. Another $15 \mathrm{~cm}$ ( 6 in.) of silica sand was added to the borehole. Bentonite was added next and the installation process continued.

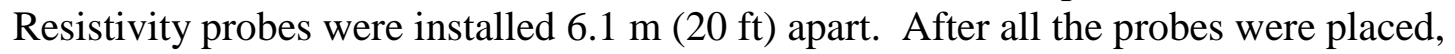
bentonite was added to the borehole up to the surface as the tubing was back-pulled. A protective steel casing was cemented in place approximately $31 \mathrm{~cm}$ (12 in.) deep at the surface to protect the protruding probe wiring.

A statistical performance analysis is performed on all depth electrode data to assure only high quality data are included in the numerical inversion modeling. A benefit in using the HGI designed Geotection-180 Resistivity Monitoring System is that it provides unique recorded survey performance parameters that can be directly used in the analysis. The performance from the different types of electrodes was explored through output current, point error, reciprocal error, and contact resistance. Table 5 lists the summary statistics from each of the electrodes. Thirteen of the 41 depth electrodes were deemed unacceptable for inclusion in the 3D inversion models based on the performance parameters. These electrodes are highlighted in red, with the failing criteria highlighted in orange. 
Table 5. Depth Electrode Performance Measure for the C Tank Farm 200-Series Tanks Electrical Resistivity Survey.* (2 sheets)

\begin{tabular}{|c|c|c|c|c|c|c|}
\hline Name & Electrode & \# Records & Current & $\begin{array}{c}\text { Contact } \\
\text { Resistance }\end{array}$ & $\begin{array}{l}\text { Point } \\
\text { Error }\end{array}$ & $\begin{array}{c}\text { Reciprocal } \\
\text { Error }\end{array}$ \\
\hline C8763-1 & 324 & 284 & 930.99 & 238.52 & 0.65 & 0.58 \\
\hline C8763-2 & 325 & 284 & 917.12 & 242.15 & 0.61 & 2.92 \\
\hline C8763-3 & 326 & 284 & 723.79 & 307.13 & 1.15 & 0.50 \\
\hline C8763-4 & 327 & 284 & 893.71 & 248.54 & 0.55 & 0.45 \\
\hline C8763-5 & 328 & 284 & 822.15 & 270.27 & 0.64 & 0.44 \\
\hline C8763-6 & 329 & 284 & 1032.20 & 215.07 & 0.39 & 0.44 \\
\hline C8763-7 & 330 & 284 & 438.73 & 507.50 & 1.93 & 0.41 \\
\hline C8763-8 & 331 & 284 & 205.78 & 1083.53 & 9.09 & 0.69 \\
\hline C8763-9 & 332 & 157 & 1078.92 & 181.00 & 0.39 & 0.33 \\
\hline C8765-1 & 333 & 284 & 861.48 & 257.90 & 0.98 & 0.83 \\
\hline C8765-2 & 334 & 284 & 775.68 & 286.55 & 0.89 & 0.59 \\
\hline C8765-3 & 335 & 284 & 581.38 & 382.73 & 1.45 & 0.52 \\
\hline C8765-4 & 336 & 284 & 510.78 & 435.78 & 1.67 & 0.44 \\
\hline C8765-5 & 337 & 284 & 361.11 & 616.95 & 2.84 & 0.48 \\
\hline C8765-6 & 338 & 284 & 407.01 & 547.23 & 1.95 & 0.52 \\
\hline C8765-7 & 339 & 284 & 261.52 & 852.45 & 4.02 & 0.66 \\
\hline C8765-8 & 340 & 284 & 168.85 & 1321.06 & 8.10 & 0.45 \\
\hline C8765-9 & 341 & 284 & 193.71 & 1151.28 & 5.33 & 0.42 \\
\hline C8766-1 & 342 & 284 & 1079.00 & 183.36 & 0.58 & 0.56 \\
\hline C8766-2 & 343 & 284 & 1078.88 & 200.04 & 0.50 & 0.69 \\
\hline C8766-3 & 344 & 284 & 735.75 & 302.24 & 0.87 & 0.60 \\
\hline C8766-4 & 345 & 284 & 899.09 & 247.14 & 0.54 & 0.42 \\
\hline C8766-5 & 346 & 284 & 507.98 & 438.27 & 1.33 & 0.45 \\
\hline C8766-6 & 347 & 284 & 727.77 & 305.58 & 0.58 & 0.48 \\
\hline C8766-7 & 348 & 284 & 242.28 & 920.37 & 3.81 & 0.38 \\
\hline C8766-8 & 349 & 284 & 222.88 & 1000.63 & 3.60 & 0.35 \\
\hline C8766-9 & 350 & 284 & 305.14 & 730.45 & 1.85 & 0.45 \\
\hline C8767-1 & 351 & 284 & 975.60 & 227.67 & 0.90 & 1.07 \\
\hline C8767-2 & 352 & 267 & 637.47 & 350.64 & 1.29 & 0.55 \\
\hline C8767-3 & 353 & 267 & 687.46 & 325.07 & 0.98 & 4.25 \\
\hline C8767-4 & 354 & 267 & 1033.33 & 215.91 & 0.44 & 0.48 \\
\hline C8767-5 & 355 & 267 & 517.21 & 432.47 & 1.36 & 0.42 \\
\hline C8767-6 & 356 & 267 & 512.49 & 436.48 & 1.20 & 0.45 \\
\hline C8767-7 & 357 & 267 & 366.69 & 610.52 & 1.82 & 0.43 \\
\hline C8767-8 & 358 & 267 & 211.48 & 1059.55 & 3.99 & 0.33 \\
\hline C8767-9 & 359 & 267 & 331.80 & 674.82 & 1.68 & 0.33 \\
\hline C7465-1 & 360 & N/A & N/A & N/A & N/A & N/A \\
\hline
\end{tabular}


Table 5. Depth Electrode Performance Measure for the C Tank Farm 200-Series Tanks Electrical Resistivity Survey.* (2 sheets)

\begin{tabular}{|c|c|c|c|c|c|c|}
\hline Name & Electrode & \# Records & Current & $\begin{array}{c}\text { Contact } \\
\text { Resistance }\end{array}$ & $\begin{array}{l}\text { Point } \\
\text { Error }\end{array}$ & $\begin{array}{c}\text { Reciprocal } \\
\text { Error }\end{array}$ \\
\hline C7465-2 & 361 & 267 & 364.59 & 614.03 & 3.47 & 0.53 \\
\hline C7467-1 & 362 & 267 & 482.36 & 463.81 & 1.49 & 0.45 \\
\hline C7467-2 & 363 & 267 & 614.40 & 363.89 & 1.63 & 0.58 \\
\hline C8105 & 364 & N/A & N/A & N/A & N/A & N/A \\
\hline
\end{tabular}

Each of these underperforming depth electrodes performed poorly in terms of low current output, high contact resistance, and/or high point (repeat) error. Low current and-or high contact resistance may indicate poor electrical contact between the electrodes and the surrounding earth, high point error indicates lack of repeatability between multiple measurements on the same electrode (generally instability of contact between electrode and earth or electrode and cable connection), and high reciprocal error may indicate unstable electrodes conditions, ground anisotropy, electrical interference or a host of other completion problems. The C8105 and one of the C7465 electrodes were instrumented but the acquisition system was not able to transmit current through them.

The remaining depth electrodes performed well, exhibiting high current transmission, low contact resistance, and low error. Each of these underperforming depth electrodes performed poorly in terms of low current output, high contact resistance, and/or high point (repeat) error. Low current and-or high contact resistance may indicate poor electrical contact between the electrodes and the surrounding earth, high point error indicates lack of repeatability between multiple measurements on the same electrode (generally instability of contact between electrode and earth or electrode and cable connection), and high reciprocal error may indicate unstable electrodes conditions, ground anisotropy, electrical interference or a host of other completion problems. The C8105 and one of the $\mathrm{C} 7465$ electrodes were instrumented but the acquisition system was not able to transmit current through them. The remaining depth electrodes performed well, exhibiting high current transmission, low contact resistance, and low error.

\subsubsection{D Inverse Modeling}

Popular use of the RES3DINV series of resistivity inversion codes has led both professional and academic users to regard these codes as industry standard software. The C Tank Farm modeling effort used RES3DINVx64, a 64-bit multi-threaded version developed specifically for a large number of electrodes.

In general, inverse modeling can be summarized in the following five steps:

1. The study site's voltage data has been measured and is discretized into grid nodes using a finite difference or finite element mesh. The meshing parameters used in either case, to design the computational grids, are dependent on electrode spacing used in site-specific data acquisition. 
2. The inversion will set out to estimate the true resistivity at every grid node. An initial estimate of the subsurface properties is made based on the literal translation of the pseudo-section to a true resistivity, a constant value, or some other distribution from a priori information. A forward model run with these initial estimates is made to obtain the distribution of voltages in the subsurface. The root-mean-square (RMS) error is calculated between the measured voltage and the calculated voltage resulting from the forward run.

3. Based on the degree of model fit to field measurements, the initial estimate of resistivity is changed to improve the overall model fit and the forward model with the updated estimates is rerun. The iterative method linearizes a highly nonlinear problem using Newton's method. Using this method, the inverse modeling code essentially solves the linearized problem to obtain the change in modeled resistivity $(\Delta \mathrm{m})$ for the next iteration.

4. The resistivity model is updated using the general formula $m_{i+1}=m_{i}+\Delta m$, where $m_{i+1}$ is the resistivity in a model cell at the next iteration, and $\mathrm{m}_{\mathrm{i}}$ is the current value.

5. Steps 3 and 4 are repeated until the RMS error change between successive iterations reaches an acceptable level.

A priori modeling of the major infrastructure reduces the effect of infrastructure, resulting in improved data quantity for inverse modeling of subsurface soil resistivity changes.

\subsection{MODELING RESULTS}

Upon completion of data reduction, measured apparent resistivity data from the 200-Series tanks survey area were inverse modeled using the RES3DINVx64 software package (Geotomo Software, Malaysia). For specific details of the SGE electrical resistivity method and theoretical basis applied to inverse modeling, the reader is referred to discussions provided in RPP-34690, Surface Geophysical Exploration of the B, BX, and BY Tank Farms at the Hanford Site.

To accomplish the 3D inversion, every surface, depth, and long electrode was geo-referenced (using the Washington State Plane - Meters coordinate system) to allow absolute placement of an electrode within the inversion algorithm. The model was then run with a set of input parameters that have been demonstrated to work well in tank farm environments. After inversion, the final 3D inversion results were interpolated to a regular grid and visualized using the Rock Works ${ }^{\mathrm{TM}}$ visualization software package and Surfer ${ }^{\circledR}$ surface contouring package. The visualization allows discrimination of low resistivity targets that could be associated with increased moisture, increased ionic strength of the pore water, infrastructure, or a combination of these items. It is anticipated that mineralogy and porosity would have minimal effects on the resistivity outcome.

The model results presented below include using point electrodes on the surface and within boreholes. 


\subsection{POINT ELECTRODE MODELING}

Point electrode data from the 200-Series tanks survey efforts were compiled for the current numerical inverse modeling. The initial starting points for the modeling included measurements on 318 surface electrodes and 40 depth electrodes. However, not all of these data were of acceptable quality and some data and entire electrodes were dropped from the model data set. To create the final dataset for inversion, two types of data reduction occurred between the data acquisition and final plotting phases. First, data quality was inspected to eliminate unacceptable data that may have resulted from instrumentation error, electrical interference, or high data misfit with respect to neighboring points. The process of removing spurious data points is referred to as reduction and is performed prior to the first inversion run. Second, data were filtered after each inverse model was completed to remove data points that contributed to a high model RMS error. This process is referred to as a filter run, and the objective of a filter run was to reduce the final RMS to an acceptable level, usually below 10 percent. Each trial model run was assigned a model number which designated a specific data set or set of modeling parameters and each filter run was assigned a number. An example label for a model with a filter run is "Model_001i."

The initial model for point electrode data focused on the 3D data set using only the highest quality measured point electrode resistivity data, with no long electrodes. The high quality dataset for inversion was obtained by removing those data with reciprocal errors greater than 2 percent and anomalously low current and resistance (V/I) values. After data reduction (discussed in Section 3.4.1) 88,862 measurements remained for inclusion in the inversion model. After completing three inversion filter runs to remove additional spurious data 72,661 measurements remained. Table 6 lists the statistics for the modeling.

Table 6. Inverse Modeling Convergence and Error Statistics.

\begin{tabular}{|l|c|c|}
\hline \multicolumn{1}{|c|}{ Model } & Surface to Surface & Model RMS Error (\%) \\
\hline $\begin{array}{l}\text { Initial inversion input data file } \\
\text { (C200_StS_007) }\end{array}$ & 88,862 & 23.4 \\
\hline $\begin{array}{l}\text { Filtered inversion data file } \\
\text { (C200_StS_007iii) }\end{array}$ & 72,661 & 16.1 \\
\hline Percent Data Remaining after filter & $81.8 \%$ & \\
\hline
\end{tabular}

A model mesh was created, as with any numerical modeling, whereby the subsurface was discretized into cells and nodes. The equations that describe the potential field during electrical current transmission are then solved at every node, with the appropriate boundary conditions. The RES3DINVx64 software automatically generates the model mesh for this forward model calculation by placing grid lines at the intersection of electrodes. Additional requirements of the numerical model include explicitly assigning every block an initial resistivity value and every node a current source (if any).

For the inverse model calculations, where the resistivity values are changed in the model domain until the measured and modeled voltages are nearly equal, a separate model mesh was created that did not align with the forward model mesh. The arbitrary gridding for the inverse model mesh prevented the creation of very small cells due to the depth electrode locations not being aligned to the surface electrode grid. A $3 \times 3 \mathrm{~m}(9.8 \times 9.8 \mathrm{ft})$ grid cell was selected for the inverse model (Figure 25) based on initial testing of a number of starting grid dimensions, which created 25 cells 
in the $\mathrm{x}$-direction and 41 cells in the y-direction. There are a number of cells which contain no electrodes within the model grid; this is normally due to infrastructure affecting surface electrode placement, but in this case is primarily due to the expansion of the model domain to accommodate the inclusion of a priori modeling for the 100-Series tanks adjacent to the survey grid. In the z-direction, 14 layers were used. Although the model mesh extends to a depth of more than $100 \mathrm{~m}(328 \mathrm{ft}) \mathrm{bgs}$, the model sensitivity decreases significantly below $66 \mathrm{~m}(216.5 \mathrm{ft})$ bgs so these layers are not presented.

Figure 25. 3D Model Inversion Mesh.

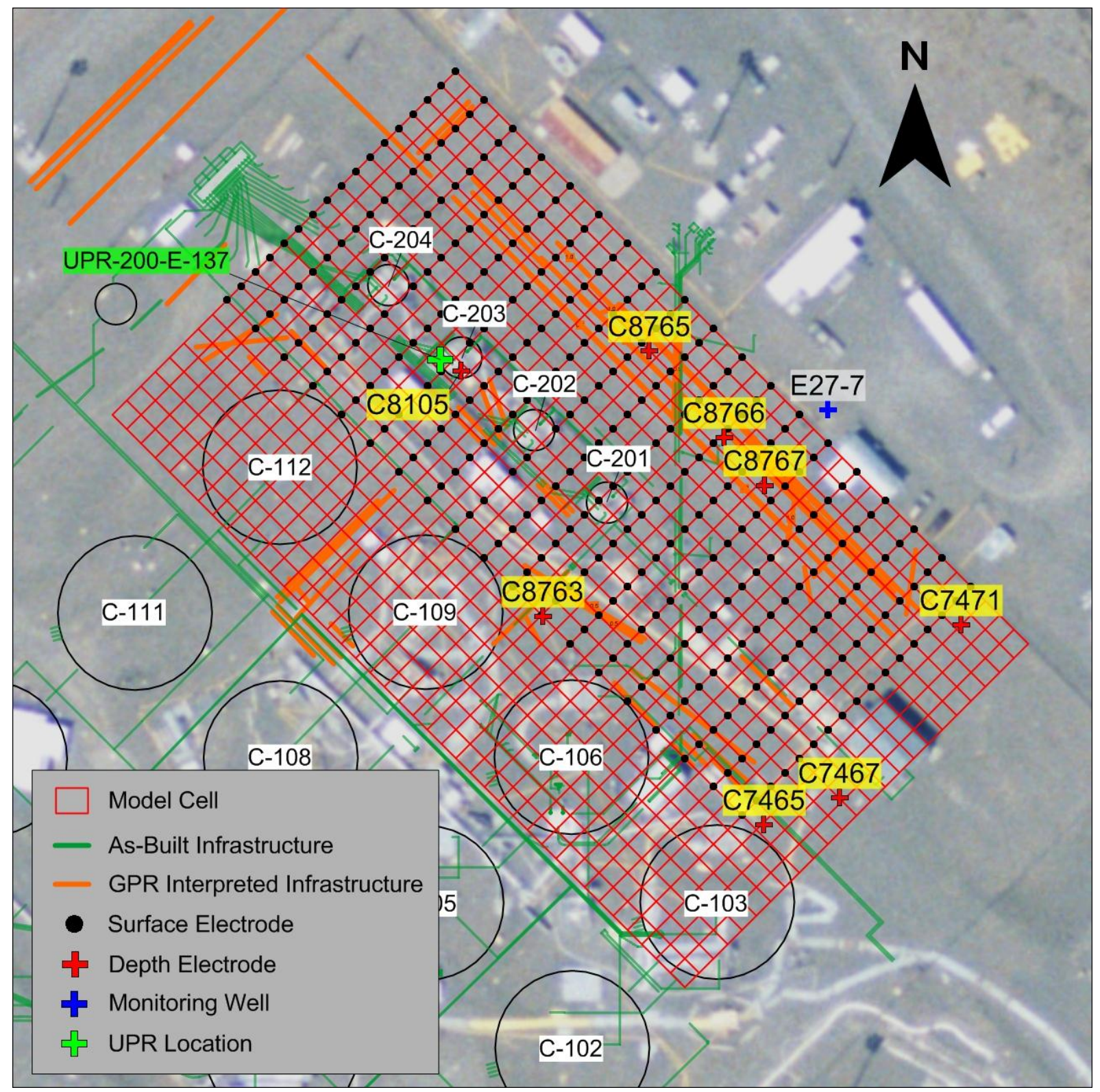


The survey area contains significant topographic relief, ranging from approximately $198 \mathrm{~m}$ (650 ft) elevation (above mean sea level [amsl]) down to $194 \mathrm{~m}(636.5 \mathrm{ft})$. As such, the topography was included in the modeling and the results are presented in elevation rather than depth below ground surface (bgs).

The locations of the storage tanks within the $\mathrm{C}$ Tank Farm were incorporated into the inverse model input file as a priori information, due to their known conductive effects. In past modeling efforts the storage tanks have been approximated using a simple rectilinear block representation. For the current 200-Series survey tank modeling, the circular storage tanks were more closely approximated by using a series of overlapping blocks, extending between a depth of 3.8 and $11.8 \mathrm{~m}$ (12.5 and $38.7 \mathrm{ft}$ ) bgs for the 100-Series tanks and between a depth of 1.75 and $11.5 \mathrm{~m}$ (5.7 and $37.7 \mathrm{ft}$ ) bgs for the 200-Series tanks. Each block was assigned a resistivity value of $0.1 \mathrm{ohm}-\mathrm{m}$ by the modeler based on results from previous modeling (Rucker et al., 2011, Environmental monitoring of leaks using time lapsed long electrode electrical resistivity). Upon entering a priori information in the RES3DINVx64 software, the user is given the option for stating the confidence of the chosen resistivity value given to these model blocks to account for the presence of the storage tanks (a confidence level ranging between 1 and 10). A low value is indicative of low confidence, and allows the model to change a priori information to improve the fit with the measured data. A high confidence would not allow the model to change the a priori information. For the final model we provided a confidence value of 2 , thereby providing the model some flexibility to change the exact resistivity values of the tanks. Although the survey grid was not located over the 100-Series tanks, they were included in the modeling because it appeared that due to their close proximity to the model grid the resistivity measurements were being influenced by these tanks. Figure 26 displays the a priori blocks added to the model; the remaining 100-Series tanks that were not included in the model are also shown for reference.

Figure 26. A Priori Modeling of Storage Tanks.

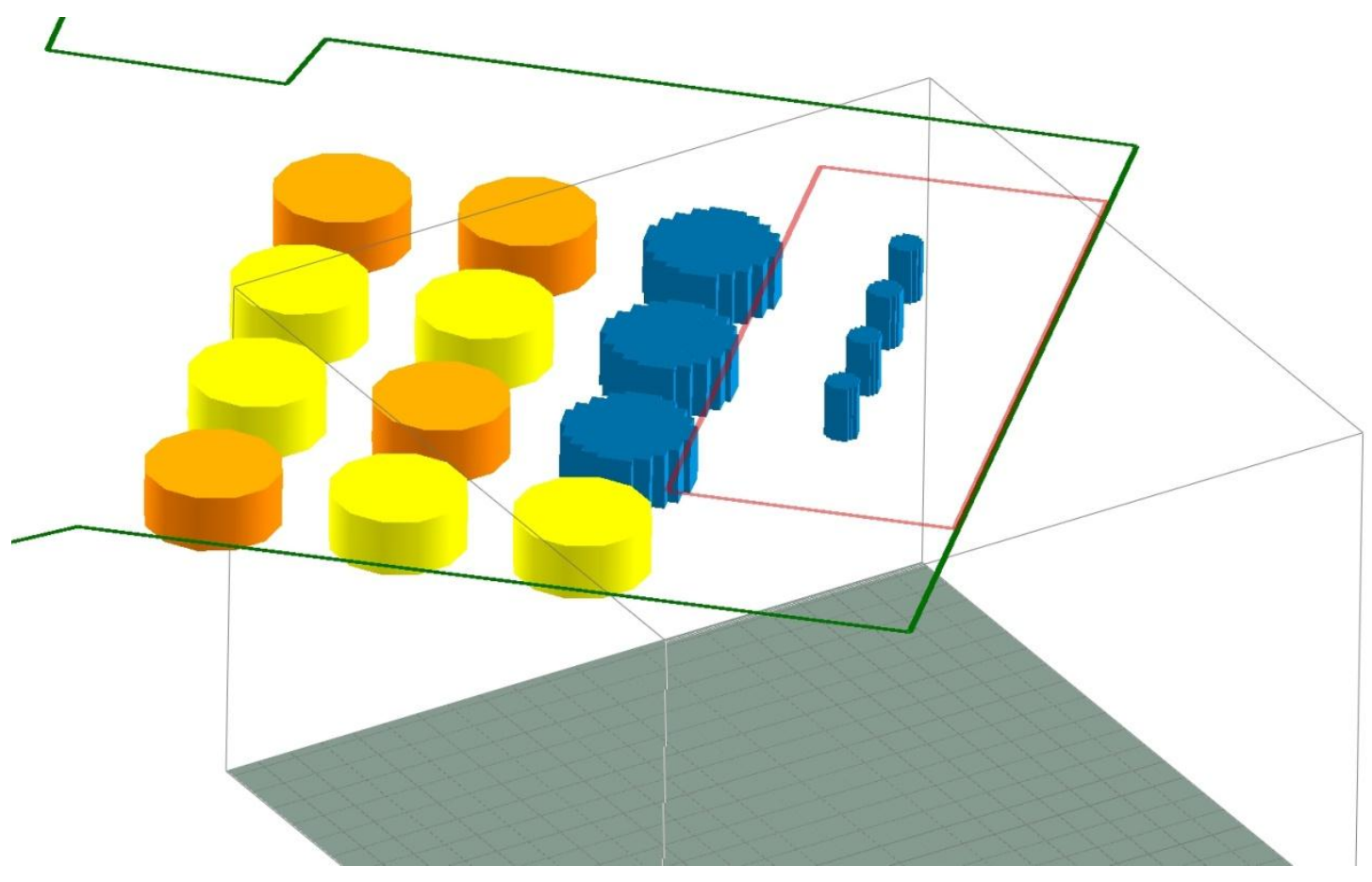


The average measured and modeled resistivity values within the 200-Series survey area are remarkably similar to values from the FY 2013 U Tank Farm (to date the only other SGE survey conducted using the Geotection system at Hanford). A distribution of resistivity values from C Tank Farm 200-Series and the U Tank Farm surveys are displayed in Figure 27. The distributions share a number of similar features:

- A localized peak at a $\log _{10}$ resistivity value of $-1(0.1 \mathrm{ohm}-\mathrm{m})$, representing the modeled metallic features values (such as tanks and infrastructure)

- A second localized peak possibly representing low resistivity targets

- A third peak that may represent the higher moisture content soils and diffuse targets within the backfill and natural material.

The potential background value peaks are located at a $\log _{10}$ resistivity value of 1.32 (21 ohm-m) for the C Tank Farm 200-Series results and 1.37 (23 ohm-m) for the U Tank Farm results. While these are virtually identical, the C Tank Farm 200-Series results differ in that the background curve shows a second rise in $\log _{10}$ resistivity value at approximately $1.75(56 \mathrm{ohm}-\mathrm{m})$. This may represent the difference in electrical resistivity measurements between a tank farm environment versus the adjacent areas that consist mostly of backfilled soils with markedly less metallic infrastructure.

Figure 27. Distribution of Modeled Resistivity Values.

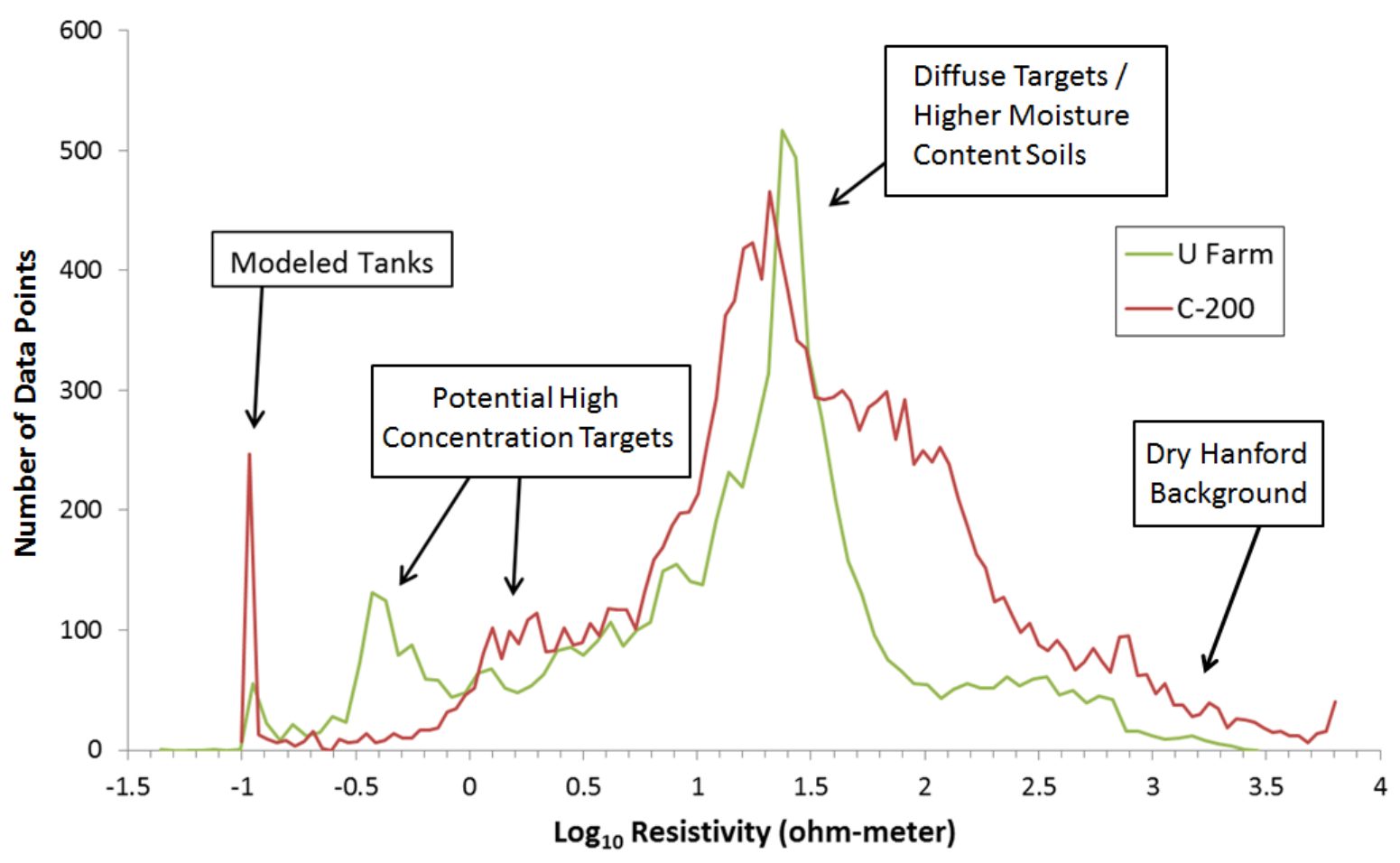




\subsubsection{D Model Results}

The results of the inverse modeling are displayed in Figure 28 and Figure 29. The figures were constructed from the output file for the third iteration of the filtered model run (with a final RMS error of 16.1 percent) and displays slices at select elevations within the model domain. The RMS error is relatively high compared to previous SGE surveys in other areas at the Hanford Site, this could be a result of a combination of the strong infrastructure response observed in the survey area and the sharp topographic change running through the survey area. For reference, the surface elevation is approximately $198 \mathrm{~m}(649.6 \mathrm{ft})$ amsl near the tanks in the southwest half of the survey area and approximately $194 \mathrm{~m}(636.5 \mathrm{ft})$ amsl in the northeast half. The elevations are indicated in each subplot within the mosaic of different slices. The water table in this region is at elevation $122 \mathrm{~m}(400.3 \mathrm{ft})$ amsl, well below the depth of investigation for this inversion model. Those layers with a priori tank information include a grayed out area indicating the modeled position of the tanks, with the intention being that blocking the highly conductive modeled tank will allow the viewer to observe the areas immediately surrounding the tank without being distracted by the modeled tanks themselves. Furthermore, the true outlines of the tanks are traced in black and red - the latter to denote tanks that are classified as historically leaking tanks to show their effects on the final resistivity distribution. The color scale uses warmer hues to represent more resistive regions and cooler hues to represent less resistive regions. The color scale range was chosen to be similar to that used for previous SGE projects from differing areas at the Hanford Site. Lastly, the outline of the surface electrode grid is shown to indicate areas of the model where resistivity values were calculated but no direct measurements were made, with the exception of the two depth electrode strings at C7465 and C7467. 
Figure 28. Inverse Model Results for the C-200 Area Survey.

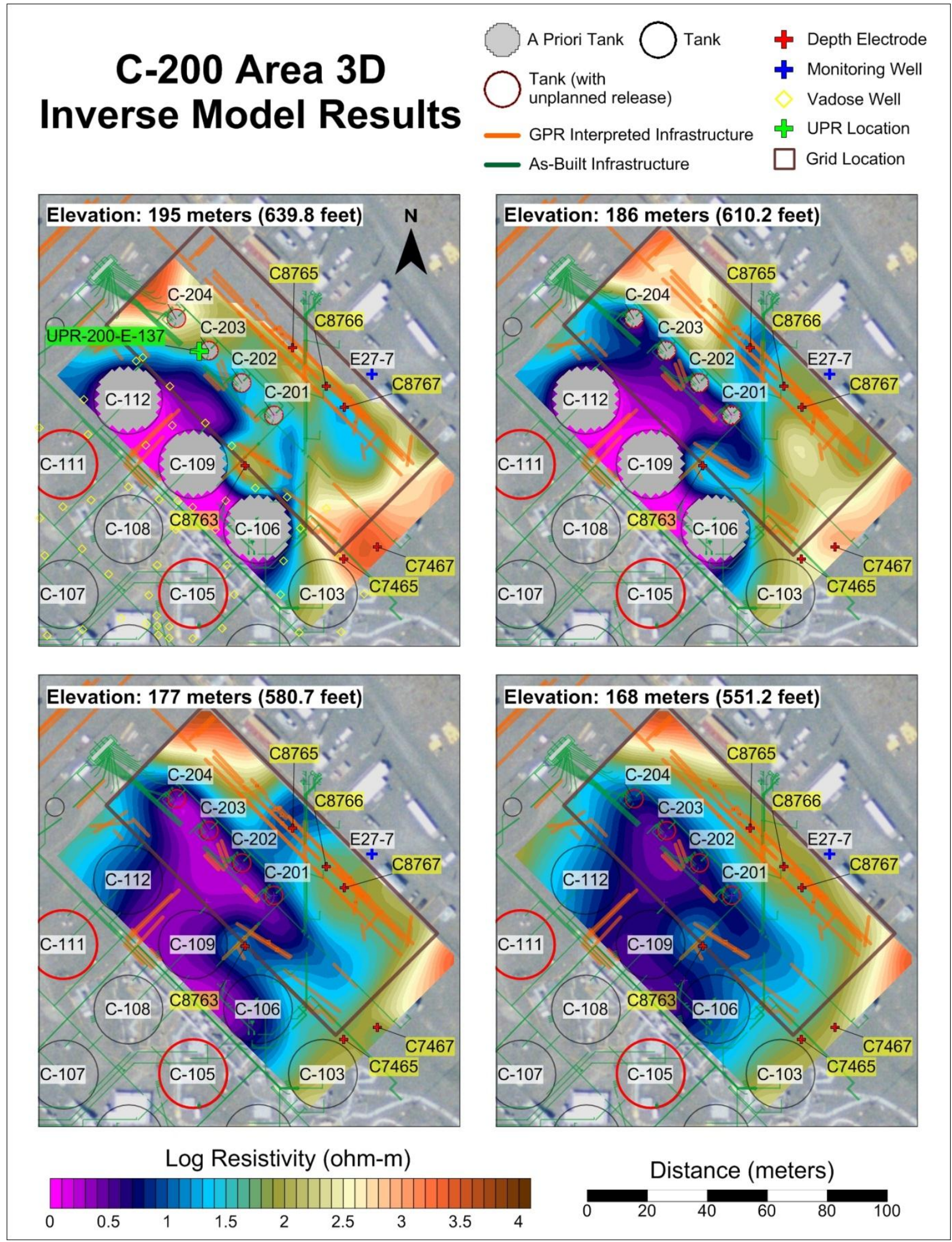


Figure 29. Inverse Model Results for the C-200 Area Survey.

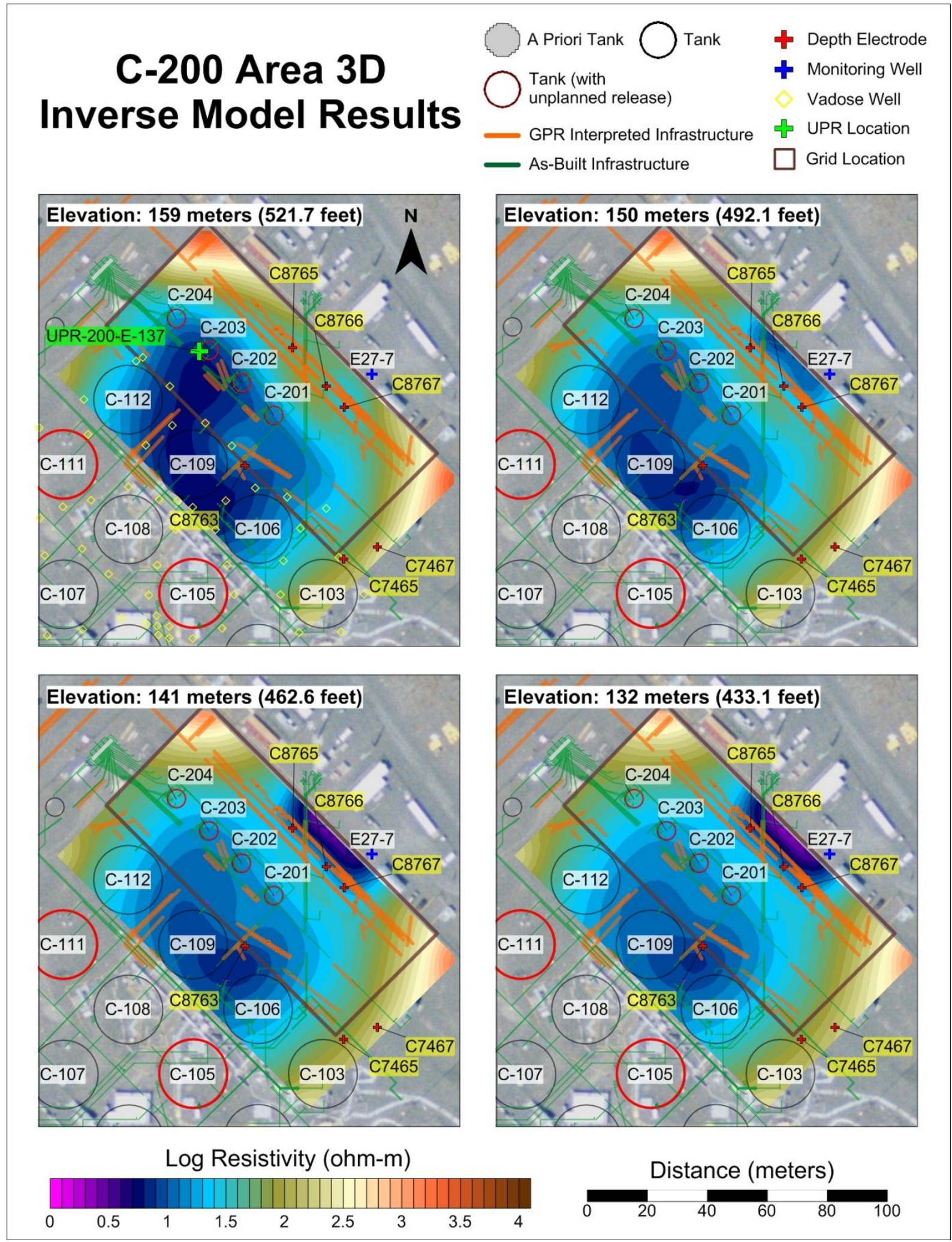


The slice at $195 \mathrm{~m}(639.8 \mathrm{ft})$ amsl (Figure 28) is just below the top of the 100-Series tanks

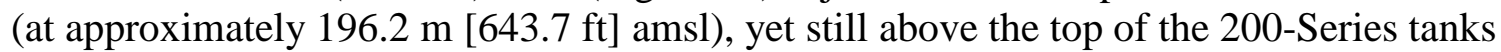
(at approximately $194.2 \mathrm{~m}[637.1 \mathrm{ft}]$ amsl). Areas of relatively higher resistivity associated with the backfilled soils can be seen in the northwestern and southeastern portions of the model. A highly conductive area is observed in the regions between the 100-Series tanks C-112 and C-109, and C-109 and C-106, and extending between the 100-Series and 200-Series tanks. The regions between tanks C-112 and C-109 and C-109 and C-106 display resistivity values $<3$ ohm-m $\left(\log _{10}\right.$ resistivity values $\left.<0.5\right)$ and potentially represent subsurface infrastructure (pipelines for example) above or at the tank level. In addition, these regions are located in areas with a high density of linear interpretations identified in FY 2012 and FY 2013 GPR site clearance surveys or infrastructure from the as-built drawings where there is no GPR coverage. A smaller conductive region is observed in the region around borehole C8767, which corresponds to an area with a high density of linear interpretations identified in the FY 2012 and FY 2013 GPR site clearance surveys. A linear conductive target is observed near the eastern edge of tank C-106, trending to the north in the direction of tank C-201. This target is located directly adjacent to infrastructure as indicated in the overlaid as-built drawings. Although there was limited GPR coverage due to above ground obstacles and topographic constraints, a small section of this pipeline was confirmed. A large portion of the infrastructure indicated in both asbuilt drawings and interpreted from the GPR surveys does not seem to have had a significant effect on the resistivity measurements in this slice. The type of subsurface infrastructure (e.g., water, electrical, mechanical); the composition (e.g., steel, PVC, aluminum); and dimensions of the piping and trenches greatly determines the magnitude of influence on the resistivity data.

The slice at $186 \mathrm{~m}(610.2 \mathrm{ft})$ amsl slice, in Figure 28, is near the base of both the 100-Series and 200-Series tanks, whose bases are at approximately $186.5 \mathrm{~m}(611.9 \mathrm{ft})$ amsl and $186.2 \mathrm{~m}$ (610.9 ft) amsl, respectively. The regions surrounding the 200-Series tanks are more conductive in this slice. The majority of the regions between 200 -Series tanks display resistivity values $<3 \mathrm{ohm}-\mathrm{m}\left(\log _{10}\right.$ resistivity values $\left.<0.5\right)$ and potentially represent subsurface infrastructure (pipelines for example) at the tank level. These regions are located in areas with a high density of linear interpretations identified in the GPR results. The regions between the 100-Series tanks C-112 and C-109, and C-109 and C-106, and extending between the 100-Series and 200-Series tanks remain very conductive in this slice, potentially representing a response to infrastructure at or above this elevation. The 200-Series tanks are thought to have suffered potential waste losses through spare inlets at different times between 1955 and 1970, potentially leading to tank wastes residing in, or migrating through the subsurface soils. Electrical resistivity measurements are not sensitive to contaminants such as cesium and uranium; however, it is believed that conductive salts and nitrates present in the liquid waste releases are associated with radioactive contaminants of concern. Increased levels of salts/nitrates in the ground will result in high conductivity (low resistivity) anomalies. The results of the resistivity modeling clearly show a conductive region between and surrounding the $200-$ Series tanks. The conductive target observed in the $195 \mathrm{~m}(639.8 \mathrm{ft})$ amsl slice near borehole C8767 is no longer apparent in the $186 \mathrm{~m}(610.2 \mathrm{ft})$ amsl slice. This is additional evidence that this target was a response to near-surface infrastructure. A continuation from the linear response observed in the $195 \mathrm{~m}(639.8 \mathrm{ft})$ amsl slice trending north from tank C-106 towards tank C-201 is present in this slice. It can be observed in proximity to tank C-201 and trending to the north past borehole $\mathrm{C} 8765$ and to the edge of the inversion model. The significant decrease in surface 
elevation from south to north that would have controlled construction of this infrastructure is consistent with the relative depth that the signature appears in the slices.

Infrastructure responses appear to dominate the $177 \mathrm{~m}(580.7 \mathrm{ft})$ amsl slice (Figure 28). This

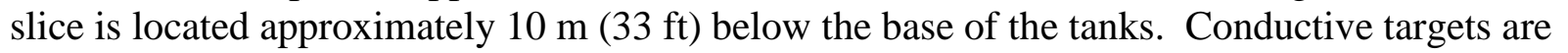
again observed between the 100-Series tanks C-112 and C-109, and C-109 and C-106, extending between the 100-Series and 200-Series tanks, and between the four 200-Series tanks. In some areas of the inversion model the a priori modeled tanks are still having an influence. However, it should be noted that the model resolution in the area of the 100-Series tanks will be low because they are outside of the surface electrode grid and distant from the majority of depth electrodes. At this elevation, the linear conductive target related to the north-south orientated infrastructure is less evident. Several regions, directly to the north-east of tank C-202 and to the north of tank C-103, are more conductive. This could be a result of the decreasing resolution with depth contributing to a smearing of the responses from higher elevations or due to an increase in levels of salts/nitrates in the ground. Subsurface information from geophysical logging and borehole characterizations is limited in this survey area. There are no drywells surrounding the 200-Series tanks that would provide information on the migration of the potential waste losses from these tanks. The gamma logging and soil moisture measurements from the boreholes installed in FY 2013 (C8763, C8765, C8766, and C8767) indicated elevated

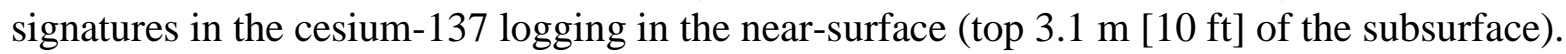
Additionally, there is a sharp increase in gross gamma indicated at a depth of approximately $13 \mathrm{~m}$ (42 ft) bgs (181 m [594.5 ft] amsl) for boreholes C8765, C8766, and C8767 (the top $27.4 \mathrm{~m}$ [90 ft] of data for borehole C8763 was unavailable). Boreholes C8765, C8766, and C8767 are located some distance away from the conductive targets of interest at this elevation. However, we observe a slight increase in conductivity of the subsurface compared to higher elevation slices in the area of these three boreholes. Gamma logging data from this elevation near the 100-Series tanks show an increased cobalt-60 response to the north-east of tank C-109, between tanks C-108 and C-109, and between tanks C-103, C-105, and C-106. These results were detected outside the model domain for this survey, but when combined with the geological data suggests that the predominant direction of subsurface migration for tank waste is towards the east, from the location of releases within C Tank Farm (RPP-RPT-42294). Hence, we would expect releases from and around the 100-Series tanks to migrate downwards and towards the current survey area over time. This could explain the conductive target we observe between the 100-Series and 200-Series tanks, because elevated signatures are observed in the cobalt-60 logging in well 30-12-13 (north of tank C-112) at $186.4 \mathrm{~m}(612 \mathrm{ft}$ ) amsl and well 30-09-02 (northeast of tank C-109) at $181 \mathrm{~m}(594 \mathrm{ft})$ amsl. Both wells are in close proximity to and to the west of this target. In addition, the region to the north-east of tank C-106 is observed to begin to become more conductive at this elevation while we observe elevated signatures in the cobalt-60 logging in wells 30-03-09, 30-05-02, and 30-05-03 (east of tank C-103) at $174 \mathrm{~m} \mathrm{(572} \mathrm{ft)} \mathrm{amsl} \mathrm{and}$ 30-03-09 and 30-03-03 (east and west of tank C-103, respectively) at $171 \mathrm{~m}(561 \mathrm{ft})$ amsl. These drywells are again in close proximity and to the west of this conductive target and could represent a response to the subsurface migration of this potential waste release.

In general, the slice at $168 \mathrm{~m}(551.2 \mathrm{ft})$ amsl displays a similar structure to the conductive targets observed in the previous depth slice. However, while the region directly below and to the south of tank C-203 remains very conductive, the majority of the remaining targets around the 100-Series and 200-Series tanks are more resistive in this slice. For example, the conductive target to the northeast of tank C-202 is significantly more diffuse at this elevation. In contrast, 
the conductive target to the northeast of tank C-106 appears to have expanded in area and become more conductive. We observe elevated signatures in the cobalt-60 logging in well 30-03-01 (northeast of tank C-103) at 166, 163, and $160 \mathrm{~m}(546,536$, and $525 \mathrm{ft}$ ) amsl, which is in close proximity to this conductive target. Therefore, there is again potential that this represents a response to the subsurface migration of this potential waste release. It should be noted that there is a significant reduction in the number of drywells that penetrate below $27 \mathrm{~m}$

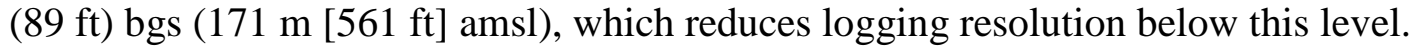

The slices in Figure 29 indicate that the conductive region in proximity to the 100-Series and 200-Series tanks continues to become more resistive with depth. A new conductive target that begins to form along the northeast edge of the inversion model, near the C8765, C8766, and C8767 boreholes and monitoring well E27-7 is noted. The $159 \mathrm{~m}(521.7 \mathrm{ft})$ amsl slice indicates that the center of mass of the conductive region in proximity to the 100-Series and 200-Series tanks to be to the southwest of tanks C-202 and C-203, trending south towards tank C-109. It should be noted that outside of the survey grid the target resolution of the inversion model is low due to the absence of surface or depth electrodes. An area of increasing conductivity is observed, located between boreholes C8766 and C8767, and the groundwater monitoring well E27-7. While the geophysical logging in the two boreholes did not show any notable elevated signatures at this elevation, well E27-7 displayed elevated signatures in the U-235 and U-238 logging between 164 and $160 \mathrm{~m}$ (538 and $525 \mathrm{ft})$ amsl. The remaining slices at $150 \mathrm{~m}$ (492.1 ft) amsl, $141 \mathrm{~m}(462.6 \mathrm{ft})$ amsl, and $132 \mathrm{~m}(433.1 \mathrm{ft})$ amsl, display this conductive region near the boreholes and well E27-7 increasing in area towards the northwest and becoming more conductive. Elevated signatures associated with cobalt-60 were also noted in well E27-7 at two separate intervals, between 152 and $151 \mathrm{~m}$ amsl (499 and $495 \mathrm{ft}$ ) and 147 and $144 \mathrm{~m} \mathrm{(482} \mathrm{and}$ $472 \mathrm{ft}$ ) amsl. Boreholes C8765, C8766, and C8767 display a gradual increase in soil moisture at these elevations, which is likely linked with the change in lithology between the Hanford formation $\mathrm{H} 1$ unit and the more fine grained $\mathrm{H} 2$ unit. It is difficult to source the origin for this conductive target, since the inversion model becomes equally conductive in the area between this target and the 200-Series tanks and towards the southwest (to the northeast of tanks C-103 and C-106).

Figure 30 and Figure 31 display plan view 3D renderings of the low resistivity features; these are not depth slices but rather an overhead view of the selected 3D resistivity contours. Two isosurfaces representing resistivity magnitudes of $3 \mathrm{ohm}-\mathrm{m}$ (dark blue), and $10 \mathrm{ohm}-\mathrm{m}$ (transparent light blue) are presented. For these depictions, the inversion model areas outside of the survey grid have been clipped from the 3D rendering. Figure 30 displays the northeast edge of the C Tank Farm and the 200-Series tanks survey in plan view, with the extent of the survey grid shown in red. The areas encompassed by the 3 and $10 \mathrm{ohm}-\mathrm{m}$ resistivity bodies are primarily surrounding the 200-Series tanks and extending away from them toward tanks C-112 and $\mathrm{C}-109$. A section of the linear, north-south trending potential infrastructure response is observed extending from tank $\mathrm{C}-106$. The main region of interest in the figure is the low resistivity feature in proximity to boreholes $\mathrm{C} 8765$, C8766, and $\mathrm{C} 8767$, extending to the northeastern edge of the inversion model in the direction of the monitoring well E27-7. Additional regions of interest include (1) the low resistivity feature between the 100-Series and 200-Series tanks, particularly the area to the southwest of tanks C-202 and C-203 where little infrastructure is indicated by the GPR surveys and (2) the as-built drawings and the low resistivity features to the northwest of tank C-106, below the shallow potential infrastructure response. Figure 31 shows the same representations in a 3D view, as seen looking from the 
northeast. This viewing angle gives the reader a better idea of the vertical extent of the previously described features.

Figure 30. 3D Rendered Bodies of the Low Resistivity Features from the Inversion Model, Plan View.

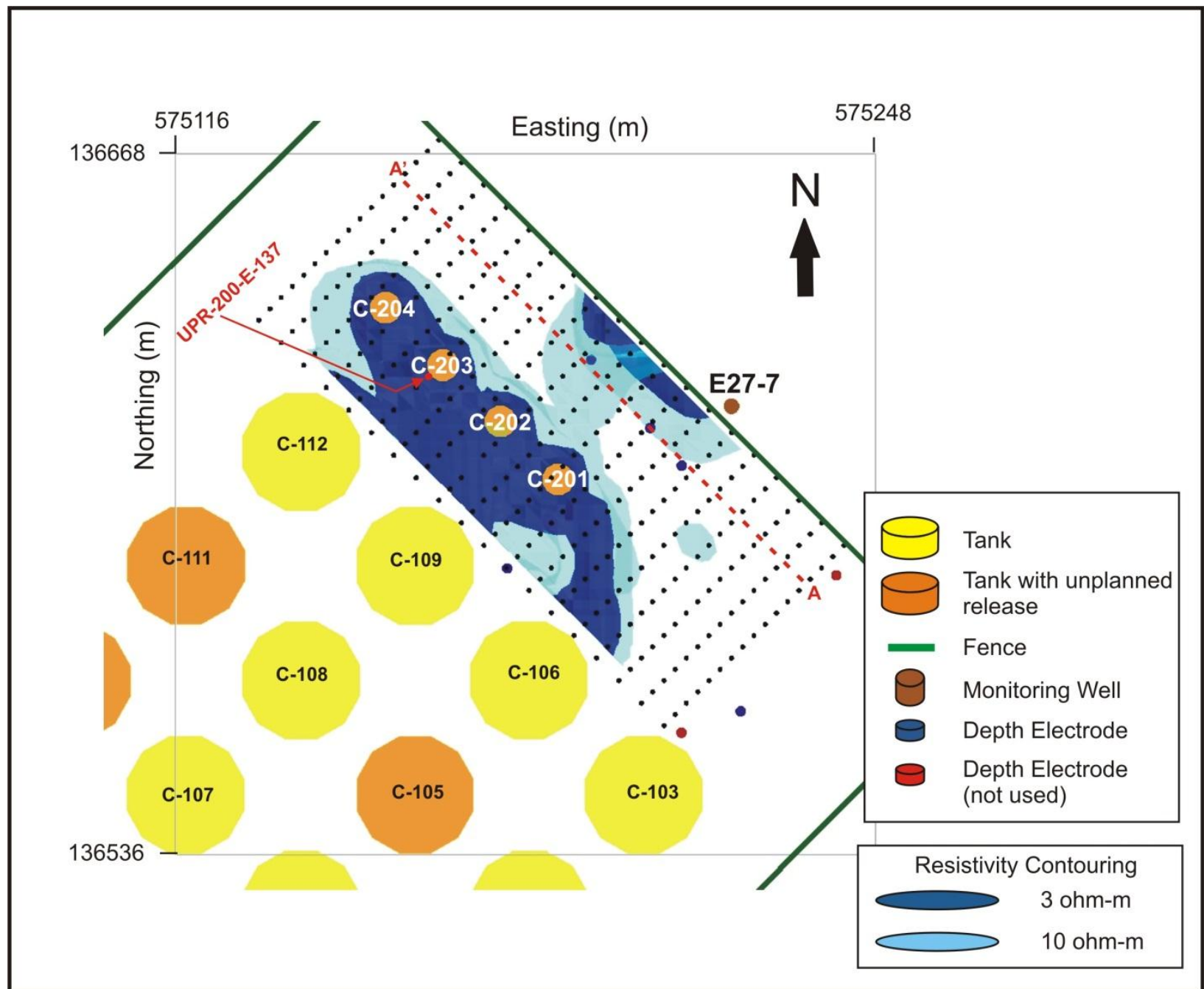




\section{Figure 31. 3D Rendered Bodies of the Low Resistivity Features from the Inversion Model, View Looking from the Northeast.}

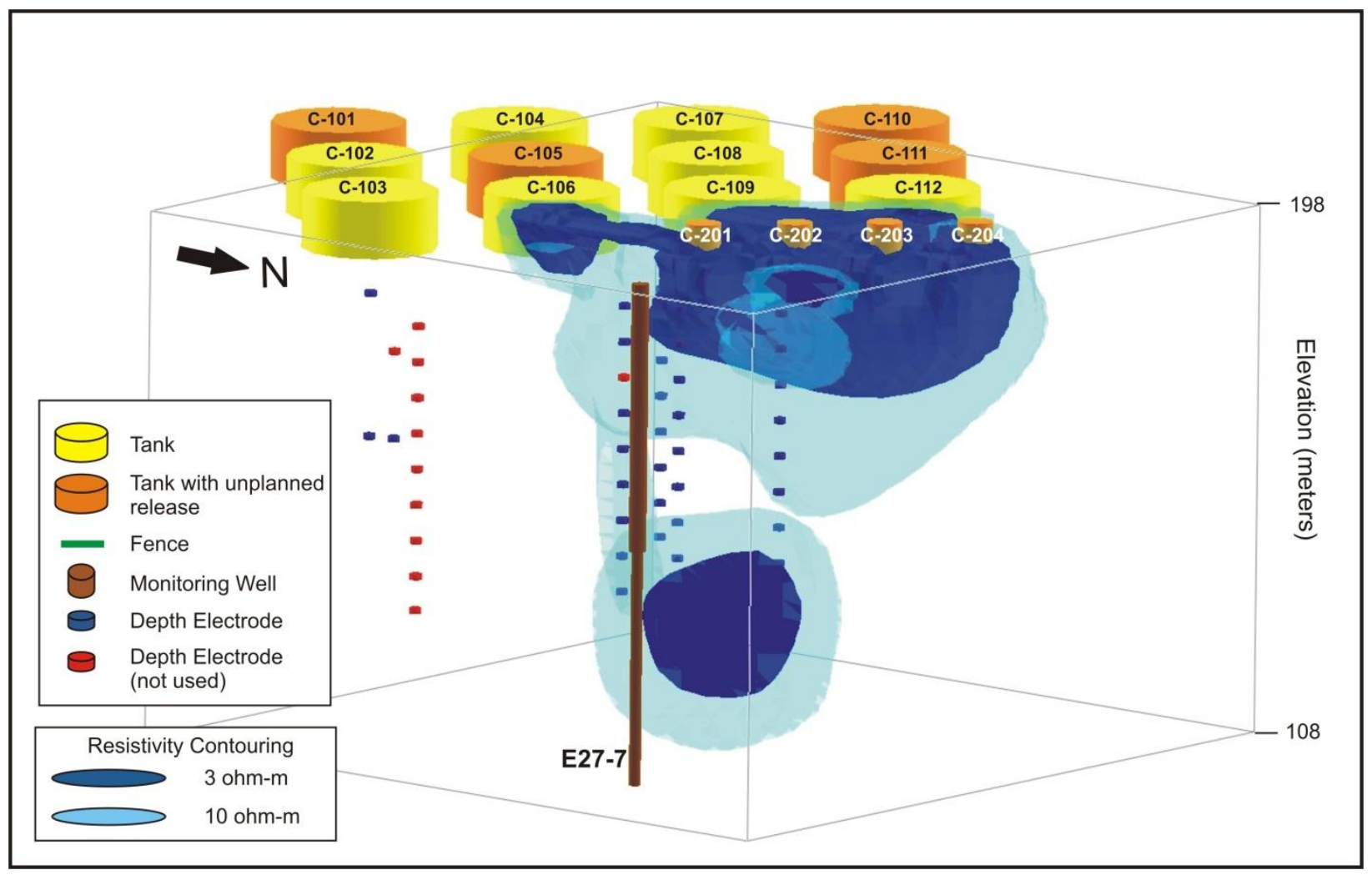

\subsubsection{D Representation of 3D Model Results}

To further explore the conductive region at depth near monitoring well E27-7, and to gain an improved insight of the region interrogated by boreholes C8765, C8766, and C8767, a vertical 2D slice was obtained from the 3D inversion model along transect A-A' (Figure 32). The state plane coordinates (in meters) for the start (A) are $575242 \mathrm{E}, 136594 \mathrm{~N}$, and for the end (A') are $575166 \mathrm{E}, 136670 \mathrm{~N}$. The $2 \mathrm{D}$ slice was extracted from the 3D model and plotted as a vertical profile (Figure 33). Boreholes C8765, C8766, and C8767 and monitoring well E27-7 are projected onto this profile. While all the boreholes are located within $\pm 3 \mathrm{~m}( \pm 9.8 \mathrm{ft})$ of the transect, the monitoring well is located approximately $12 \mathrm{~m}(39.4 \mathrm{ft})$ out of the plane of the

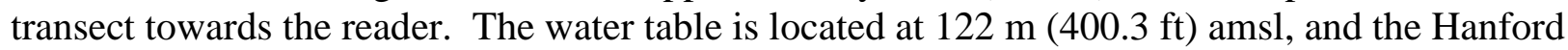
formation $\mathrm{H} 1 / \mathrm{H} 2$ geologic unit boundary is displayed at approximately $170 \mathrm{~m}(557.7 \mathrm{ft})$ amsl. The borehole results showing both moisture logging and gross gamma results and the well E27-7 uranium and cobalt results have been superimposed onto the 2D profile (Figure 34), the full results can be found in the following reports:

- RPP-RPT-55481

- HGLP-LDR-174, 299-E27-07 (A4816) Log Data Report. 
RPP-RPT-56760, Rev. 0

Figure 32. Location of A-A' Transect for 2D Profile Representation.

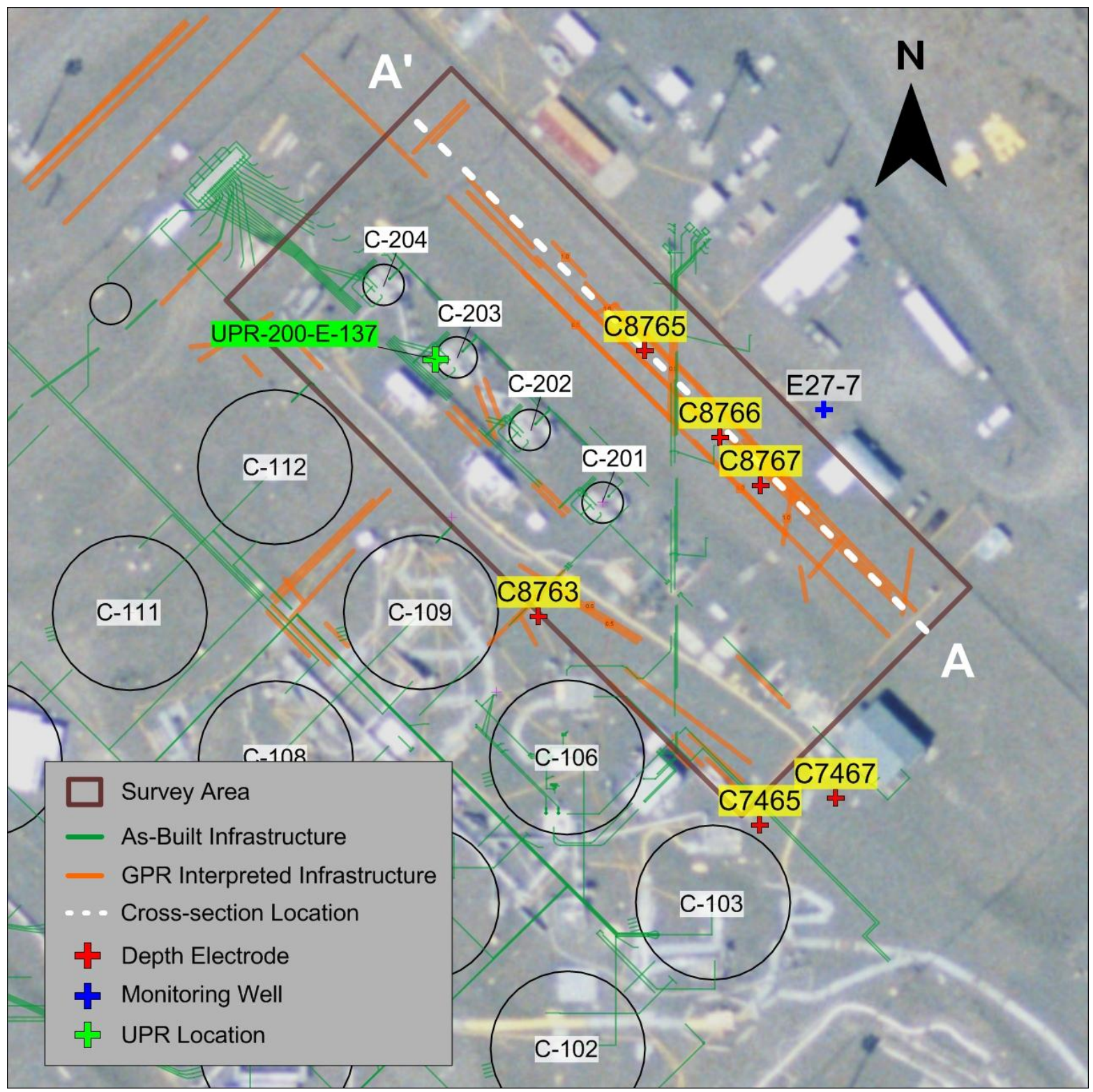


Figure 33. 2D Vertical Profile, Extracted from 3D Model.

\section{0-Series Tanks Survey Area - Vertical 2D Slice Extracted from 3D Inverse Model Results}

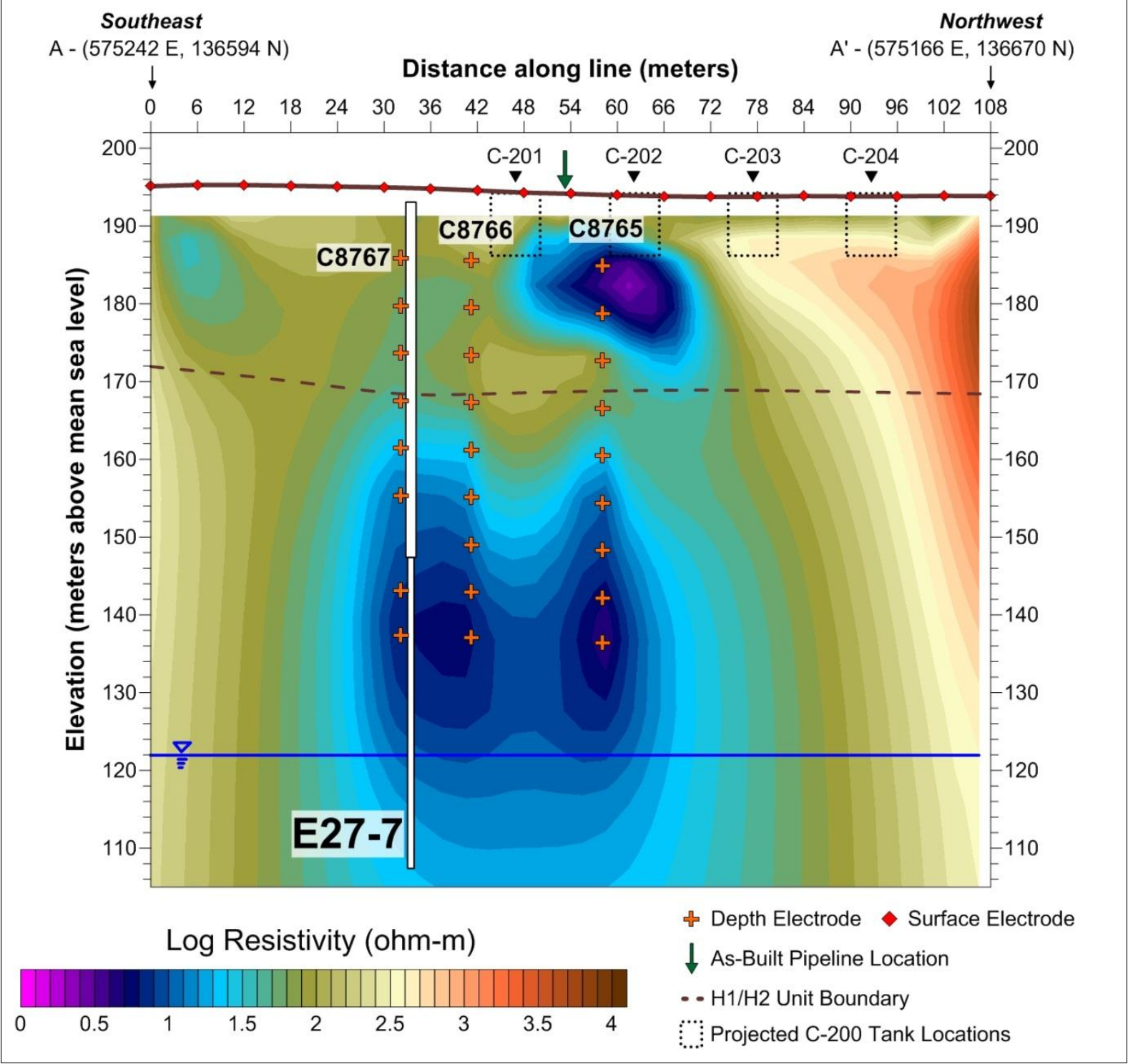


RPP-RPT-56760, Rev. 0

Figure 34. Vertical Slice with Borehole and Well Logging Results.

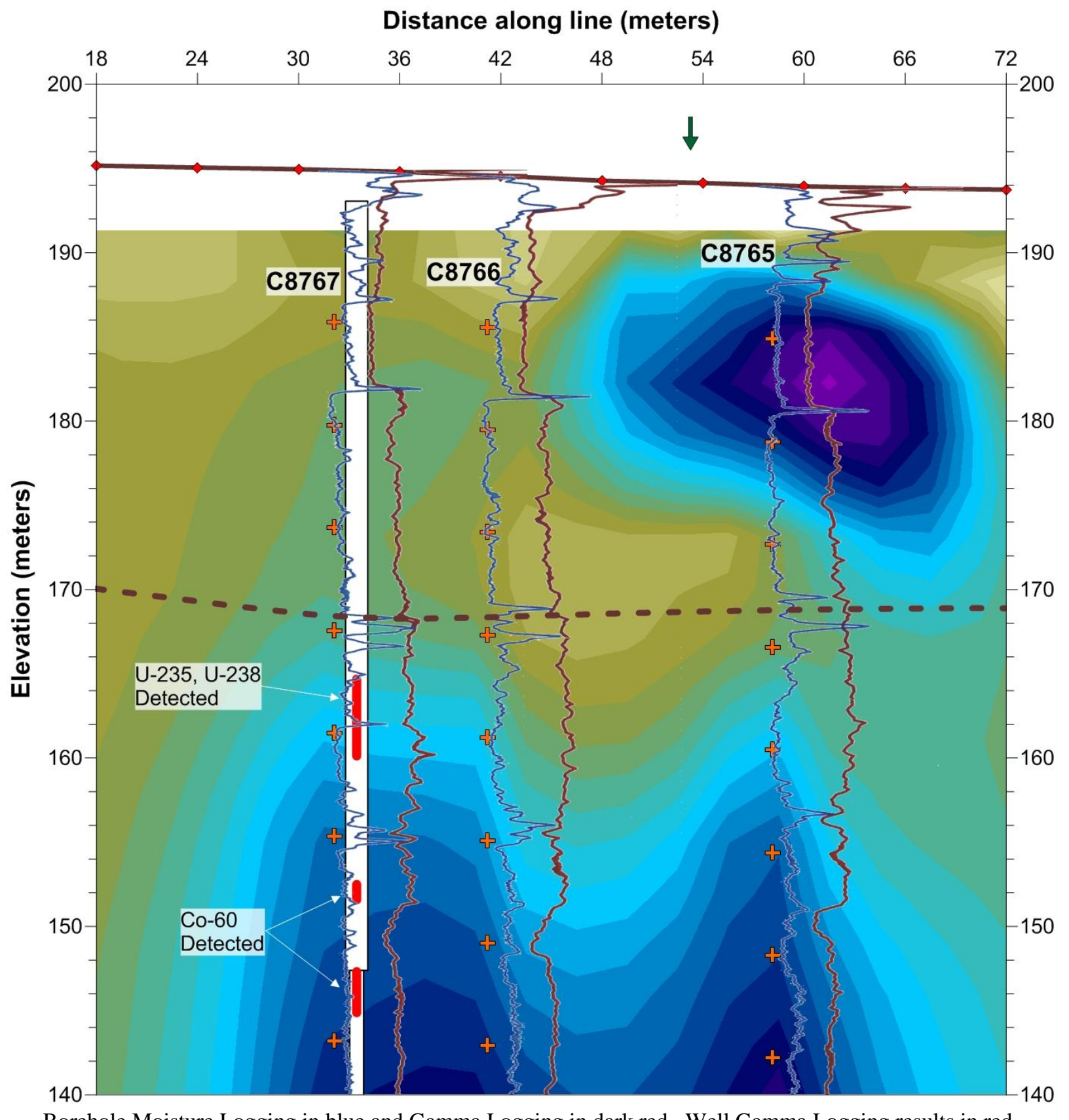

Borehole Moisture Logging in blue and Gamma Logging in dark red. Well Gamma Logging results in red. 
The vertical profile displays two prominent low resistivity features; the first is located near the ground surface at approximately $60 \mathrm{~m}(196.9 \mathrm{ft})$ along the profile and centered at approximately $182 \mathrm{~m}(597.1 \mathrm{ft}) \mathrm{amsl}$, or $12 \mathrm{~m}(39.4 \mathrm{ft}) \mathrm{bgs}$. The second feature is located between approximately $30 \mathrm{~m}(98.4 \mathrm{ft})$ and $60 \mathrm{~m}(196.9 \mathrm{ft})$ along the profile and centered at $138 \mathrm{~m}$ $(452.8 \mathrm{ft}) \mathrm{amsl}$, or $58 \mathrm{~m}(190.3 \mathrm{ft}) \mathrm{bgs}$. The first near-surface feature is located slightly to the

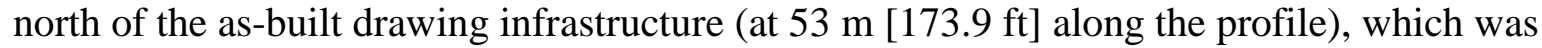
noted earlier to have exhibited a strong linear response in the inversion model results at these elevations. It is difficult to determine the extent of the relationship between the low resistivity feature and the infrastructure. As noted earlier, this conductive feature (in plan view) appears to change orientation with decreasing elevation from the inversion model results, with the center of mass located some distance from the as-built drawing infrastructure location. The logging results for borehole C8765 (Figure 34) displays elevated levels for moisture content and gamma between approximately 0 and $6 \mathrm{~m}(0$ and $20 \mathrm{ft}) \mathrm{bgs}$ and a localized spike at about $14 \mathrm{~m}$ $(45.9 \mathrm{ft}) \mathrm{bgs}$. However, this cannot adequately explain this feature as it extends over much larger area than the elevated moisture logs suggest and we do not observe a similar low resistivity feature for similar elevated levels in the logging in boreholes C8766 and C8767.

The second low resistivity feature is observed in the profile between approximately $150 \mathrm{~m}$ $(492.1 \mathrm{ft})$ amsl and $120 \mathrm{~m}(393.7 \mathrm{ft})$ amsl, or $46 \mathrm{~m}(150.9 \mathrm{ft})$ and $76 \mathrm{~m}(249.3 \mathrm{ft}) \mathrm{bgs}$. The profile appears to show two centers of mass for this feature, located on either side, although this is likely a result of the location of the depth electrodes (which control model resolution) relative to the feature. It is fair to assume that this feature is continuous between boreholes C8765 and C8767. Additionally, the lateral extent of the feature is likely underestimated by the model because of the lack of further coverage of depth electrodes. The borehole logging results (Figure 34) display a gradual increase in soil moisture with depth in the region of this feature, however this is potentially related to the change in lithology between the Hanford formation $\mathrm{H} 1$ unit and the more fine grained $\mathrm{H} 2$ unit that occurs around $170 \mathrm{~m}(557.7 \mathrm{ft})$ amsl. There are a number of spikes in the moisture content and gamma logging but these are too small scale for a direct response from the inversion model results. The logging results from the monitoring well E27-7 display some potential correlation to this feature. An elevated signature in the uranium235 and uranium-238 logging was observed at an elevation of $163 \mathrm{~m}(534.8 \mathrm{ft})$ amsl, or a depth

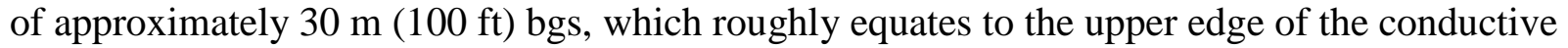
feature. Elevated signatures in the cobalt-60 logging were observed at approximately $152.5 \mathrm{~m}$ $(500.3 \mathrm{ft})$ amsl and $147.3 \mathrm{~m}$ (483.3 ft) amsl, or depths of $40.5 \mathrm{~m}(133 \mathrm{ft})$ and $45.7 \mathrm{~m}(150 \mathrm{ft}) \mathrm{bgs}$. While these do not correlate perfectly with the entire conductive region, they do fall within it and may indicate a larger plume of material that is the contributing transport mechanism for these radionuclides.

Figure 35 demonstrates historical groundwater monitoring results for groundwater monitoring well E27-7. Starting in the mid to late 1990s there was increasing concentrations of nitrate, uranium and technetium-99 in observed at this groundwater monitoring well. By 2003, the uranium and technetium-99 values decreased to a background trend. The nitrate concentrations continued to increase until 2012 where the values have begun to return to background conditions. Of the three analytes presented here, the resistivity data is only directly sensitive to the presence of nitrates; however, it would seem that the deeper anomaly in Figure 33 may be in fact be related to this increase in nitrate observed at well E27-7. 
Figure 35. Well E27-7 Groundwater Analytical Results for: A) Nitrate, Uranium, and B) Technetium.
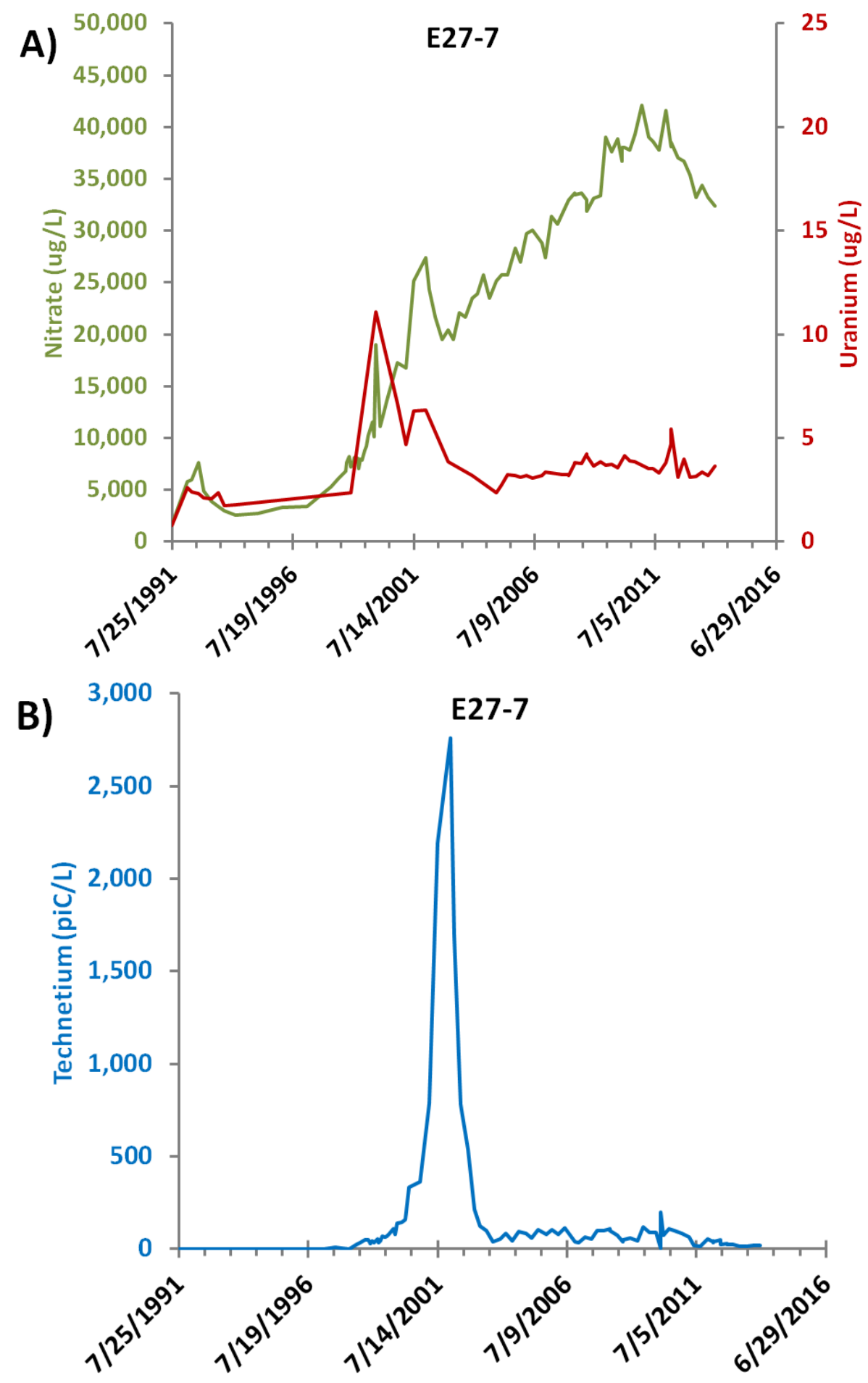

Data source: http://phoenix.pnnl.gov/. 


\subsubsection{Infrastructure Modeling}

The 200-Series tank electrical resistivity survey area was somewhat unique in comparison to other SGE surveys in that, the voltage measurements were acquired across a survey grid that had a relatively modest amount of subsurface infrastructure, aside from the tanks themselves. Furthermore, the modeling results appeared to show that one particular north-south trending infrastructure had a significant effect on the inversion model results. It has been shown in previous SGE modeling efforts that including a priori information for the storage tanks can improve modeling results. Given the strong influence of this particular infrastructure on the 200-Series tanks inversion modeling, we hoped to enhance results with a priori modeling of the infrastructure. The infrastructure was modeled using a series of small, overlapping blocks which were placed in the location of the infrastructure from the GPR responses and as-built drawings. The width and depth of the blocks were varied, together with the assigned resistivity value provided as a starting point for the inversion model. Figure 36 displays an example of the a priori infrastructure model blocks (yellow) along with the a priori tank model blocks (blue). The example shows how the infrastructure follows the contour of the surface elevation.

Figure 36. A Priori Modeling of Infrastructure.

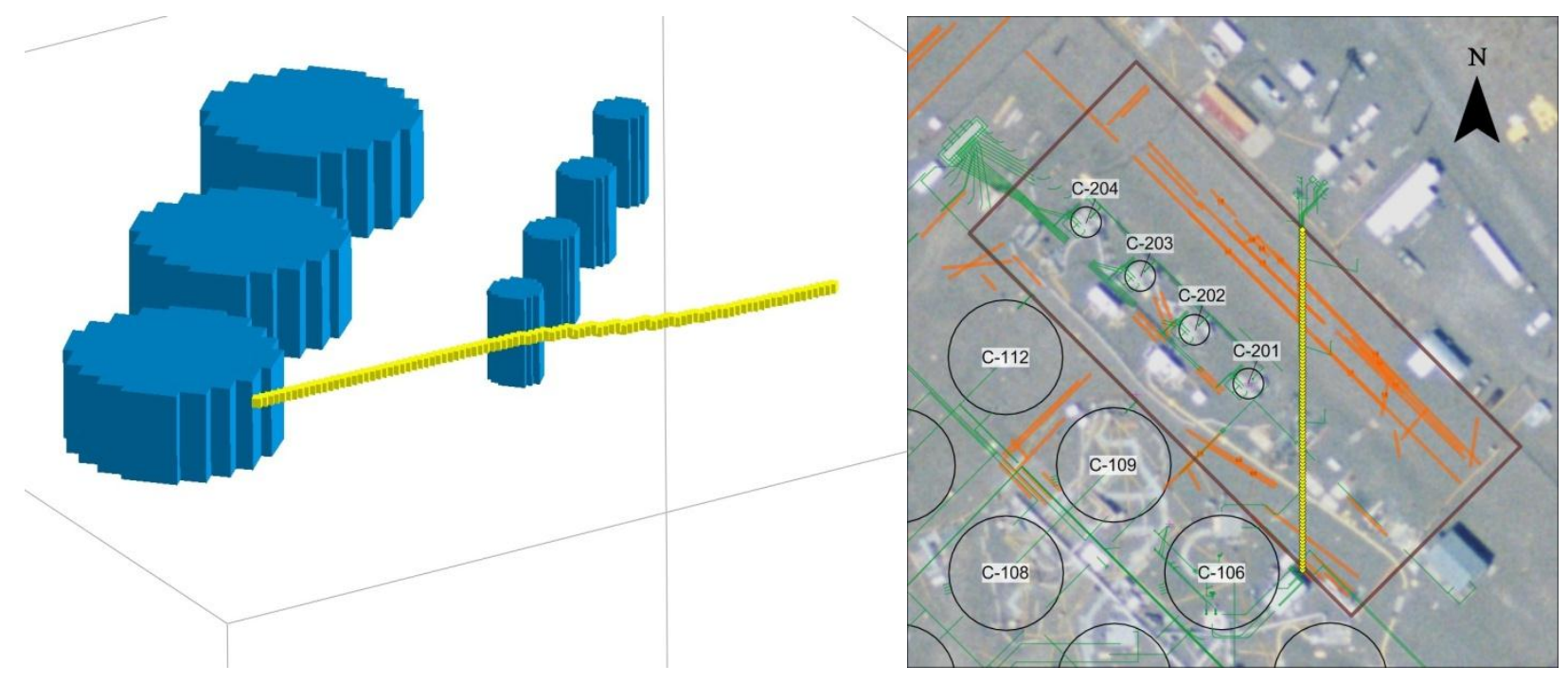

An example from the infrastructure inversion model results are displayed in Figure 37. The infrastructure in this particular model was comprised of a series of $1 \mathrm{~m}^{3}\left(35.3 \mathrm{ft}^{3}\right)$ blocks at a depth of $0.5 \mathrm{~m}$ (1.64 ft) bgs. Several variations of block size and depth were tested, together with starting resistivity value of the blocks, and provided negligible changes to the inversion model result from that provided here. In Figure 37, the color contours represent percent changes in the a priori inversion model with respect to the original inversion model result without an $a$ priori infrastructure, presented in Figure 28 and Figure 29. Warmer hues (reds and browns) indicate an increase in modeled conductivity while cooler hues (blues and purples) indicate a decrease in modeled conductivity. A solid black line was added along the contour for zero percent change. Four near-surface depth slices are presented. It should be noted that the percent change has been presented because the overall changes to the model are not significant and difficult to observe when looking at contoured resistivity values. 
Figure 37. Inverse Model Results for Pipeline Infrastructure Modeling. Contours Displayed in Percent Difference from Original Inversion Model Presented in Figure 28.

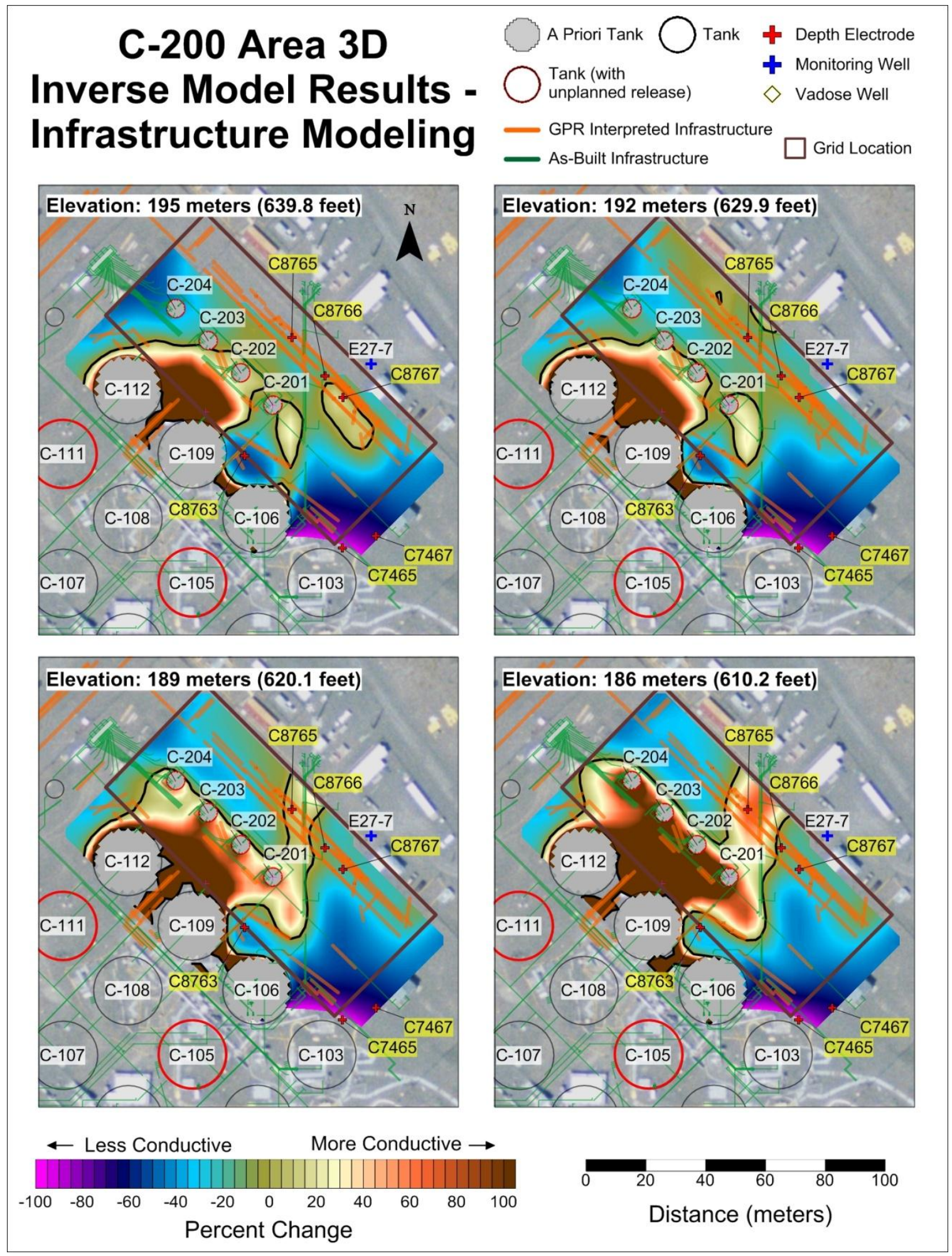


In the depth slices, we can see a few key areas that appear to be influenced by the introduction of the pipeline blocks into the model, primarily the location of the a priori infrastructure and the region surrounding the 200-Series tanks. There also appears to be some influence in the areas near the northwest-southeast trending as-built drawing infrastructure in the northeast section of the survey area. Along the a priori infrastructure location, we can see that the $195 \mathrm{~m}(639.8 \mathrm{ft})$ amsl and $192 \mathrm{~m}(629.9 \mathrm{ft})$ amsl slices show a "more conductive" change to the south of tank C-201, trending towards tank C-106. While, in the $189 \mathrm{~m}(620.1 \mathrm{ft})$ and $186 \mathrm{~m}(610.2 \mathrm{ft})$ amsl slices the "more conductive" change extends north from tank C-201 to the edge of the model domain. This is likely a result of the topography which has been added to the model (the infrastructure is at a lower elevation to the north). The original model results without the pipeline showed these areas to be more conductive in the near surface, relative to surrounding areas, which may explain the model's sensitivity when a very conductive body is introduced (infrastructure). Near-surface conductive features, which tend to be indicative of metallic infrastructure, become more conductive in the a priori infrastructure inversion model, and the surrounding areas become less conductive.

In this example, we have singled out and attempted to model merely one portion of the subsurface infrastructure within the C Tank Farm. While we do have limited information regarding the location of this infrastructure, from as-built drawings and the results from GPR surveying, these infrastructure maps are by no means complete. Furthermore, the original model without the a priori pipeline indicates some of the known infrastructure has obvious effects on the voltage measurements, while some do not appear to have any at all.

\subsection{CONCLUSIONS}

An SGE survey was conducted within the C Tank Farm at the Hanford Site in FY 2013. The survey consisted of a 3D electrical resistivity survey of the subsurface concentrated in the vicinity of the 200-Series tanks, which included measurements on 318 surface electrodes placed within a grid, 50 depth electrodes, and 1 monitoring well acting as a long electrode. Data collection for the two surveys was completed between July 24, 2013 and August 1, 2013.

The combined 3D electrical resistivity results of the model showed a continuous distribution of resistivity data within the $\mathrm{C}$ Tank Farm, with modeled resistivity spanning from 0.1 to $6942 \mathrm{ohm}-\mathrm{m}$, or approximately 4.5 orders of magnitude difference between the lowest and highest resistivity values. The primary low resistivity (high conductivity) target, not associated with the underground storage tanks or interpreted infrastructure responses, was observed in the region between boreholes C8765, C8766, and C8767 and the monitoring well E27-7, on the northeast edge of the inversion model. The target was qualitatively verified by gamma logging data from the appropriate depths, obtained from the monitoring well outside the tank farm. Elevated signatures of uranium-235 and uranium-238 were observed occurring between approximately 164 and $160 \mathrm{~m}(538$ and $525 \mathrm{ft})$ amsl, with elevated signatures of cobalt-60 occurring between approximately 152 and $151 \mathrm{~m}(499$ and $495 \mathrm{ft})$ amsl and 147 and $144 \mathrm{~m}$ (482 and $472 \mathrm{ft}$ ) amsl (GJO-98-39-TARA). Although not directly comparable to the resistivity data, the gamma information can provide an indication of past releases. The electrical resistivity results do not conclusively suggest a source for this target. Additional low resistivity regions are observed between the 100-Series and 200-Series tanks and to the northwest of tank C-106. Both 
of these regions are located at depths below potential underground storage tanks or interpreted infrastructure responses. Additional information to validate these regions is very limited in this area of the tank farm. Potentially these conductive targets represent the ionic constituents of waste releases associated with the 100-Series tanks and infrastructure that have migrated though the subsurface. While there is some collaborating evidence to support this further information from additional soil investigations would be required to confirm the results.

In addition, to further explore the conductive region at depth near monitoring well E27-7, and to gain an improved insight of the region interrogated by boreholes C8765, C8766, and C8767, a vertical 2D slice was obtained from the 3D inversion model. The 2D profile indicates the conductive target of interest in this region extends from approximately $166 \mathrm{~m}(545 \mathrm{ft})$ amsl to below the water table, at $122 \mathrm{~m}$ (400 ft) amsl. The elevated signatures in the uranium- 235 and uranium-238 logging correspond to the upper extent of this target, while the elevated signatures in the cobalt-60 logging occur at lower elevations close to the center of mass of the target located

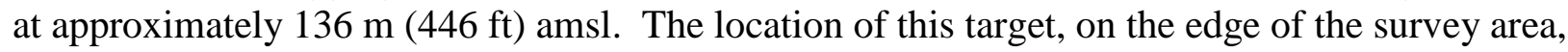
makes it difficult to determine an accurate extent and distribution of the conductive region. The electrical resistivity contours suggest that the conductive target could potentially have spread beyond the tank farm boundary and may warrant further investigation.

This survey was the second successful SGE survey to utilize the Geotection-180 Resistivity Monitoring System, which facilitated a much larger survey size and faster data acquisition rate. The 180-channel system allowed all measurement combinations of the 369 electrodes (surface, depth, and long [monitoring well] electrodes) to be collected 10 to 15 times more rapidly than previous SGE surveys using the 8-channel SuperSting R8 system.

\subsection{REFERENCES}

CEES-0360, 2007, Surface Geophysical Exploration System Design Description, Rev. 0, Columbia Energy and Environmental Services, Inc., Richland, Washington.

DOE/RL-2013-22, 2013, Hanford Site Groundwater Monitoring Report for 2012, Rev. 0, U.S. Department of Energy, Richland Operations Office, Richland, Washington.

DOE/RL-88-30, 2013, Hanford Site Waste Management Units Report, Rev. 22, U.S. Department of Energy, Richland Operations Office, Richland, Washington.

GJO-98-39-TARA, GJO-HAN-18, 2000, Vadose Zone Characterization Project at the Hanford Tank Farms, Addendum to the C Tank Farm Report, U.S. Department of Energy, Grand Junction Office, Grand Junction, Colorado.

HGLP-LDR-174, 2008, 299-E27-07 (A4816) Log Data Report, Rev. 0, Washington River Protection Solutions, LLC, Richland, Washington.

HNF-EP-0182, 2013, Waste Tank Summary Report for Month Ending July 31, 2013, Rev. 304, Washington River Protection Solutions, LLC, Richland, Washington.

RPP-14430, 2003, Subsurface Conditions Description of the C and A-AX Waste Management Area, Rev. 0, CH2M HILL Hanford Group, Richland, Washington. 
RPP-15408, 2003, Origin of Wastes C-200 Series Single-Shell Tanks, Rev. 0, CH2M HILL Hanford Group Inc., Richland, Washington.

RPP-23748, 2006, Geology, Hydrogeology, Geochemistry, and Mineralogy Data Package for the Single-Shell Tank Waste Management Areas at the Hanford Site, Rev. 0, CH2M HILL Hanford Group, Inc., Richland, Washington.

RPP-29441, 2006, Post-Retrieval Waste Volume Determination for Single-Shell Tank 241-C201, Rev. 0, Washington River Protection Solutions, LLC, Richland, Washington..

RPP-34690, 2006, Surface Geophysical Exploration of the B, BX, and BY Tank Farms at the Hanford Site, Rev. 0, Washington River Protection Solutions, LLC, Richland, Washington.

RPP-35484, 2008, Field Investigation Report for Waste Management Areas C and A-AX, Rev. 1, CH2M HILL Hanford Group, Inc., Richland, Washington.

RPP-PLAN-39114, 2012, Phase 2 RCRA Facility Investigation/Corrective Measures Study Work Plan for Waste Management Area C, Rev. 2, Washington River Protection Solutions, LLC, Richland, Washington.

RPP-PLAN-54755, 2013, Work Plan for a 3D Electrical Resistivity Survey Encompassing the 200-Series Tanks at the 241-C Tank Farm, Rev. 0, Washington River Protection Solutions, LLC, Richland, Washington.

RPP-RPT-26475, 2006, Retrieval Data Report for Single-Shell Tank 241-C-203, Rev. 1, CH2M HILL Hanford Group Inc., Richland, Washington.

RPP-RPT-29095, 2006, Retrieval Data Report for Single-Shell Tank 241-C-202, Rev. 0, CH2M HILL Hanford Group Inc., Richland, Washington.

RPP-RPT-30181, 2006, Retrieval Data Report for Single-Shell Tank 241-C-201, Rev. 0B, CH2M HILL Hanford Group Inc., Richland, Washington.

RPP-RPT-31558, 2006, Surface Geophysical Exploration of C Tank Farm at the Hanford Site, Rev. 0, Washington River Protection Solutions, LLC, Richland, Washington.

RPP-RPT-34062, 2007, Retrieval Data Report for Single-Shell Tank 241-C-204, Rev. 0, CH2M HILL Hanford Group Inc., Richland, Washington.

RPP-RPT-41236, year, Surface Geophysical Exploration of UPR 200-E-81 Near the C Tank Farm, Rev. 0, Washington River Protection Solutions, LLC, Richland, Washington.

RPP-RPT-42294, 2010, Hanford Waste Management Area C Soil Contamination Inventory Estimates, Rev. 1, Washington River Protection Solutions, LLC, Richland, Washington.

RPP-RPT-42714, 2009, Completion Report for Single-Shell Tank 241-C-103 Direct Push Soil Investigation, Rev. 0, Washington River Protection Solutions, LLC, Richland, Washington.

RPP-RPT-47461, 2010, Completion Report for Direct Push Characterization at Three Sites in 241-C Tank Farm, Rev. 0, Washington River Protection Solutions, LLC, Richland, Washington.

RPP-RPT-47486, 2010, Surface Geophysical Exploration of UPR 200 E 86 Near the C Tank Farm, Rev. 0, Washington River Protection Solutions, LLC, Richland, Washington. 
RPP-RPT-49288, 2011, C Farm Surface Geophysical Exploration-Reprocessing, Rev. 0, Washington River Protection Solutions, LLC, Richland, Washington.

RPP-RPT-50052, 2011, Surface Geophysical Exploration of UPR-200-E-82 Near the C Tank Farm, Rev. 0, Washington River Protection Solutions, LLC, Richland, Washington.

RPP-RPT-51384, 2012, Completion Report for the 241-C Tank Farm C-203 Angle Direct Push Characterization, Rev. 1, Washington River Protection Solutions, LLC, Richland, Washington.

RPP-RPT-53055, 2013, Waste Management Area C Resistivity Depth Electrode Locations, Rev. 1, Washington River Protection Solutions, LLC, Richland, Washington.

RPP-RPT-55481, 2013, Completion Report for 241-C Tank Farm 200 Series Tank Activities, Rev. 0, Washington River Protection Solutions, LLC, Richland, Washington.

RPT-2013-001, 2013, Summary of C-farm Site Clearance Survey, Rev. 0, Washington River Protection Solutions, LLC, Richland, Washington.

Rucker, D.F., J.B. Fink, and M.H. Loke, 2011. Environmental monitoring of leaks using time lapsed long electrode electrical resistivity. Journal of Applied Geophysics 74(4):242254. 
RPP-RPT-56760, Rev. 0

Appendix A

Quality Assurance 


\section{A1.0 QUALITY ASSURANCE}

Collection and analysis of surface geophysical exploration (SGE) data are performed under a project-specific quality assurance plan using a graded approach that conforms to applicable requirements from Columbia Energy quality assurance procedures (CEES-0333, Quality Assurance Plan for Surface Geophysical Exploration Projects). These procedures implement the requirements of ASME NQA-1, Quality Assurance Requirements for Nuclear Facility Applications and DOE O 414.1C, Quality Assurance. Work not covered in the quality assurance plan will conform to accepted industry standards for SGE and sound engineering principles.

This quality assurance plan implements the criteria of DOE O 414.1C and the following requirements from ASME NQA-1, Quality Assurance Requirements for Nuclear Facility Applications:

- Requirement 1 Organization

- Requirement 2 Quality Assurance Program

- Requirement 5 Instructions, Procedures, and Drawings

- Requirement 6 Document Control

- Requirement 16 Corrective Action

- Requirement 17 Quality Assurance Records.

Columbia Energy and Environmental Services, Inc. and hydroGEOPHYSICS, Inc. (HGI) collect data using designed systems or off-the-shelf commercially available hardware. Designed systems conform to applicable requirements in approved procedures that address design, design analysis, design verification, and engineering drawing.

A project specific software management plan, CEES-0338, Software Management Plan for Surface Geophysical Exploration Projects, was prepared to implement a graded approach to software management in accordance with the following requirements documents:

- ASME NQA-1, Subpart 2.7, "Quality Assurance Requirements for Computer Software for Nuclear Facility Applications"

- CEES-0333

- CE-ES-3.5, Software Engineering

- Contract 28090, High Resolution Resistivity Characterization of Single Shell Tank Farm Waste Management Areas

- DOE O 414.1C.

\section{A1.1 CALIBRATION AND MAINTENANCE OF EQUIPMENT AND INSTRUMENTS}

Calibration and maintenance of equipment used for data collection is addressed in CEES-0360, Surface Geophysical Exploration System Design Description. Where periodic calibration and/or maintenance of instruments used to collect quality affecting data is recommended those instruments were current on calibration at the time the instrument was used for data collection and the calibration certificate is maintained in the project files. 
Field notes are used to document the specific instruments used. Electronic logs are utilized to provide traceable documentation for each data set collected. Information recorded in the electronic field log includes date, instrument identification, operator, and applicable settings for each data set collected. All instruments have current calibration certificates and documentation is maintained in the project files. Instrument calibration frequency and calibration tests performed in the field are documented in the system design description (CEES-0360).

\section{A1.2 DATA COLLECTION}

The setup, operation, and maintenance of the SGE equipment used in collecting and analyzing resistivity data is described in CEES-0360. This document identifies the requirements for the hardware/software used for data collection and analysis and provides a rationale for the hardware/software selected for use.

Data accuracy will be evaluated by performing reciprocal data collection. Reciprocal collection is used as a tool to assure the data collected is accurate and repeatable. The transfer, storage, and management of data collected in the field are described in the system design description (CEES-0360).

\section{A1.2.1 Selection of Resistivity Data Acquisition Equipment}

In response to Washington River Protection Solutions, LLC (WRPS) desire for rapid data acquisition to reduce tank farm work restriction times, the Geotection ${ }^{\mathrm{TM}}-180$ Resistivity Monitoring System, designed and fabricated by HGI, is to be used. Similar equipment is currently in use at the $\mathrm{C}$ Tank Farm as part of the leak detection and monitoring program. HGI will deploy a larger and easily portable version of this system for this project, which is typically used for commercial applications. This new system has several capabilities that make it ideal for this application:

- $\quad$ Improved Speed: The system has 180 channels in comparison to the 8 channels available on the SuperSting ${ }^{\circledR}$ system previously used. This equates to a data collection rate that is 15 to 20 times faster.

- Improved Data Quality: Side-by-side comparison testing performed as part of acceptance testing for the leak detection and monitoring project showed the Geotection system is more sensitive, more accurate, has a larger dynamic range, and is better equipped to deal with electrical interference.

- $\quad$ Better Depth Electrode Sampling: Geotection has a greater number of channels, which in turn decreases the number of times the depth electrodes are transmitted on by a factor of 20 . On previous surveys it was possible to overuse the depth electrodes through continuous current transmission, which reduced the available moisture. In addition, the improved dynamic range allows us to reduce the output electrical power while still producing a usable signal; improving the lifespan of the, historically fragile, depth electrodes.

- $\quad$ Improved Safety: Geotection is UL-compliant, whereas the previously used equipment was not UL listed which required additional inspection for approved 
use. In addition, Geotection automatically detects breaks in cables and will suspend current transmission to any conductors that are broken.

- $\quad$ Improved Lock Out/Tag Out: Lock Out/Tag Out procedures are already in place within the Hanford complex as part of use on the leak detection and monitoring program.

A specific listing of the functional requirements and how the selected instruments meet those requirements is contained in Tables A-1, A-2, and A-3.

\section{Table A-1. Physical Characteristics of the Geotection ${ }^{\text {TM-180 }}$ Resistivity Data Acquisition System.}

\begin{tabular}{|c|c|c|}
\hline $\begin{array}{l}\text { Physical } \\
\text { Characteristics }\end{array}$ & Requirement & $\begin{array}{l}\text { Selected Resistivity Data } \\
\text { Acquisition Instrument }\end{array}$ \\
\hline Portability & $\begin{array}{l}\text { Must be field portable such that the } \\
\text { components can be easily operated } \\
\text { within the cab of a vehicle or field } \\
\text { trailer. }\end{array}$ & $\begin{array}{l}\text { Geotection-180 system is mounted in a mobile, } \\
\text { trailer based enclosure that can be temporarily or } \\
\text { permanently deployed at a project site using mains } \\
\text { or generator power. }\end{array}$ \\
\hline Temperature Range & $\begin{array}{l}32^{\circ} \text { Fahrenheit to } 105^{\circ} \text { Fahrenheit } \\
\left(0^{\circ} \text { Celsius to } 40^{\circ} \text { Celsius }\right) \text {. }\end{array}$ & Trailer based enclosure is fully climate controlled. \\
\hline Power & $\begin{array}{l}\text { Input power should be minimum of } \\
12 \mathrm{~V} \text { DC. }\end{array}$ & $\begin{array}{l}220 \text { V AC, Single Phase, } 3 \text { pole, } 50 \text { A (requires } \\
\text { neutral). }\end{array}$ \\
\hline Water Protection & $\begin{array}{l}\text { Must be able to operate in rainy } \\
\text { conditions. }\end{array}$ & $\begin{array}{l}\text { Trailer based enclosure can operate in any weather } \\
\text { conditions. }\end{array}$ \\
\hline
\end{tabular}

\section{Table A-2. Performance Characteristics of the Geotection ${ }^{\mathrm{TM}} \mathbf{- 1 8 0}$ Resistivity Data Acquisition System. (2 sheets)}

\begin{tabular}{|c|c|c|}
\hline $\begin{array}{l}\text { Performance } \\
\text { Characteristic }\end{array}$ & Requirement & $\begin{array}{l}\text { Selected Resistivity Data } \\
\text { Acquisition Instrument }\end{array}$ \\
\hline Availability & $\begin{array}{l}\text { Commercially available hardware } \\
\text { with support for part } \\
\text { repair/replacement. }\end{array}$ & $\begin{array}{l}\text { Geotection-180 Resistivity Monitoring System } \\
\text { manufactured by hydroGEOPHYSICS, Inc, Tucson } \\
\text { Arizona } \\
\text { Website: } \\
\text { http://www.hgiworld.com/equipment/geotection/ }\end{array}$ \\
\hline
\end{tabular}




\section{Table A-2. Performance Characteristics of the Geotection ${ }^{\mathrm{TM}} \mathbf{- 1 8 0}$ Resistivity Data Acquisition System. (2 sheets)}

\begin{tabular}{|c|c|c|}
\hline $\begin{array}{l}\text { Performance } \\
\text { Characteristic }\end{array}$ & Requirement & $\begin{array}{l}\text { Selected Resistivity Data } \\
\text { Acquisition Instrument }\end{array}$ \\
\hline Use & $\begin{array}{l}\text { Acquire Earth resistivity data using } \\
\text { the pole-pole electrode array. }\end{array}$ & $\begin{array}{l}\text { Resistivity imaging surveys using the pole-pole } \\
\text { electrode array. }\end{array}$ \\
\hline Operating Modes & $\begin{array}{l}\text { Must be capable of automated } \\
\text { multi-channel (minimum of } \\
\text { six channels) data acquisition using } \\
\text { a user defined set of electrode } \\
\text { measurement instructions. }\end{array}$ & $\begin{array}{l}\text { Automated data acquisition for up to } 180 \text {-channels } \\
\text { using a command file that is created manually by an } \\
\text { operator. }\end{array}$ \\
\hline Measurement Modes & Apparent resistivity and resistance. & $\begin{array}{l}\text { Apparent resistivity, resistance, self-potential, } \\
\text { contact resistance, transmitter current and voltage, } \\
\text { receiver voltage, weather (in/out temp, rain, wind, } \\
\text { humidity). }\end{array}$ \\
\hline Number of Electrodes & $\begin{array}{l}\text { Must be able to integrate with a } \\
\text { minimum of } 200 \text { electrodes. }\end{array}$ & $\begin{array}{l}\text { System can support a maximum of } 66,000 \text { electrode } \\
\text { channels. }\end{array}$ \\
\hline Measurement range & $\pm 5 \mathrm{~V} \mathrm{DC}$ & $\pm 10 \mathrm{~V} \mathrm{DC}$ \\
\hline $\begin{array}{l}\text { Measurement } \\
\text { Resolution }\end{array}$ & Not defined. & 16-bit ( $15 \mu \mathrm{V}$ per $\pm 10 \mathrm{~V}$ range $)$ \\
\hline Output Current & Minimum of $1 \mathrm{~A}$. & $1 \mathrm{~mA}-8 \mathrm{~A}$. \\
\hline Output Power & Minimum of $100 \mathrm{~W}$. & 200W. \\
\hline Input Impedance & >10 MOhms. & >10 MOhms. \\
\hline Data Storage & $\begin{array}{l}\text { Greater than } 56,280 \text { data points in } \\
\text { resistivity mode. }\end{array}$ & $\begin{array}{l}\text { Redundant enterprise grade laptop hard drives, SQL } \\
\text { database storage, ASCII CSV summary files, binary } \\
\text { full waveform files. }\end{array}$ \\
\hline Depth of Investigation & $\begin{array}{l}\text { Up to } 82 \mathrm{ft}(25 \mathrm{~m}) \text { to image target } \\
\text { body. }\end{array}$ & $\begin{array}{l}\text { Dependent on electrode spacing, total number of } \\
\text { electrodes, array type, power output and } \\
\text { signal-to-noise ratio. } \\
\text { Under optimal conditions, a depth greater than } 82 \mathrm{ft} \\
(25 \mathrm{~m}) \text { can be achieved with } 262 \mathrm{ft}(80 \mathrm{~m}) \times 216 \mathrm{ft} \\
(60 \mathrm{~m}) \text { survey grid. }\end{array}$ \\
\hline Calibration & $\begin{array}{l}\text { System must provide a } \\
\text { manual/external calibration } \\
\text { protocol, instrument must contain } \\
\text { internal calibration function, or } \\
\text { manufacturer must specify that no } \\
\text { calibration is required for the } \\
\text { intended purpose. }\end{array}$ & $\begin{array}{l}\text { Externally calibrated using NIST traceable } \\
\text { calibration box or upgradeable to internal } \\
\text { calibration modules. }\end{array}$ \\
\hline $\begin{array}{ll}\mathrm{ASCII} & = \\
\mathrm{CSV} & = \\
\mathrm{SQL} & =\end{array}$ & \multicolumn{2}{|c|}{$\begin{array}{l}\text { American Standard Code for Information Interchange. } \\
\text { comma separated values. } \\
\text { structured query language. }\end{array}$} \\
\hline
\end{tabular}



Table A-3. Interface Requirements of the Geotection ${ }^{\mathrm{TM}}-180$
Resistivity Data Acquisition System.

\begin{tabular}{|c|c|c|}
\hline $\begin{array}{c}\text { Interface } \\
\text { Requirements }\end{array}$ & Requirement & $\begin{array}{l}\text { Selected Resistivity Data } \\
\text { Acquisition Instrument }\end{array}$ \\
\hline $\begin{array}{l}\text { Data Storage } \\
\text { Channels }\end{array}$ & $\begin{array}{l}\text { Data output file must } \\
\text { include: record, data, time, } \\
\text { V/I, I, V, Error. }\end{array}$ & $\begin{array}{l}\text { Geotection-180 data stored in SQL database and contain the } \\
\text { following information: } \\
\text { Decimal Time, Sequence Filename, Hardware Ver, Software Ver, } \\
\text { Operator, Current Sense Scale (V/A), Site, Tx Frequency, Tx Duty } \\
\text { Cycle (\%), Tx Num Cycles, Tx Max Voltage (V), Tx Max Current } \\
\text { (mA), Rx Sampling Rate, Data Window Min (\%), Data Window } \\
\text { Max (\%), Error Cutoff (\%), Trigger Multiplier, Trigger Duration } \\
\text { Pts, Contact Resistance Test Current (mA), Contact Resistance Test } \\
\text { Voltage (V), Max Contact Resistance (Ohms), Tx Voltage Divider, } \\
\text { Overvoltage Protection (V), Error Type, Num Step Retries, GPIB } \\
\text { Delay Compensation (msecs), Pwr Relay Delay Compensation } \\
\text { (msecs), Auto Gain, Auto Gain Num Cycles, Auto Gain Scaling } \\
\text { Factor, Low-Pass Filter, Site Notes, Record, Date, Time, Dec Time, } \\
\text { Tx Chn, Rx Chn, File Name, Step Skipped, Reason Skipped, } \\
\text { Contact Resistance (Ohms), Tx Voltage (V), Tx Voltage Saturated, } \\
\text { Tx Voltage Gain, Tx Current (mA), Tx Current Saturated, Tx } \\
\text { Current Gain, Rx Voltage (V), Resistance (Ohms), Pulse Error (\%), } \\
\text { Point Error (\%), SP (V), Gain, Data Status }\end{array}$ \\
\hline $\begin{array}{l}\text { Output } \\
\text { Channels }\end{array}$ & $\begin{array}{l}\text { Must have a serial or } \\
\text { universal serial bus channel } \\
\text { to download data to a } \\
\text { personal computer using } \\
\text { Microsoft Windows } \mathrm{XP}^{\mathbb{Q}^{*}} \text {. }\end{array}$ & Data is written direct to desktop hard drive in trailer. \\
\hline GPIB & General Purpose Interface Bus. & Self Potential. \\
\hline $\operatorname{Max}$ & Maximum. & Structured Query Language. \\
\hline Min & Minimum. & Version. \\
\hline
\end{tabular}

\section{A1.3 ELECTRICAL INTERFERENCE MONITORING}

Electrical interference can affect resistivity measurements in two ways:

1. Grounded conductive infrastructure (pipes, tanks, fences) may provide a preferential current pathway that distorts predictable current flow paths within the earth.

2. Electrical noise (voltage/current) sources from electrical systems (cathodic protection, pumps, motors, earth grounding arrays, etc.) may inject a competing signal.

Electrical noise interference can be minimized by identifying noise sources and then turning off electrical sources where possible for the duration of the resistivity surveying.

A passive monitoring system will be used to detect and map possible electrical noise interference prior to the start of resistivity measurements. For previous surveys, the process consisted of temporarily wiring several electrodes or steel-cased monitoring wells, distributed over a tank farm (inside and outside of the farm fence), to a distribution panel. A digital recording oscilloscope was connected the electrode measuring points (two at a time) and the background 
electrical field was digitally recorded via a laptop computer. The oscilloscope operates via the universal serial bus port on the laptop computer and does not transmit signal into the ground. The data would be assessed at an offsite location and recommendations to minimize electrical interference will be made.

However, the new Geotection-180 System has a built in passive monitoring system that is capable of detecting electrical noise from any grounded electrical system. For this survey, the Geotectio-180 System will be used to identify the magnitude, frequency, and cycle time of possible interference. Noise will be monitored on all sensor types (well, surface electrode, and depth electrode) to generate a representative snapshot of electrical noise conditions. The primary focus will be to validate the suspension of cathodic protection systems.

\section{A1.4 EQUIPMENT TESTING}

\section{A1.4.1 Geotection-180 18}

Daily inspection of the entire system calibration is performed onsite using the manufacturersupplied calibration resistor test box. The supplied test box is connected to the Geotection-180 before commencing the daily survey. A specific calibration test sequence file is used to test all possible measurement combinations. The resulting data file is copied into a controlled spreadsheet that contains the known National Institute of Standards and Technology (NIST) resistance values. The sheet identifies if any of the channels fail, a recalibration or repair is required.

\section{A1.4.2 Passive Resistivity Cables}

The passive resistivity cables shall be tested for continuity and current leakage in accordance with test procedure CEES-0399, Test Procedure for SGE Passive Cables Using Porta Scan. The cable sections shall be tested prior to initiating the survey, opportunistically during the survey, and at the completion of the survey. The test instrument is designed to provide a screening level field test to verify cable integrity and functionality. Test records shall be maintained in the project files.

\section{A1.4.3 SuperSting $\mathbf{R 8}^{\circledR}$}

Daily inspection of the receiver calibration is performed onsite using the manufacturer-supplied calibration resistor test box. The supplied test box is connected to the SuperSting R8 before commencing the daily survey. A specific calibration test firmware is provided within the SuperSting and provides the operator with a pass/fail indication for each of the eight receiver channels. If any of the channels fail, a recalibration or repair is required.

\section{A1.4.4 SwitchBoxes}

The operator connects a switchbox or switchboxes to the SuperSting R8 and performs the relay test that is incorporated into the SuperSting R8 firmware. This test sends a signal to each switchbox electrode to assess the functionality of the relays on each switchbox electrode channel. 
The SuperSting reports the success or failure of each relay (switchbox electrode channel) as a pass or fail. The relay test only inspects the operability of each relay.

As part of field equipment testing on all resistivity surface exploration geophysics deployments at the Hanford site, it is necessary to provide equipment evaluation specifically with regard to the functionality of the Advanced Geosciences Inc. Super Sting R8 Resistivity meter ("Sting”) electrode multiplexors (switchboxes). The switchboxes come in three standard capacities, all in increments of 28 switches, e.g., 28, 56, and 84 switches. Any combination of these switchboxes may be used on a Hanford Site deployment of SGE.

A Switchbox test was performed on all switchboxes used on a weekly, and as needed basis. For the Switchbox test, the operator connects a switchbox to the SuperSting R8 and to a switchbox diagnostic tester (SBDT) (HGI). The SBDT simulates an actual resistivity survey using a network of resistors of known resistance. The measured data is compared to the known resistances for the SBDT and success or failure is reported for each switchbox electrode channel as a pass or fail. The switchbox test evaluates the operability of each relay and in addition evaluates any possible shorting, lack of isolation or failures of internal electronics that control the relays. If a relay fails in the opened or closed state during typical testing, relatively high measurement errors, sometimes exceeding 100 percent relative to the standard baseline results recorded for the SBDT by the High Resolution Resistivity ${ }^{\circledR}$ Leak Detection and Monitoring ${ }^{\circledR}$ Data Acquisition System (DAS), can be expected.

The selection of an appropriate error threshold for passing or failing needs to be consistent with the type of survey being performed and environmental conditions that could be encountered during testing. A 5 percent error threshold is typical for industry use in bench-scale testing of equipment and this level could be very appropriate for some applications. Under a bench testing setting, where environmental conditions are generally controlled, our own experience shows that recorded Sting measurements for operational relays within a switchbox can be much less than 5 percent of standard baseline values for the SBDT. The 5 percent level is also supported by the manufacturer, Advanced Geosciences, Inc. in bench-scale evaluation of switchbox relays in their facilities.

However, under field conditions, where changes in ambient temperature, wind conditions, and electrical interference can potentially affect measurement error during data acquisition, it is possible that this 5 percent pass/fail threshold may not be adequate and could potentially result in apparent relay failures in a fully operational switchbox. Geophysical resistivity data taken in less than ideal environment conditions can often exceed a 5 percent error in repeatability, but can still be used to produce usable results. Therefore, to account the additional effects of field conditions, our professional judgment is that a 10 percent threshold would be a more appropriate level to use and this level was initially used in switchbox testing for this project. As we gain additional experience with SBDT field testing, we will reevaluate this value as an effective pass/fail threshold.

\footnotetext{
${ }^{\circledR}$ High Resolution Resistivity HRR is a trademark of hydroGEOPHYSICS, Inc., Tucson, Arizona.

${ }^{\circledR}$ Leak Detection and Monitoring LDM is a registered trademark of hydroGEOPHYSICS, Inc., Tucson, Arizona
} 


\section{A1.5 DATA PROCESSING}

The process used to filter the raw data is described in the system design description (CEES-0360). Data are downloaded from the resistivity instrument and parsed into a usable format. Data filtering techniques are then used to remove data spikes or anomalous data caused by data acquisition card instabilities, or extraneous current sources.

Data filtering is performed by copying the parsed raw data into an Excel data filtering template that contains a series of graphs that show the various data parameters. The process of filtering eliminates data points, but no data modification (rounding, averaging, smoothing, or splining) is permitted. The rationale is to seek out and remove spurious points that do not conform to the data population or points that violate potential theory.

The final step is to inverse model the measured data to obtain the spatio-temporal distribution of electrical resistivity. Inverse modeling is accomplished using either EarthImager3DCL (EI3DCL) or RES3DINVx64 (RES3D). Verification and testing of the inversion software was performed and documented in RPP-34974, Verification and Testing of the EarthImager Series of Electrical Resistivity Inversion Codes - A Benchmark Comparison. Verification and testing was performed on the existing two-dimensional (2D) and three-dimensional (3D) versions of the software as well as the upgraded 64-bit, multi-threaded versions developed for tank farm projects.

The objective of the verification and testing study was to demonstrate that the resistivity inversion codes were comparable to known conditions from a pilot-scale field resistivity experiment. The pilot-scale field experiment was used to test the well-to-well inversion methodology by establishing a known conductive target in the subsurface and making measurements with a set of 27 simulated wells. To date, there is no industry standard for the well-to-well resistivity imaging technique, which necessitated the field experiment. The field experiment was designed to test the inversion code's ability to replicate a target of known geometry. The subsurface geophysical target was an amended, electrically conductive soil, buried approximately $1.6 \mathrm{ft}(0.5 \mathrm{~m})$ below ground surface. The 27 wells were distributed around the target in a pattern similar to tank B-105 in the B Tank Farm.

From the above descriptions, it is obvious that data processing is performed using a number of software packages. The requirements and responsibilities for the identification, evaluation, development, testing, and maintenance of quality-affecting software acquired, developed, or modified in support of the SGE efforts are defined in the CEES-0338.

\section{A2.0 REFERENCES}

ASME NQA-1, 2004, Quality Assurance Requirements for Nuclear Facility Applications, American Society of Mechanical Engineers, New York, New York.

CEES-0333, 2006, Quality Assurance Plan for Surface Geophysical Exploration Projects, as revised, Columbia Energy and Environmental Services Inc., Richland, Washington.

CEES-0338, 2006, Software Management Plan for Surface Geophysical Exploration Projects, Rev. 0, Columbia Energy and Environmental Services Inc., Richland, Washington.

CEES-0360, 2007, Surface Geophysical Exploration System Design Description, Rev. 0, Columbia Energy and Environmental Services, Inc., Richland, Washington. 
RPP-RPT-56760, Rev. 0

Contract 28090, Requisition 123974, High Resolution Resistivity Characterization of Single Shell Tank Farm Waste Management Areas, Rev. 3, CH2M HILL Hanford Group, Inc.

DOE O 414.1C, Quality Assurance, U.S. Department of Energy, Washington, D.C.

RPP-34974, 2007, Verification and Testing of the EarthImager Series of Electrical Resistivity Inversion Codes - A Benchmark Comparison, Rev. 0, CH2M HILL Hanford Group, Inc., Richland, Washington. 